\title{
A GENERAL FRAMEWORK FOR SUSTAINABILITY ASSESSMENT OF
}

\section{MANUFACTURING PROCESSES}

by

Mohammed Hassoun Saad

\author{
A Thesis presented to the Faculty of the \\ American University of Sharjah \\ College of Engineering \\ In Partial Fulfillment \\ of the Requirements \\ for the Degree of \\ Master of Science in \\ Mechanical Engineering
}

Sharjah, United Arab Emirates

November 2018 
(C) 2018 Mohammed Hassoun Saad. All rights reserved. 


\section{Approval Signatures}

We, the undersigned, approve the Master's Thesis of Mohammed Hassoun Saad

Thesis Title: A General Framework for Sustainability Assessment of Manufacturing Processes.

Signature

Date of Signature (dd/mm/yyyy)

Dr. Basil Darras

Associate Professor, Department of Mechanical Engineering Thesis Advisor

Dr. Mohammad Nazzal

Associate Professor, Department of Mechanical Engineering Thesis Co-Advisor

Dr. Maen Abdelqabder Alkhader

Associate Professor, Department of Mechanical Engineering Thesis Committee Member

Dr. AbdulRahim Shamayleh

Assistant Professor, Department of Industrial Engineering Thesis Committee Member

Dr. Mamoun Abdel-Hafez

Head, Department of Mechanical Engineering

Dr. Ghaleb Husseini

Associate Dean for Graduate Affairs and Research

College of Engineering

Dr. Richard Schoephoerster

Dean, College of Engineering

Dr. Mohamed El-Tarhuni

Vice Provost for Graduate Studies 


\section{Acknowledgement}

I would like to thank my advisors Dr. Basil Darras and Dr. Mohammad Nazzal for providing me with knowledge and guidance, and for their continuous support, and motivation throughout my research stages. I'm deeply beholden for their great assistance, worthy discussions, meetings and suggestions. I would like also to thank the technicians of the manufacturing lab at the American University of Sharjah (AUS), Mr. Ronald and Mr. Denis for their continuous assistant during my practical work.

I would like to give special thanks to AUS for providing me a Graduate Teaching Assistantship (GTA) which greatly availed me not only financially, but also academically by giving me the chance to gain significant teaching experience.

I would like to thank the professors of the Mechanical Engineering department who taught me the master level courses with mighty teaching methods and skills. I am really appreciate their dignified advices and motivation.

I would like to thank my friend Mohammed Al Rammash for his great efforts in reviewing and editing my thesis. Also, I would like to thank my friends and colleagues Mustafa Al Yousef and Mohammed Yousef for providing valuable assistance during practical and experimental work.

I would like to give special thanks to my family, especially my parents, for always being beside me during my study with their supports, motivations, emotions and prayers. 


\section{Dedication}

To my family and friends... 


\begin{abstract}
The manufacturing sector has a major impact on the three sustainability dimensions represented by social, economic, and environmental aspects. Most of the work on sustainability assessment in the field of manufacturing is conducted at the product level or for specific processes; mainly machining with a limited number of indicators that do not capture all three dimensions of sustainability. The aim of this work is to develop a new systematic and comprehensive framework for the sustainability assessment of manufacturing processes that covers the three sustainability dimensions. Guidelines to select and quantify the relevant indicators, convert the quantified weighted indicators into dimensionless quantities, and rank the alternatives based on the aggregated scores are presented. The proposed framework combines objective and subjective weighting methods to reduce the uncertainty associated with subjective weighting. It also captures the interaction among different indicators by utilizing multi-criteria decision making methods instead of the traditional statistical methods. Sensitivity analysis is proposed to ensure the reliability and robustness of the aggregated results (final scores). A case study is carried out by applying the proposed framework to evaluate the sustainability level of four welding processes, which are Friction Stir Welding (FSW), Gas Metal Arc Welding (GMAW), Gas Tungsten Arc Welding (GTAW) and Shielded Metal Arc Welding (SMAW). The four processes are used to weld aluminum 5083 plates with a thickness of $5 \mathrm{~mm}$. Physical performance of the welded plates is considered as a fourth sustainability dimension to assess the quality of the welded parts. The assessment is carried out using three multi-criteria decision making methods, which are the TOPSIS, GRA and COPRAS. The results obtained from the assessment reflect that the FSW welding is the most sustainable welding process for this case with an overall sustainability score of 0.611 based on TOPSIS method, 0.753 based on GRA, and 0.317 based on the COPRAS method.
\end{abstract}

Keywords: Sustainability Assessment; Indicators; Multi-Criteria Decision Making methods; Sensitivity Analysis; Manufacturing processes; Welding Processes 


\section{Table of Contents}

Abstract

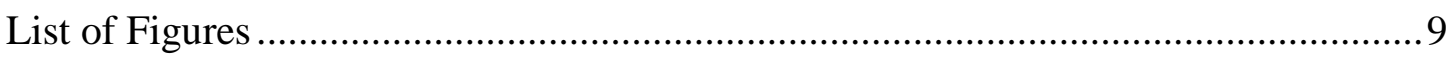

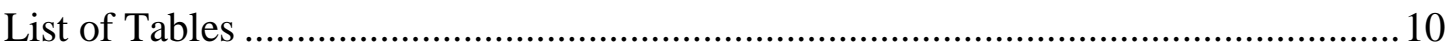

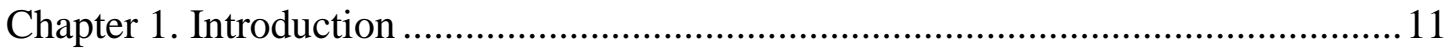

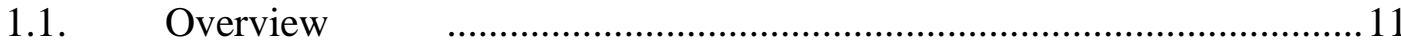

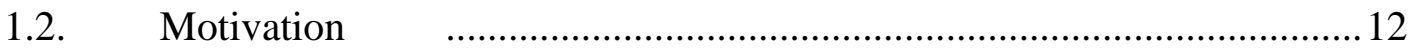

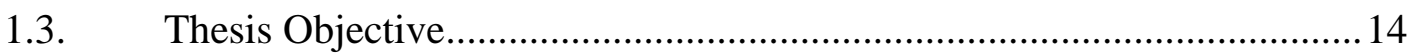

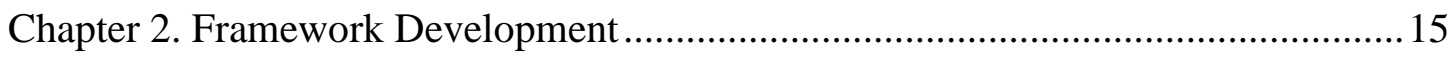

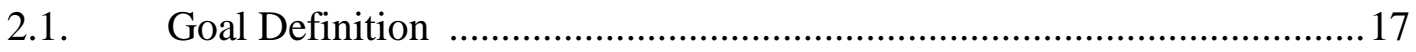

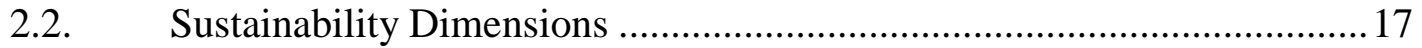

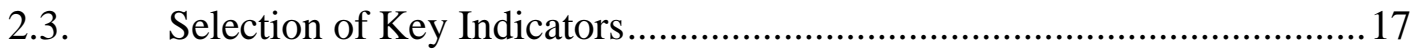

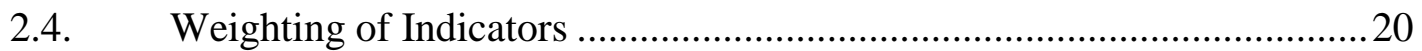

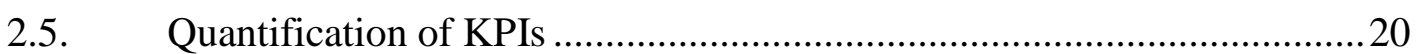

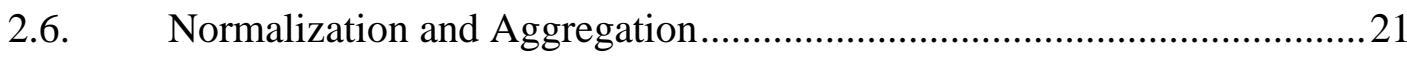

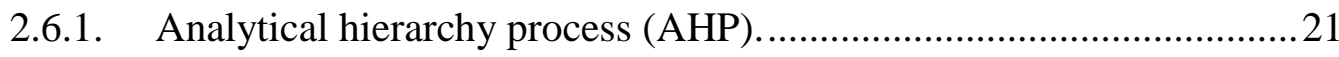

2.6.2. Analytical network process (ANP) .................................................24

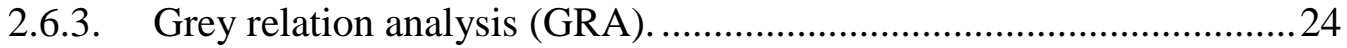

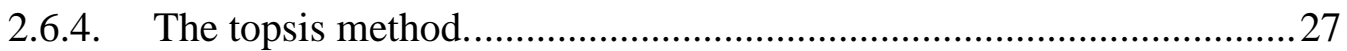

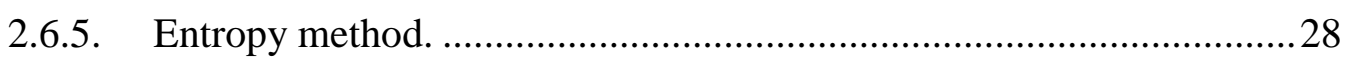

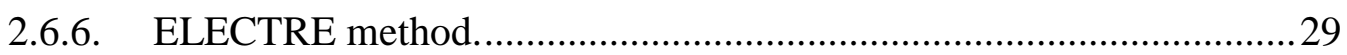

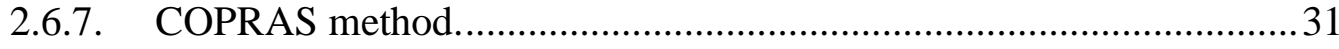

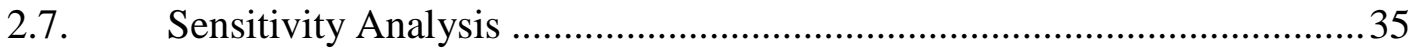

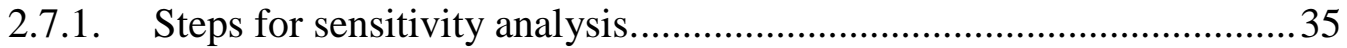

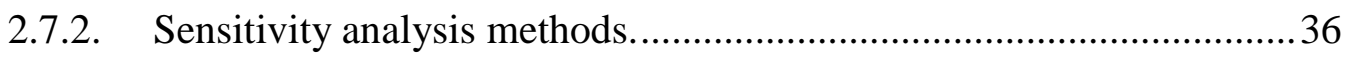

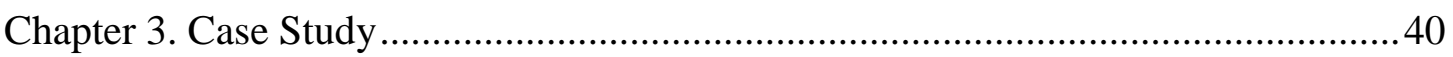

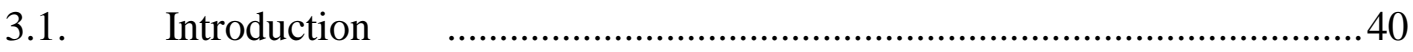

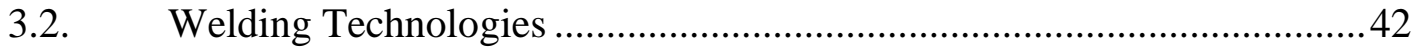

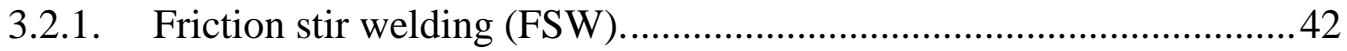

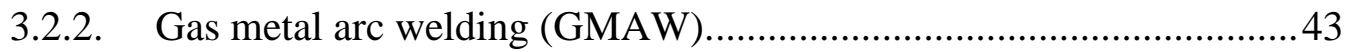

3.2.3. Gas tungsten arc welding (GTAW) ............................................... 43

3.2.4. Shielded metal arc welding (SMAW). .......................................... 44 


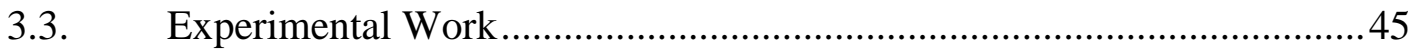

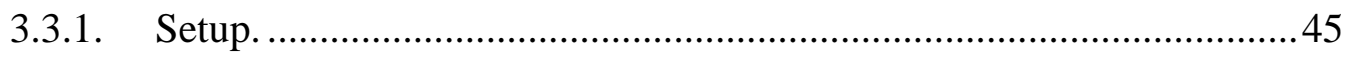

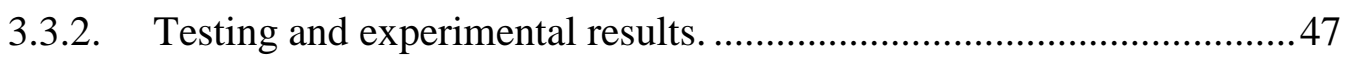

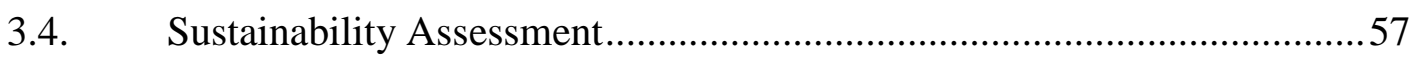

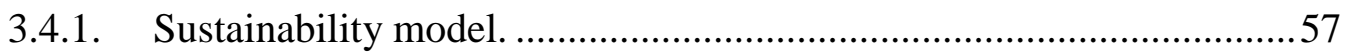

3.4.2. Indicators for sustainability assessment. ........................................59

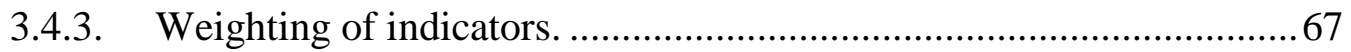

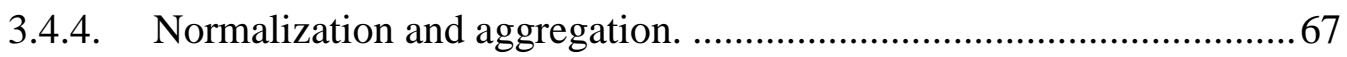

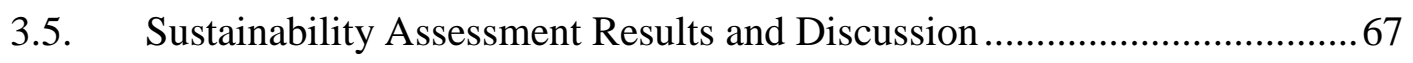

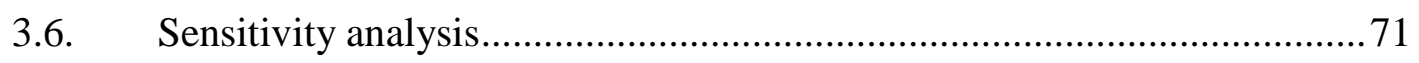

Chapter 4. Conclusion and Future Outlook ……..................................................... 74

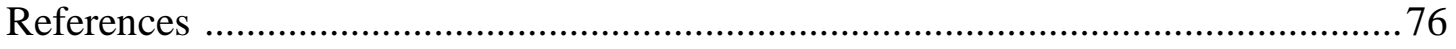

Vita 


\section{List of Figures}

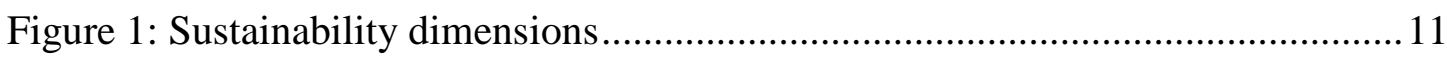

Figure 2: Greenhouse gas emissions by economic activity, EU-28, 2013 ….............. 12

Figure 3: Proposed framework for sustainability assessment of manufacturing process

Figure 4: NIST indicator categorization structure developed by the NIST [5] ........... 19

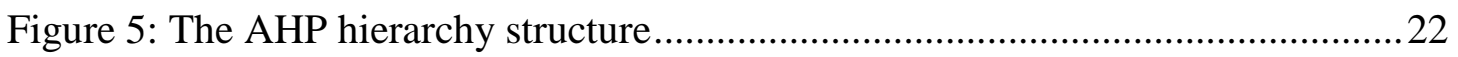

Figure 6: Example of the structural difference between a hierarchy and a network: (a)

a three-level hierarchy and (b) a three-cluster network ..............................................2 24

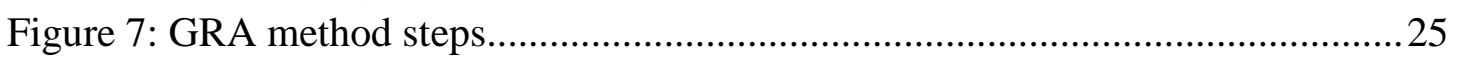

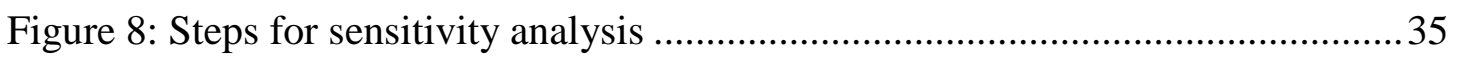

Figure 9: The principle of friction stir welding process ...........................................42

Figure 10: The principle of gas metal arc welding process .......................................43

Figure 11: The principle of gas tungsten arc welding process................................... 44

Figure 12: The principle of shielded metal arc welding process .................................45

Figure 13: Metallic plates to be welded ......................................................................46

Figure 14: Welds using A) FSW, B) TIG, C) MIG and D) SMAW ............................47

Figure 15: Tensile, microstructural and impact toughness test specimens ..................47

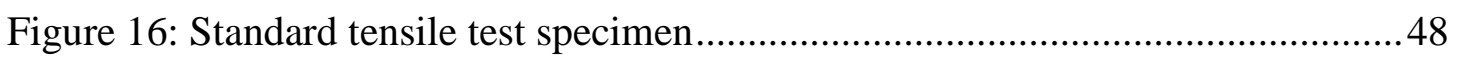

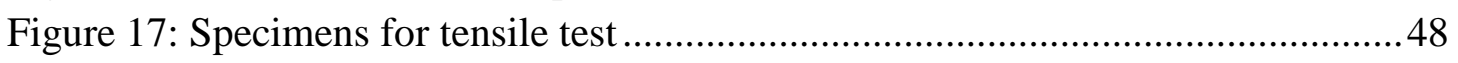

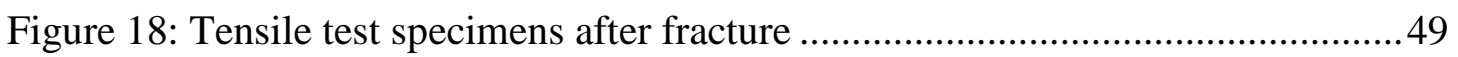

Figure 19: Stress-Strain curves for welded base and welded samples........................ 49

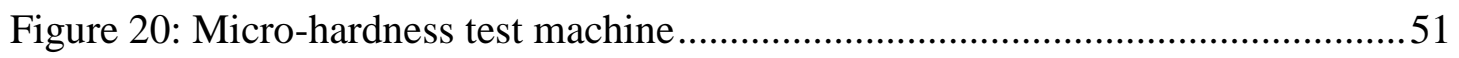

Figure 21: Micro-hardness samples placed in mounting cups ..................................52

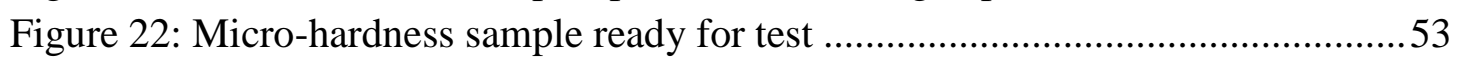

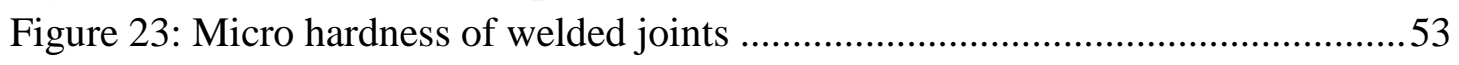

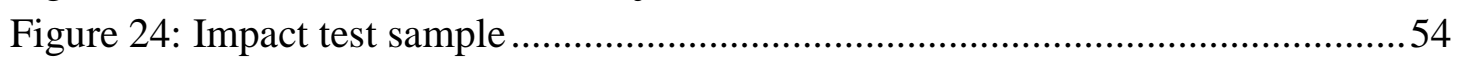

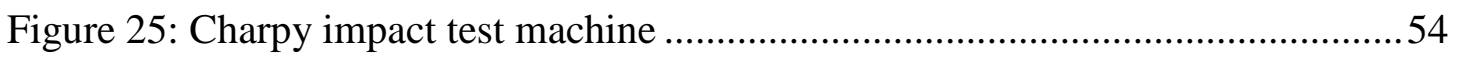

Figure 26: Standard impact test specimen's dimensions..........................................55

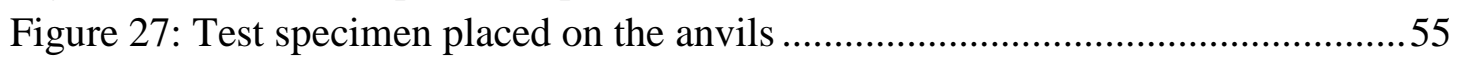

Figure 28: Impact toughness of welded joints .......................................................56

Figure 29: General Algorithm for Sustainability Assessment of Welding Processes .58

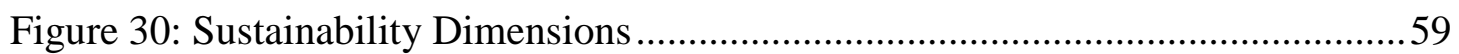

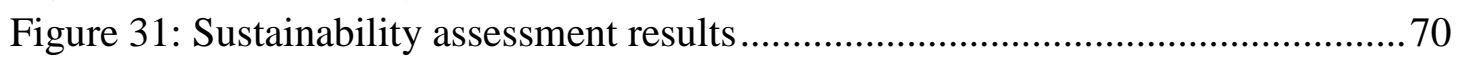




\section{List of Tables}

Table 1: Common indicator sets reviewed by Joung et al. ...................................... 19

Table 2: The fundamental scale of absolute numbers...............................................23

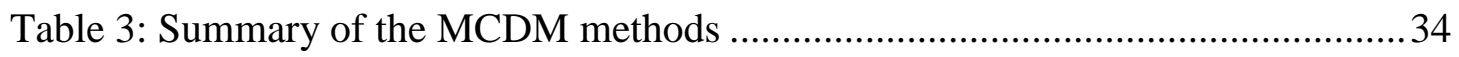

Table 4: Summary of the suggested sensitivity analysis methods ................................39

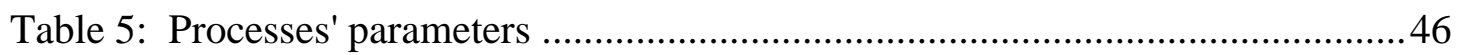

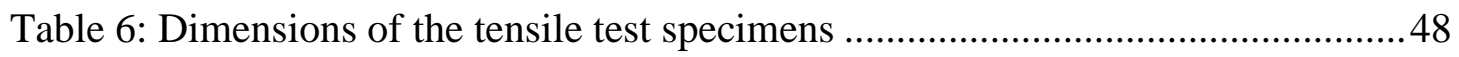

Table 7: Mechanical properties obtained from the stress-strain curves......................50

Table 8: Power consumption for each process .........................................................6 60

Table 9: CO2 emissions produced by each process .................................................61

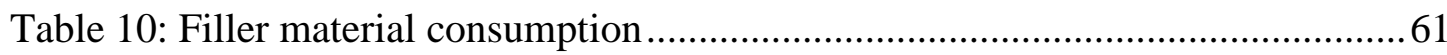

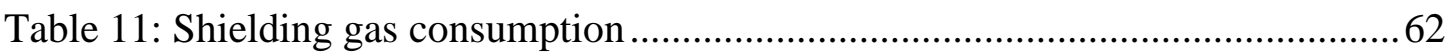

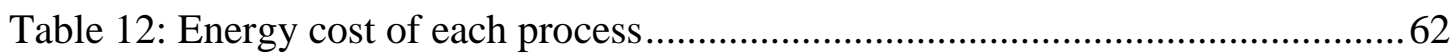

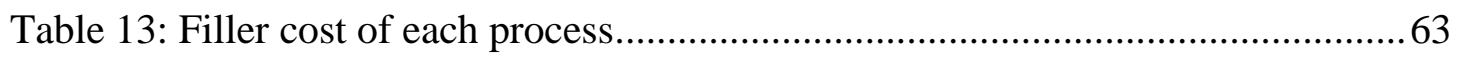

Table 14: Labor cost/ Job satisfaction of each process .............................................64

Table 15: Average welding time of each process .......................................................64

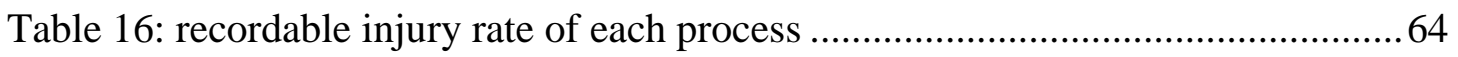

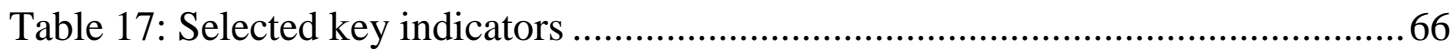

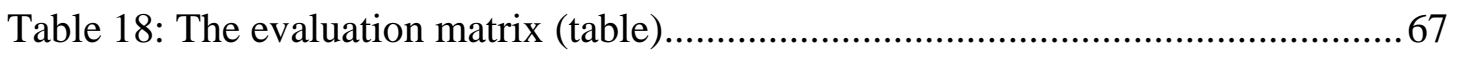

Table 19: Indicators' weights assigned using the entropy method...............................68

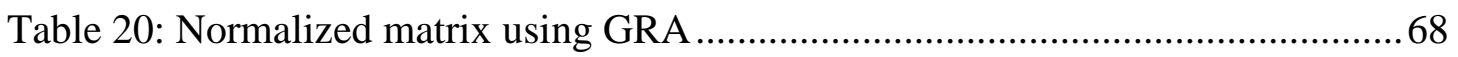

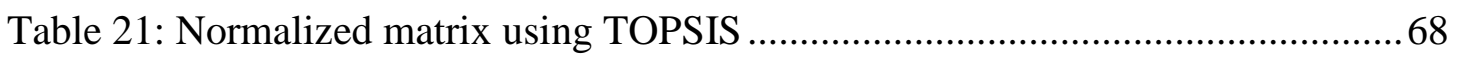

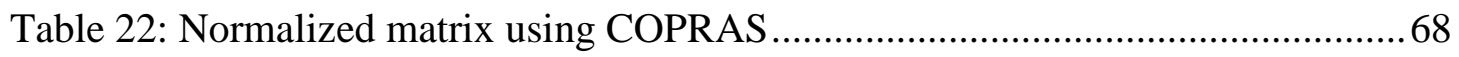

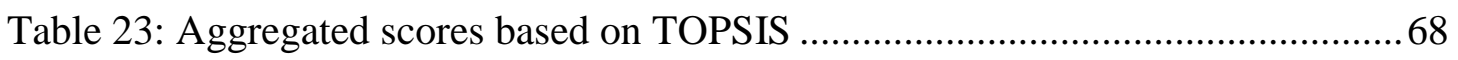

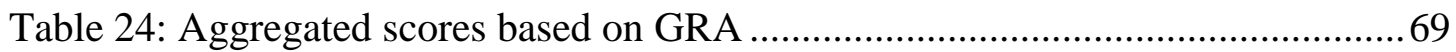

Table 25: Aggregated scores based on COPRAS .....................................................69

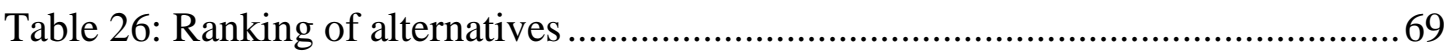

Table 27: Sensitivity analysis with respect to energy consumption ........................... 72

Table 28: Sensitivity analysis with respect to welding time ...................................... 72 


\section{Chapter 1. Introduction}

\subsection{Overview}

Over the past few decades, there has been growing interest in sustainability assessment as an essential tool towards sustainable development. The standard definition of sustainable development provided by the Brundtland report (1987) is "development that meets the needs of the present generation without compromising the ability of future generations to meet their own needs" [1]. According to the U.S. National Academy of Sciences [2], there are three important components of sustainable development; the first component is what to be sustained, the second is what to be developed, and the third is the relation between the first and second components. These components identify three areas to be sustained which are nature, life-support systems and community. In the year 2002, the World Summit on Sustainable Development marked the introduction of the three dimensions or pillars of sustainable development which are economic development, social development and environmental protection [3], as shown in Figure 1.

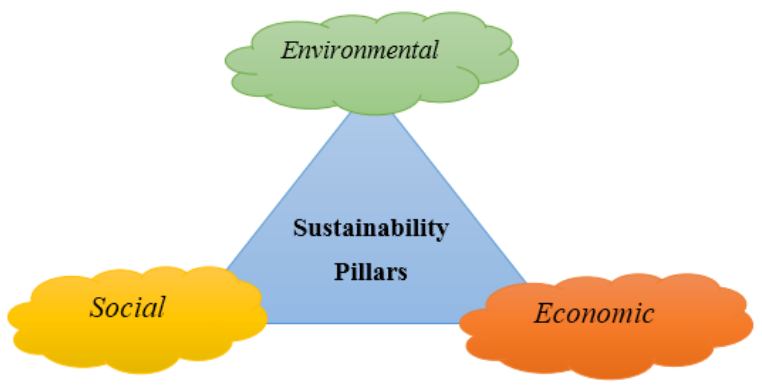

Figure 1: Sustainability dimensions

An essential part of sustainable development is the concept of 'sustainability assessment'. In general, sustainability assessment is defined as a methodology "that can help decision-makers and policy-makers decide what actions they should take and should not take in an attempt to make society more sustainable" [4]. Since the 1990s, many substantial and promising sustainability assessment efforts were made in different engineering applications such as energy systems, urban planning, building and construction sector, water treatment and mining and mineral industry [1,5-20]. Ness et al. [1] have introduced a framework to categorize the sustainability assessment tools based on three main categories: indicators/indices, product-related assessment, and 
integrated assessment tools. Singh et al. [6] have provided an overview of various sustainability assessment indices. They have compiled the information related to the strategies of formulating sustainability indices or scores which mainly consist of three central steps: normalization (scaling), weighting and aggregation. Xing et al. [16] have reported on the development of an Urban Development Sustainability Assessment Model (UD-SAM) that helps policymakers and decision makers to identify sustainability indicators from the three sustainability dimensions (environmental, economic and social), and could lead to more comprehensive evaluation of the sustainability impact on elements of the urban environment.

\subsection{Motivation}

The manufacturing sector is a major contributor to economic expansions and improvement of standard of living globally. However, manufacturing processes have negative impacts on the environment and society as they consume excessive scarce resources and produce hazardous wastes and emissions. According to the National Association of Manufacturers, the industrial sector accounts for $31 \%$ of all the energy consumed in the United States, from which manufacturing industry alone accounts for around $65 \%$ of the industrial sector's energy consumption [21]. The manufacturing industries also produce significant amounts of greenhouse gases (GHGs) such as CO2. Figure 2 shows the Greenhouse gas emissions by economic activity in the European Union countries (EU-28) in 2013 [22].

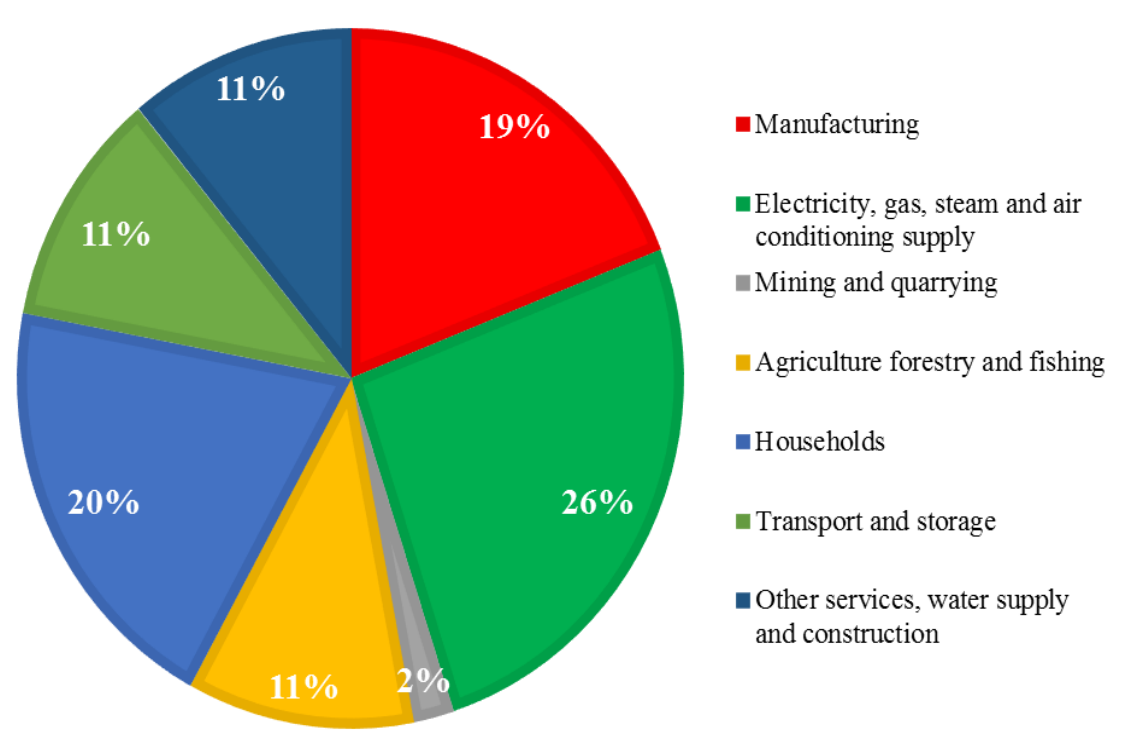

Figure 2: Greenhouse gas emissions by economic activity, EU-28, 2013 [22] 
The manufacturing sector is responsible for $19 \%$ of the total GHG emissions produced by various economic activities in the EU countries. Therefore, the amount of effort and research on developing sustainability assessment tools for the manufacturing processes is rapidly increasing [5].

Several studies have been conducted in the field of sustainability assessment in the manufacturing sector [11, 13, 23-39]. A significant amount of this work focused on evaluating the sustainability performance of the manufactured product [37, 40-42]. Hapumatte et al. [37] presented a total life sustainability assessment of additively manufactured products through a Product Sustainability Index (ProdSI) framework which was recently established. The authors validated the ProdSI matrices by conducting a case study with two iterations of additively manufactured products. Similarly, Zhang et al. [43] presented a new methodology for generating the five-level Product Sustainability Index (ProdSI) based on a set of product sustainability metrics, which included methods of data normalization, weighting and aggregation. The ProdSI framework focuses mainly on evaluating the sustainability performance of the manufactured product without considering the manufacturing processes used to produce it.

In contrast, the efforts done to assess the sustainability at the process level are relatively limited, and most of them concentrated mainly on specific machining processes such as turning, milling or grinding [23, 25, 29, 31, 44-46]. Bhanot N. et al. [23] introduced a framework for sustainability assessment of turning processes in an automobile firm. Furthermore, Lu et al. [29] proposed a metrics-based sustainability assessment method to address the impact of a drilling process from the economic, environmental and societal points of view. Moreover, Lu T. and Jawahir I. [31] evaluated the performance of Cryogenic Machining experimentally using a metricsbased Process Sustainability Index evaluation. The aforementioned studies evaluated the sustainability performance of different machining processes. However, they did not follow a unified assessment approach. In addition, sensitivity analysis of the final scores was considered.

Limited work has been done on the evaluation of other processes such as casting, joining, shaping and forming [24, 47-50], although they could have negative environmental, economic and social impacts. For instance, casting and some joining 
processes like welding can have serious environmental and social impact, as they consume significant amount of energy and cause safety risks due to the exposure of workers to high temperatures and toxic gases. Sproesser et al. [49] applied a weight space partitioning sustainability assessment tool to evaluate the sustainability performance of two welding processes with respect to three indicators that reflect their environmental and economic performance. Chang et al. [48] used Life Cycle Assessment (LCA) and Social Life Cycle Assessment (SLCA) tools to evaluate the possible social and environmental impact of candidate welding technologies. Ingarao et al. [24] have compared the efficient use of energy and material between two sheet metal forming processes; a single point incremental sheet forming operation and a classical stamping one, by conducting a sensitivity analysis which is based on experimental and numerical data. Singh et al. [47] have proposed a new computer-aided system named Sustainability Analyzer for Die Casting Process where they used the proposed system to analyze three sustainability indicators, which are energy use, solid waste and carbon emissions. In the aforementioned studies [24, 47-49], a limited number of indicators that do not cover the three dimensions of sustainability were considered in the assessment tools.

\subsection{Thesis Objectives}

As seen earlier, most of the available manufacturing sustainability assessment tools presented in literature focus on the assessment at the product level, while others focus on specific processes such as machining processes for a limited number of indictors that do not capture the three dimensions of sustainability. Therefore, the objective of this thesis is to develop a general comprehensive framework for sustainability assessment of different manufacturing processes. Unlike most of the assessment tools used in the manufacturing sector, the proposed framework is comprehensive in the way that it takes into account all sustainability dimensions in the analysis. Guidelines to choose and quantify relevant indicators are presented. A combination of subjective and objective weighting methods is proposed. Multi-criteria decision making methods (MCDM) are considered for normalizing and aggregating the indicators' to address any possible interaction among different sustainability indicators. Sensitivity analysis of the obtained results is discussed and integrated into the proposed framework to ensure the reliability and robustness of the final scores. 


\section{Chapter 2. Framework Development}

This section discusses the structure of a general framework that policymakers or decision-makers can follow to evaluate the sustainability performance of various manufacturing processes. Figure 3 shows a flow chart of the proposed framework.

The first step in the proposed framework is to define the goal of the analysis, which is selecting the most sustainable manufacturing process for producing a certain product for a specific application. Once the objective is well defined, all dimensions of sustainability need to be considered to have a comprehensive evaluation. The key sustainability indicators, including qualitative and quantitative ones, have to be carefully selected to capture all sustainability dimensions. Weights for dimensions and selected key indicator should be assigned to indicate the relative importance. Different weighting (subjective and/or objective) methods can be used. The weighted indicators should then be quantified by the means of different measurement tools and quantification techniques depending on the type of indicators (qualitative or quantitative). The indicators should then be normalized into dimensionless quantities. Methods such as Multi-Criteria Decision Making (MCDM) methods, Min-Max, Zscore and others may be used for normalization. After that, the normalized quantities are to be aggregated into a single score (index) using the MCDM methods. It is of high importance to conduct sensitivity analysis on the aggregated scores of the considered alternatives. If the results are found to be non-sensitive to changes in the indicators' values or the assigned values of weights, then the decision-maker can use the obtained scores to rank the different alternative processes and choose the best one. Otherwise, modifications such as changing the methods used for weighting, normalizing and aggregating are required.

Detailed explanation of each block of the framework is presented in the upcoming subsections. 


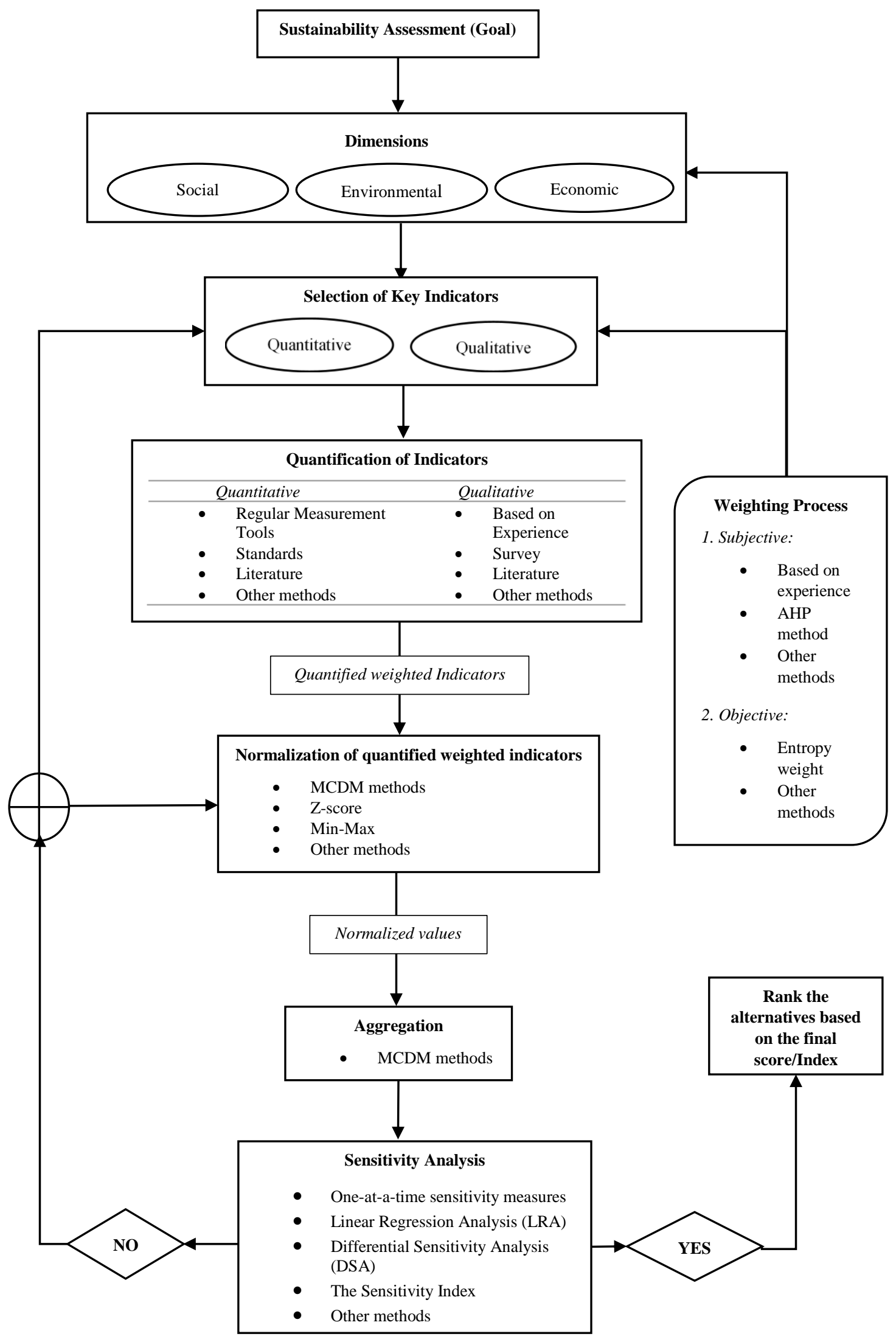

Figure 3: Proposed framework for sustainability assessment of manufacturing process 


\subsection{Goal Definition}

Sustainability assessment of any manufacturing process should begin with a statement of sustainability problem that needs to be addressed, e.g., global climate change and toxicity release[51]. In this step, a decision-maker needs to clearly define the aim of the assessment. For the proposed framework, the goal of the analysis will be selecting the most sustainable manufacturing process among several alternatives for a certain application.

\subsection{Sustainability Dimensions}

After defining the objective of the assessment, the decision maker should consider the three dimensions of sustainability, which are the environmental, social and economic aspects. Each dimension can be assigned a weight by the policymaker to determine its relative importance. The weight can be assigned to the dimensions by means of subjective methods, i.e. ones that depend mainly on the decision-maker's preference and judgment [52]. They are usually carried out based on experience, survey, MCDM methods such as the Analytical Hierarch Process (AHP) method, or by other methods.

\subsection{Selection of Key Indicators}

Sustainability indicators (SI) are used to determine the sustainability performance in a quantifiable form. Joung et al. [51] defined an indicator as a "measure or an aggregation of measures from which conclusions on the phenomenon of interest can be inferred". Usually, sustainability indicators are quantifiable criteria that can detect all the states and dimensions of sustainability and can be utilized in the assessment of the performance of the different manufacturing processes [6]. Sustainability indicators can be classified as follows:

- Quantitative indicators, which can be measured and calculated by regular measurement techniques formulas, such as the energy consumption and $\mathrm{CO}_{2}$ emissions.

- Qualitative indicators, which needs to be quantified by the means of surveys or based on decision makers' experience and so on, such as the product satisfaction and health risk.

Indicators must possess mainly the following criteria [53],[35]: 
- Relevant: Indicators must directly deliver a meaningful aspect of sustainability for the manufacturing process under consideration.

- Understandable: Indicators should be easy to understand even by people who are not experts.

- Measurable: Indicator must be easily measured by the means of quantitative and qualitative measurement techniques.

- Reliable/Usable: Indicator should provide information that are credible and accurate.

- Data accessible; the information is readily available or can be gathered and accessed within the process system.

- Long Term-oriented: Indicators must ensure future development and use

- Timely manner: Collecting and evaluating the data and information for an indicator should be carried out in a timely manner for informative decisionmaking.

An indicator set is a group of indicators combined from the common environmental, economic, and social sustainability dimensions [51]. There are many sustainability indicator sets that are publically used such as the Global Report Initiative (GRI) [54], the 2005 Environmental Sustainability Indicators (ESI) [55], the United Nations-Indicators of Sustainable Development (UN-CSD) [56], Ford Product sustainability Index (Ford PSI) [57] and others. They include indicators that can be effectively used to evaluate the sustainability of manufacturing processes.

A challenge that decision makers in manufacturing enterprises face is to determine which indicators to select and how to interpret these indicators to assess the sustainability on the process level. Joung et al. [51] from the National Institute of Standards and Technology (NIST) reviewed 11 indicator sets; listed in Table 1, that are commonly used. They developed an integrated sustainability indicator repository that classifies a large number of sustainability indicators into suitable categories and subcategories as shown in Figure 4. This comprehensive indicator repository is believed to be extremely helpful in the indicators selection process. 
Table 1: Common indicator sets reviewed by Joung et al. [51]

\begin{tabular}{|c|c|c|}
\hline Indicator Set & $\begin{array}{l}\text { Number of } \\
\text { Indicators }\end{array}$ & Dimensions Covered \\
\hline Global Report Initiative (GRI) & 70 & economy, environment, and society \\
\hline Dow Jones Sustainability Indexes (DJSI) & 12 & $\begin{array}{l}\text { mainly the economic dimension, but } \\
\text { also includes some aspects of the } \\
\text { environmental and social dimensions }\end{array}$ \\
\hline $\begin{array}{l}2005 \text { Environmental Sustainability } \\
\text { Indicators (ESI) }\end{array}$ & 68 & environmental stewardship \\
\hline Environment Performance Index (EPfI) & 19 & environmental \\
\hline $\begin{array}{l}\text { United Nations-Indicators of Sustainable } \\
\text { Development (UN-CSD) }\end{array}$ & 96 & economic, social, and environmental \\
\hline $\begin{array}{l}\text { Organisation for Economic Cooperation } \\
\text { and Development (OECD) Core } \\
\text { Environmental Indicators (CEI) }\end{array}$ & 46 & $\begin{array}{l}\text { environmental, social, and } \\
\text { economic }\end{array}$ \\
\hline $\begin{array}{l}\text { Ford Product Sustainability Index (Ford } \\
\text { PSI) }\end{array}$ & 8 & $\begin{array}{l}\text { environmental, } \\
\text { economic and societal }\end{array}$ \\
\hline $\begin{array}{l}\text { International Organization for } \\
\text { Standardization (ISO) Environment } \\
\text { Performance Evaluation (EPE) standard } \\
\text { (ISO 14031) }\end{array}$ & 155 & environmental \\
\hline $\begin{array}{l}\text { Environmental Pressure Indicators for } \\
\text { European Union (EPrI) }\end{array}$ & 60 & environmental \\
\hline $\begin{array}{l}\text { Japan National Institute of Science and } \\
\text { Technology Policy (NISTEP) }\end{array}$ & 150 & technological advancement \\
\hline $\begin{array}{l}\text { European Environmental Agency Core Set } \\
\text { of Indicators (EEA-CSI) }\end{array}$ & 37 & environmental \\
\hline
\end{tabular}

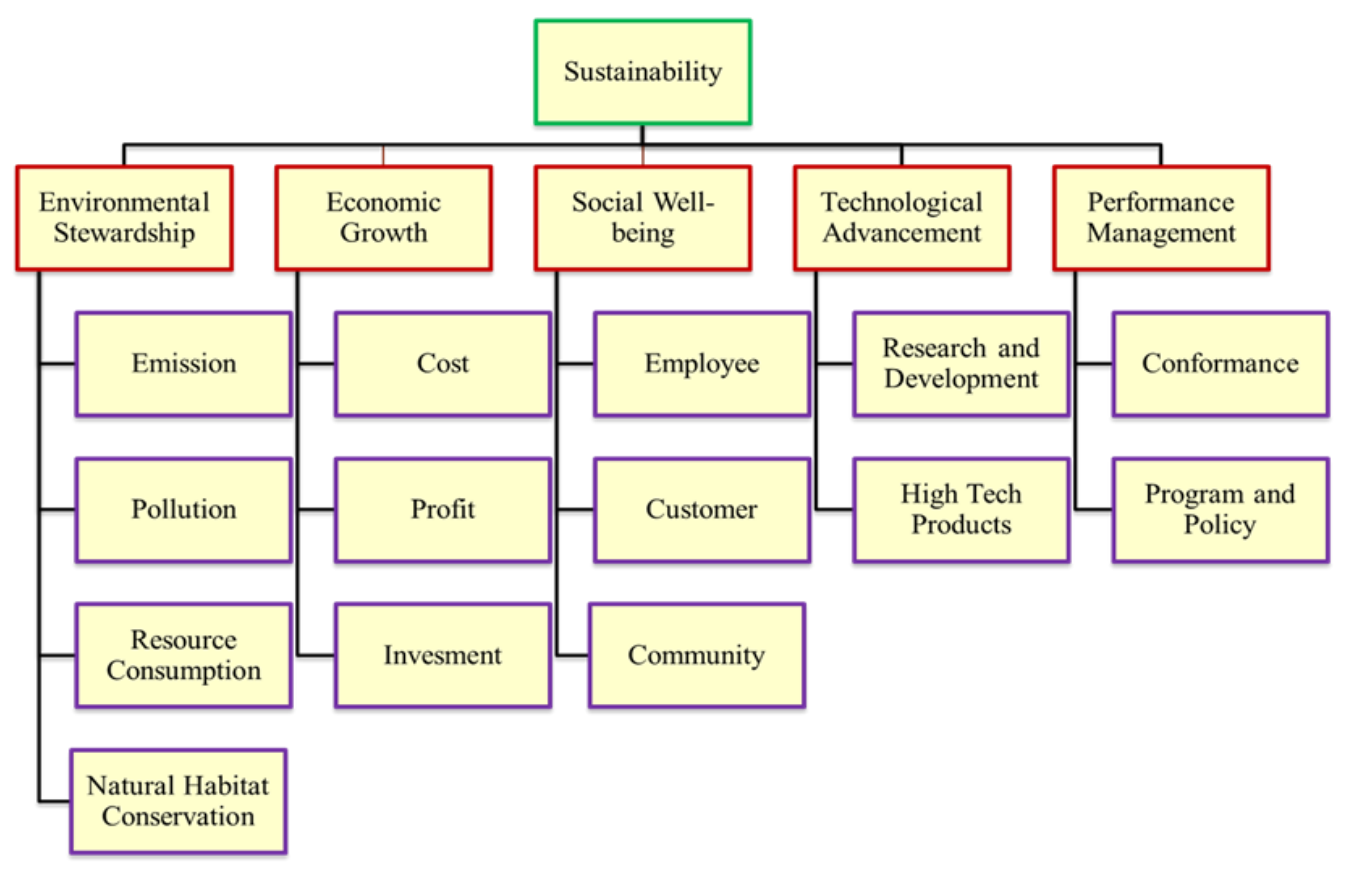

Figure 4: NIST indicator categorization structure developed by the NIST [5] 


\subsection{Weighting of Indicators}

After choosing the relevant performance indicators, the policymaker needs to assign a weight to each indicator either before or after quantifying it in order to determine the relative importance of each indicator. Unlike the dimensions, assigning weights to indicators can be done by means of both subjective methods and/or objective methods. As mentioned earlier, the subjective methods are the ones that are based on the decisions-maker's experience. However, the objective methods, such as the Entropy Weight method, assign weights to indicators based on their quantified value (real value). Contrary to the subjective methods, uncertainties are not associated with objective methods [58]. In this framework, the use of a combination of subjective and objective weighting methods is suggested to reduce the errors and uncertainties associated with pure subjective weighting.

\subsection{Quantification of KPIs}

As stated earlier, the quantification methods are the tools and formulas used to measure and calculate the value of a Key Performance Indicator (KPI), either using the total amount (absolute) or relative amount (per unit of product) or both [35]. The quantification procedure requires mainly figuring out the suitable measurement technique and collecting the measurement data. For quantitative indicator such as the energy consumption and $\mathrm{CO} 2$ emissions, the measurement is more straightforward and simple as the decision maker can depend on existing models and simulations that provide an understanding of the system and indicators [51]. In addition, some quantitative indicators can be measured using devices that provide both the value of the indicator as well as the unit. For instance, power consumption of a machine used to perform a certain process can be measured using power meter which will provide the amount of electricity consumed by the machine during the time interval of operation. Generally, the results of the measurements should include both the measured value as well as the associated measurement uncertainty. On the other hand, quantification of qualitative indicators such as product satisfaction and health risk is not as straight forward as quantification of quantitative indicators as it requires historical data, surveys or subjective judgments which are usually based on experience. Thus, higher uncertainties are associated with the qualitative indicators. 


\subsection{Normalization and Aggregation}

Different performance indicators have different physical dimensions (units). Therefore, the values of these indicators need to be scaled into dimensionless values such that they can be analyzed and compared. This process is called normalization. In general, there are different statistical methods that can be used for normalization such as the Z-score method and the Min-Max method. However, sustainability assessment is considered a complex Multi-Criteria Decision-Making (MCDM) process that involves both quantitative and qualitative factors. Therefore, MCDM methods, such as the Analytical Hierarchy Process(AHP)/Analytical Network Process (ANP), Grey Relation Analysis (GRA), Technique for Order Preferences by Similarity to Ideal Solutions (TOPSIS) and others, are the preferred methods for normalization, weight assignment, as well as aggregation especially in engineering applications such as material selection [59-64], assessment of building-integrated green technologies [65], assessment of sustainable housing [66], analysis of counter flow wet cooling tower [67] and sustainability assessment of manufacturing industries [23, 68, 69]. In the current proposed framework, the values of performance indicators can be normalized and aggregated into a single score or index using MCDM methods to account for the interactions among the different indicators. A brief overview for some of these methods is presented below.

2.6.1. Analytical Hierarchy Process (AHP). The AHP method was developed by Saaty, in 1980 [70]. It is a subjective decision making tool that is widely used for weighting determination [52]. The weights or relative importance of the attributes depends on the decision maker's preferences, which is usually based on experience. AHP decomposes the complexity of the problem in the form of a simple hierarchy, descending from overall goal to criteria, sub-criteria (if exist) and choices or alternatives as shown in Figure 5. The relative weights of criteria and sub-criteria are allocated to compare the alternative processes [71]. 


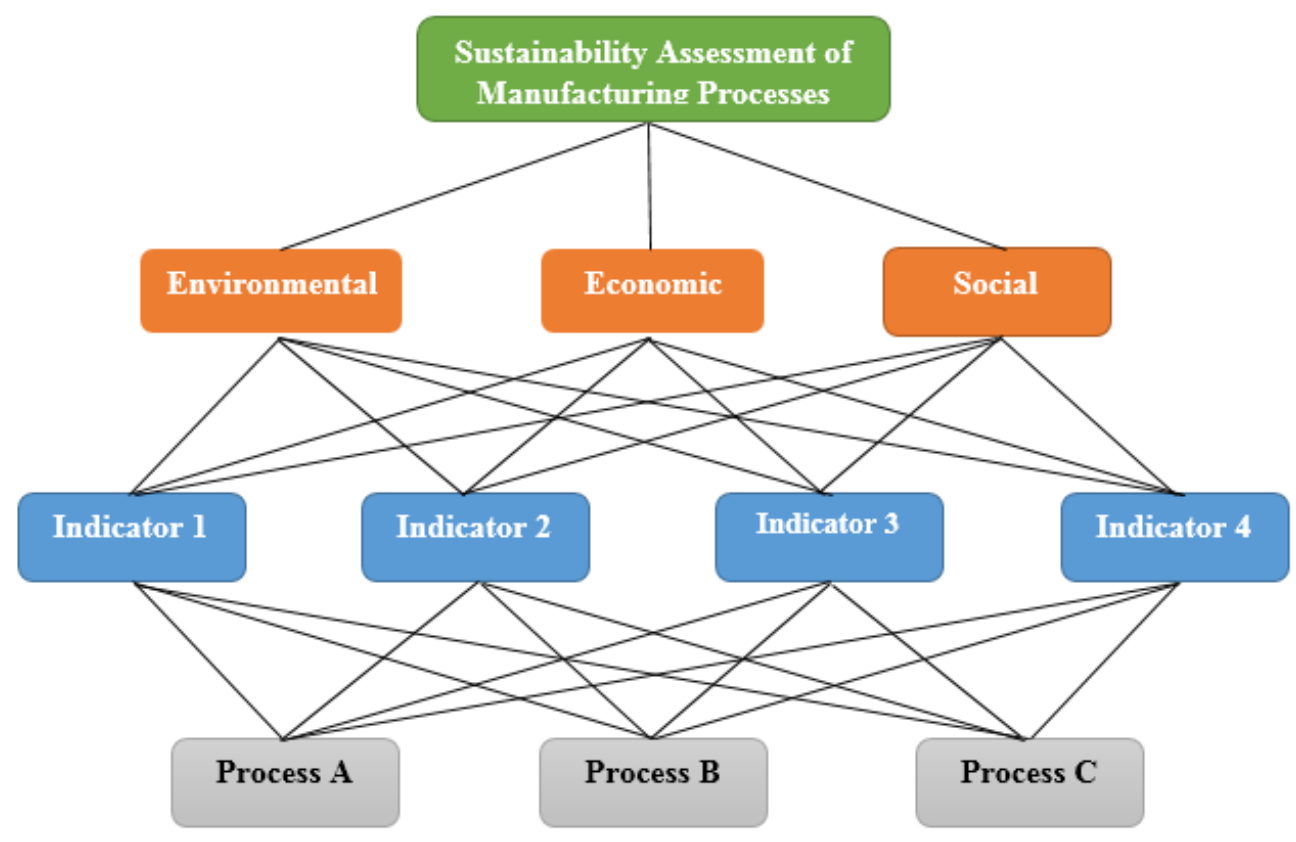

Figure 5: The AHP hierarchy structure

The AHP method is easy to use, scalable, easily adjustable to fit many sized problem and it is not data intensive. However, it has some limitations as it does not take into consideration the interdependence among criteria and alternatives in the same hierarchy level. Also, it can lead to inconsistencies between the judgment and the ranking criteria as well as rank reversal [72]. The AHP can also be used for obtaining a sustainability index or score (aggregation) by calculating the composite weight of the indicators. To make a decision in an organized way using the AHP method, Saaty [70] points out that a decision maker needs to generate priorities by decomposing the decision into the following steps:

- Defining the problem and determining the type of knowledge sought.

- Structuring the decision hierarchy from the top with the goal of the evaluation, then the dimensions of the sustainability from a broad perspective, through the intermediate levels (indicators) to the lowest level. This is mainly the set of the alternative process considered in the assessment (see Figure 5).

- Constructing a set of pairwise comparison matrices where each element in an upper level is used to compare the elements in the level just below with respect to it. In order to make these comparisons, decision makers need a scale of numbers that can be used to indicate how many times one element is more 
dominant or important over another element with respect to the attribute or indicator with respect to which they are compared. Table 2 shows the pairwise comparison scale of the indicators.

- Using the priorities obtained from step 3 to weigh the priorities in the level immediately below. After doing this for every element, the decision maker should add the weighted values of each element in the level below and obtain its overall or global priority.

- Continuing this process of weighing and adding until the final priorities of the alternatives, which are known as the composite weights, in the bottom most level are obtained.

Table 2: The fundamental scale of absolute numbers [70]

\begin{tabular}{|c|c|c|}
\hline Intensity of Importance & Definition & Explanation \\
\hline 1 & Equal Importance & $\begin{array}{l}\text { Two activities contribute equally } \\
\text { to the objective }\end{array}$ \\
\hline 2 & Weak or slight & $\begin{array}{l}\text { Experience and judgment slightly } \\
\text { favor one activity over another }\end{array}$ \\
\hline 3 & Moderate importance & $\begin{array}{l}\text { Experience and judgment strongly } \\
\text { favor one activity over another }\end{array}$ \\
\hline 4 & Moderate plus & \\
\hline 5 & Strong importance & $\begin{array}{l}\text { Experience and judgment strongly } \\
\text { favor one activity over another }\end{array}$ \\
\hline 6 & Strong plus & \\
\hline 7 & $\begin{array}{l}\text { Very strong or demonstrated } \\
\text { importance }\end{array}$ & $\begin{array}{l}\text { An activity is favored very } \\
\text { strongly over another; its } \\
\text { dominance demonstrated in } \\
\text { practice }\end{array}$ \\
\hline 8 & Very, very strong & \\
\hline 9 & Extreme importance & $\begin{array}{c}\text { The evidence favoring one activity } \\
\text { over another is of the highest } \\
\text { possible order of affirmation }\end{array}$ \\
\hline Reciprocals of above & $\begin{array}{c}\text { If activity } i \text { has one of the above } \\
\text { non-zero numbers assigned to it } \\
\text { when compared with activity } j \text {, } \\
\text { then } \mathrm{j} \text { has the reciprocal value } \\
\text { when compared with } i\end{array}$ & A reasonable assumption \\
\hline 1.1-1.9 & If the activities are very close & $\begin{array}{l}\text { May be difficult to assign the best } \\
\text { value but when compared with } \\
\text { other contrasting activities the size } \\
\text { of the small numbers would not be } \\
\text { too noticeable, yet they can still } \\
\text { indicate the relative importance of } \\
\text { the activities. }\end{array}$ \\
\hline
\end{tabular}


2.6.2. Analytical Network Process (ANP). As stated earlier, one of the major limitations for AHP method is that it normally assumes no interdependence between the indicators or alternatives at a given level of the hierarchy. However, many decisionmaking problems are not structured in a hierarchical manner and they involve inner and outer dependences (also referred to as feedbacks and interactions between indicators and/or alternatives). Therefore, the ANP method was proposed by Saaty as an extension to the AHP in order to tackle this issue [73].

In the ANP method, there is an outer dependence that refers to the situation when an alternative in a cluster could depend on some indicators that are situated at another cluster. Also, there could be an inner dependence which refers to the case when elements of a cluster can affect each other (i.e., interconnected). Figure 6 shows a typical decision making case where there is a goal, a set of performance indicators and a set of alternatives. ANP is considered a lengthy and time consuming procedure which makes it inconvenient to apply; especially for engineering applications [73].

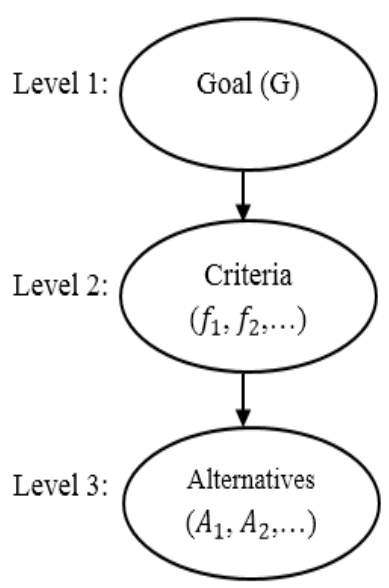

(a)

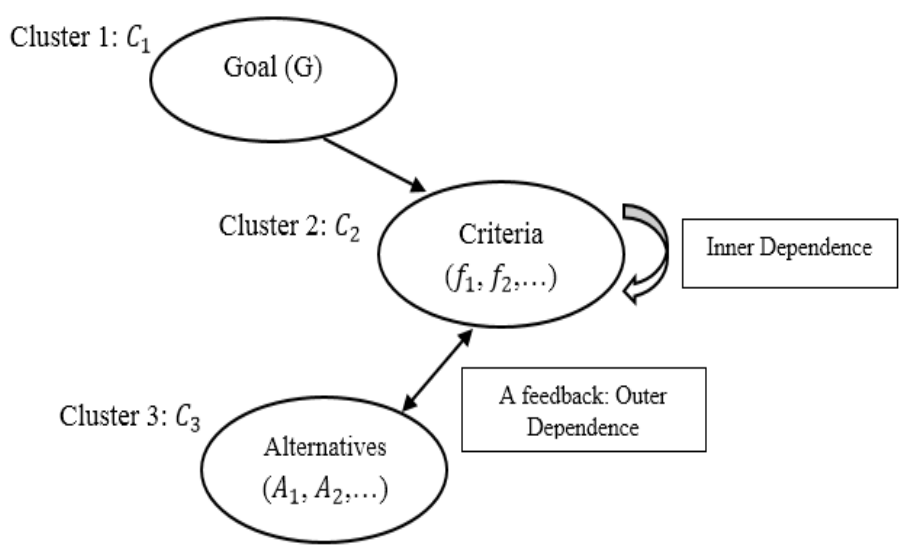

(b)

Figure 6: Example of the structural difference between a hierarchy and a network: (a) a three-level hierarchy and (b) a three-cluster network

2.6.3. Grey Relation Analysis (GRA). The grey relation method (GRA) has been developed as a quantitative approach that can assist decision-making by testing the degree of similarity or the degree of difference between two sequences based on the grade of relation[52]. The more the similarity between the two sequences, the larger the grey relational correlation is, and vice versa. 
To use the GRA method, it is important to normalize the collected data related to the sequence of selected indicator to a common scale for comparison. GRA method consists of the steps shown in Figure 7, and summarized as follows [74]:

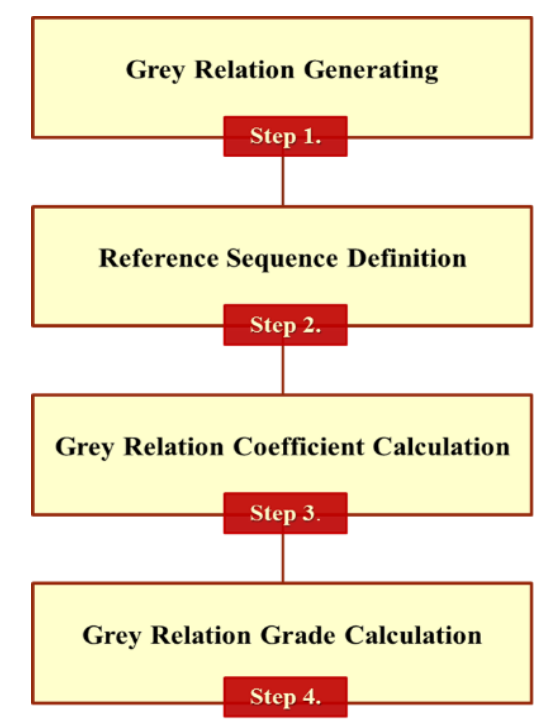

Figure 7: GRA method steps

\section{Grey relational generating (Normalization)}

This process is analogous to normalization where the different attributes or indicators are all scaled into $[0,1]$ using equations 1,2 and 3:

$$
\begin{gathered}
x_{i j}=\frac{y_{i j}-\operatorname{Min}\left(y_{i j}, i=1,2, \ldots, m\right)}{\operatorname{Max}\left(y_{i j}, i=1,2, \ldots, m\right)-\operatorname{Min}\left(y_{i j}, i=1,2, \ldots, m\right)} \quad \text { for } i=1,2, \ldots, m j=1,2, \ldots, n \\
x_{i j}=\frac{\operatorname{Max}\left(y_{i j}, i=1,2, \ldots, m\right)-y_{i j}}{\operatorname{Max}\left(y_{i j}, i=1,2, \ldots, m\right)-\operatorname{Min}\left(y_{i j}, i=1,2, \ldots, m\right)} \quad \text { for } i=1,2, \ldots, m j=1,2, \ldots, n \\
x_{i j}=1-\frac{\left|y_{i j}-y_{j}^{*}\right|}{\operatorname{Max}\left\{\operatorname{Max}\left(y_{i j}, i=1,2, \ldots, m\right)\right\}-y_{i j}^{*}, y_{i j}^{*}-\operatorname{Min}\left\{\left(y_{i j}, i=1,2, \ldots, m\right)\right.} \\
\text { for } i=1,2, \ldots, m \quad j=1,2, \ldots, n
\end{gathered}
$$

Equation 1 is used for beneficial indicators, i.e. those are the larger-the-better attributes such as the material recyclability and reusability. Equation 2 is used for nonbeneficial attributes, i.e. those are the-smaller-the-better attributes such as the energy consumption and $\mathrm{CO}_{2}$ emissions, and equation 3 is used for the-closer-to-the-desiredvalue- $y_{j}^{*}$-the-better. This step will transform all the performance values for each 
candidate process from a performance sequence $Y_{i}=\left(y_{i 1}, y_{i 2}, \ldots, y_{i j}, \ldots, y_{i n}\right)$ for every alternative process into a comparability $X_{i}=\left(x_{i 1}, x_{i 2}, \ldots, x_{i j}, \ldots, x_{i n}\right)$.

\section{Reference sequence definition}

After normalizing all the indicators values into $[0,1]$, if the value $x_{i j}$ for an indicator $j$ of process $i$, is equal to 1 , or closer to 1 than the value of the same indicators for any other process, then the process $i$ is the best one for the indicator $\mathrm{j}$. Thus, a process will be the best choice if all of its performance indicators values are equal to 1 or closest to 1 . Unfortunately, such a process does not usually exist and therefore, a reference sequence $X_{0}$ is defined as $\left(x_{01}, x_{02}, \ldots, x_{0 j}, \ldots, x_{0 n}\right)=(1,1, \ldots, 1, \ldots, 1)$. Accordingly, the goal will then become finding the alternative process that has a comparability sequence that is the nearest to the reference sequence.

\section{Grey relational coefficient calculation}

At this step, the relative closeness of $x_{i j}$ to $x_{0 j}$ is determined by the means of grey relation coefficient where the greater the grey relational coefficient, the closer $x_{i j}$ to $x_{0 j}$ is. This coefficient can be obtained using equation 4 .

$$
\gamma\left(x_{0 j}, x_{i j}\right)=\frac{\Delta_{\min }+\zeta \Delta_{\max }}{\Delta_{i j}+\zeta \Delta_{\max }} \quad \text { for } i=1,2, \ldots, m j=1,2, \ldots, n
$$

In equation $4, \gamma\left(x_{0 j}, x_{i j}\right)$ is the grey relation coefficient between $x_{0 j}$ and $x_{i j}$, and

$$
\begin{gathered}
\Delta_{i j}=\left|x_{i j}-x_{0 j}\right|, \\
\Delta_{\text {min }}=\operatorname{Min}\left(\Delta_{i j}, i=1,2, \ldots, m ; j=1,2, \ldots, n\right) \\
\Delta_{\text {max }}=\operatorname{Max}\left(\Delta_{i j}, i=1,2, \ldots, m ; j=1,2, \ldots, n\right)
\end{gathered}
$$

$\zeta$ is called the distinguishing coefficient and it is only used to enlarge or compress the range of the grey relational coefficient.

\section{Grey relational grade calculation (Aggregation)}

The last step of the GRA method is to calculate the Grey relational grade in a processes analogous to aggregation to obtain a single index that can be used later to rank the candidate processes. This can be accomplished using equation 5 .

$$
\Gamma\left(X_{0}, X_{i}\right)=\sum_{j=1}^{n} w_{j} \gamma\left(x_{0 j}, x_{i j}\right) \quad \text { for } i=1,2, \ldots, m
$$


In equation $5, \Gamma\left(X_{0}, X_{i}\right)$ shows the level of similarity between the comparability sequence and the reference sequence, and $w_{j}$ is the weight of indicator $j$ which usually depends on the judgment of the decision makers or can be calculated using suitable objective weighting methods.

2.6.4. The TOPSIS method. The Technique for Order Preferences by Similarity to Ideal Solutions (TOPSIS) approach was developed by Hwang and Yoon [75] and is used to obtain a solution that is closest to a positive ideal solution and furthest from a negative ideal solution [63]. This method needs information on relative importance of indicators which can be obtained using subjective weighting methods like the AHP or objective weighting methods such as the Entropy weight method or a combination of both. The TOPSIS approach is used not only to normalize the weighted indicators, but also to obtain a sustainability score (Aggregation) that is used later to rank the candidate processes. It is a simple process that can be used and programed easily. Also, the number of steps remains the same regardless of the number of indicators considered. However, it uses the Euclidean Distance which does not take into consideration the correlation of indicators. Also, it is somewhat difficult to assign weights for indicators and keep consistency of judgment using this method [72]. The TOPSIS methods consists of the following steps [71]:

\section{Constructing an evaluation matric}

This step is based on all the data and information available for the indicators. The matrix consists of $m$ alternatives and $n$ attributes or indicators. Each row of this matrix represents one alternative and each column represents one attribute. So, an element $x_{i j}$ in the decision matrix represents the value of the $j^{\text {th }}$ indicator in original real values for the $i^{\text {th }}$ alternative process.

2. Obtaining the normalized decision matrix (Normalization) using equation 6.

$$
R_{i j}=x_{i j} /\left[\sum_{j=1}^{n} x_{i j}{ }^{2}\right]^{0.5}
$$

3. Obtaining the weighted normalized matrix $V_{i j}$ by the multiplying each element of the matrix $R_{i j}$ with its associated weight vector $w_{j}$.

4. Finding the positive ideal (best) and negative ideal (worst) solutions. This can be done using equations 7 and 8 . 


$$
\begin{aligned}
& V^{+}=\left(\left(V_{i j}^{\max } / j\right),\left(V_{i j}^{\min } / j^{\prime}\right) / i=1,2, \ldots, n\right),=\left(V_{1}^{+}, V_{2}^{+}, V_{3}^{+}, \ldots, V_{m}^{+}\right) \\
& V^{-}=\left(\left(V_{i j}^{\max } / j\right),\left(V_{i j}^{\min } / j^{\prime}\right) / i=1,2, \ldots, n\right),=\left(V_{1}^{-}, V_{2}^{-}, V_{3}^{-}, \ldots, V_{m}^{-}\right)
\end{aligned}
$$

Where,

$$
\begin{aligned}
J & =(j=1,2, \ldots, m) / j \text { is associated with beneficial indicators and } \\
J^{\prime} & =(j=1,2, \ldots, m) / j \text { is associated with non-beneficial indicators. }
\end{aligned}
$$

5. Determining the separation of each candidate process from the ideal one by Euclidean distance which can be calculated by equations 9 and 10.

$$
\begin{gathered}
S_{i}^{+}=\left(\sum_{j=1}^{m}\left(V_{i j}-V_{j}^{+}\right)^{2}\right)^{0.5}, i=1,2, . ., n \\
S_{i}^{-}=\left(\sum_{j=1}^{m}\left(V_{i j}-V_{j}^{-}\right)^{2}\right)^{0.5}, i=1,2, . ., n
\end{gathered}
$$

6. Finding the relative closeness of every alternative process to the ideal solution, $P_{i}$, using equation 11, and then ranking the alternatives in the descending order based on the values of $P_{i}$.

$$
P_{i}=S_{i}^{-} /\left(S_{i}^{+}+S_{i}^{-}\right)
$$

2.6.5. Entropy method. The Entropy method is used to assign weights to indicators based on their quantified value (real value) [76]. It is a good approach to avoid any uncertainties and inconsistencies associated with the weights assigned by subjective judgments. In this method, the indicator with performance values that are widely different from each other have higher importance for the problem due to more influence on ranking outcomes. In other words, an indicator will have less importance if all alternatives have similar performance values for that indicator [58]. Hong et al. [76] have used the entropy weight method to determine the weights of indicators in fuzzy synthetic evaluation for water quality assessment. The evaluation result obtained by the authors showed that the entropy method for weight determination is a very effective approach for evaluating indicators. The method determines the weights of the indicators through equation 12 as following:

$$
w_{j}=\frac{1-H_{j}}{n-\sum_{j=1}^{n} H_{j}}
$$

Where $H_{j}$ is called the entropy, and can be calculated using equation 13 as following: 


$$
H_{j}=-\mathrm{k} \sum_{i=1}^{m} f_{i j} \cdot \ln \left(f_{i j}\right)
$$

Where $k=\frac{1}{\ln (m)}, f_{i j}=\frac{x_{i j}}{\sum_{j=1}^{n} x_{i j}}$, and assuming that $f_{i j}=0$ when $\ln \left(f_{i j}\right)=0$

2.6.6. ELECTRE method. The ELECTRE is an outranking method that was developed by Roy [77]. It stands for 'ELimination Et Choix Traduisant la REalité ‘ which means Elimination and Choice Expressing the Reality [71]. This method is one of the widely used MCDM method in many different applications of science and technology such as material selection [78, 79], choosing the best facility location [80] and Company Acquisition selection [81]. However, only a few applications were found in the field of manufacturing, such as manufacturing system selection [82].

The ELECTRE method is a highly efficient MCDM method because it considers the uncertainty and vagueness in the analysis which are usually inherent in data produced by estimations and predictions [71]. Another advantage of the ELECTRE method is that it can successfully deal with quantitative and qualitative indicators [71]. However, the ELECTRE has some drawbacks as it is relatively time consuming and not easy to understand because of the principles used in determining the concordance and discordance matrices. Also, it lacks in systematic way of assigning weights for the indicators. Furthermore, the thresholds calculated using these metrics are usually established according to the decision maker opinion which translates into subjectivity [83]. The procedure for decision making using the ELECTRE method is described as follows [71]:

\section{Construction of the Decision Table}

A decision table needs to be formed using the data and information available regarding the candidate processes and indicators. This step is similar to the third step in the AHP method discussed in the sec. 2.6.1

\section{Assigning Weights for the indicators}

A weight should be assigned for each indicator using subjective weighting methods like the AHP method or objective weighting method such as the entry method or using a combination of the two types.

\section{Calculations for the Final Ranking}


At this step, all the indicators are assumed to be beneficial (i.e. higher values are desired). If $f_{j}(a 1)$ is defined as the score of process " $a 1$ " on indicator, and $w_{j}$ represents the weight of indicator $j$, then the concordance index $C(a 1, a 2)$ is defined as follows:

$$
C(a 1, a 2)=\frac{1}{W} \sum_{j=1}^{M} w_{j} c_{j}(a 1, a 2), \text { where } W=\sum_{j=1}^{M} w_{j}
$$

Where,

$$
c_{j}(a 1, a 2)=\left\{\begin{array}{rr}
1, \quad \text { if } f_{j}(a 1)+q_{j} \geq f_{j}(a 2) \\
0, \quad \text { if } f_{j}(a 1)+p_{j} \leq f_{j}(a 2) \\
\frac{f_{j}(a 1)+p_{j}-f_{j}(a 2)}{p_{j}-q_{j}} \text { otherwise. } \\
j=1,2, \ldots, M
\end{array}\right\}
$$

The preference threshold $(p)$ is defined as a difference of objective values of an indicator above which the decision maker strongly prefers a process over another for the given indicator. While the indifference threshold $(q)$ is defined as a difference of indicator values below which the decision maker is indifferent between two alternative processes for the given indicator. The concordance index $C(a 1, a 2)$ shows the relative dominance of process " $a 1$ " over process " $a 2$ ", based on the assigned weights to the relevant indicators. If there exit any non-beneficial indicators, then negative of the objective values could be considered. In order to calculate the discordance index $d_{j}(a 1, a 2)$ for each indicator, a threshold, called the veto threshold, is defined. This threshold permits for the possibility of process " $a 1$ " outranking process " $a 2$ " to be totally rejected if, $f_{j}(a 1) \geq f_{j}(a 1)+v_{j}$ for any indicator $j$. The discordance index shows the degree at which process " $a 1$ " is worse than process " $a 2$ ". The discordance index is calculated as follows:

$$
d_{j}(a 1, a 2)=\left\{\begin{array}{r}
0, \quad \text { if } f_{j}(a 1)+p_{j} \geq f_{j}(a 2) \\
0, \quad \text { if } f_{j}(a 1)+v_{j} \leq f_{j}(a 2) \\
\frac{f_{j}(a 2)-p_{j}-f_{j}(a 1)}{v_{j}-p_{j}} \text { otherwise. } \\
j=1,2, \ldots, M
\end{array}\right\}
$$

The next step is combining the concordance and the discordance indices produce a measurement for the degree of outranking, which is a credibility index that 
evaluates the strength of the assertion that process $a 1$ is at least as good as process $a 2$ '.' The credibility index for each pair of processes $(a 1, a 2) \in \mathrm{A}$ is defined as:

$$
S(a 1, a 2)=\left\{\begin{array}{c}
C(a 1, a 2), \quad \text { if } d_{j}(a 1, a 2) \leq C(a 1, a 2), \forall_{j} \\
\text { where, } j \in J(a 1, a 2) \text { is the set of indicators } \\
\text { such that } d_{j}(a 1, a 2)>C(a 1, a 2) \\
C(a 1, a 2), \prod_{j \in J(a 1, a 2)} \frac{1-d_{j}(a 1, a 2)}{1-C(a 1, a 2)} \quad \text { otherwise }
\end{array}\right\}
$$

The next step is to generate the hierarchy of the alternative processes from the elements of the credibility matrix. This is accomplished by calculating the superiority ratio for each alternative process. This ratio is calculated from the credibility matrix and is defined as the fraction of the elements' sum of every process' respective column. The numerator for each alternative is also known as concordance credibility is calculated as follows:

$$
\phi^{+}(a 1)=\sum_{a 2 \in A} S(a 1, a 2)
$$

The denominator for each process i.e. discordance credibility is calculated as follows:

$$
\phi^{-}(a 1)=\sum_{a 2 \in A} S(a 2, a 1)
$$

Finally, the superiority ratio is obtained as:

$$
R(a 1)=\frac{\phi^{+}(a 1)}{\phi^{-}(a 1)}
$$

The processes are then arranged in ascending order of their superiority ratio. The processes with higher values of superiority ratio are preferred over the others.

2.6.7. COPRAS method. The COmplex PRoportional ASsessment Method (COPRAS) is widely used MCDM method in many science and technology fields. Few engineering applications of the COPRAS method were found in the literature such as sustainability assessment [84], road design [85] and construction [79, 81]. The main advantage of this method is its simplicity and flexibility of use. However, it has its limitations when dealing with qualitative indicators and attributes.

The steps of the COPRAS method for decision making in the manufacturing industries are: 


\section{Construction of the Decision Table}

Similar to the TOPSIS and ELECTREE methods, a decision table needs to be formed using the data and information available regarding the candidate processes and indicators. This step is similar to the third step in the AHP method discussed in the section 2.6.1

\section{Calculating the Weights of the Attributes}

A weight should be assigned for each indicator using subjective weighting methods like the AHP method or objective weighting method such as the entry method or using a combination of the two types.

\section{COPRAS Calculations for Final Ranking}

- Preparing a decision matrix $X$ :

$$
X=\left[\begin{array}{cccc}
m_{11} & m_{12} & \ldots & m_{1 M} \\
m_{21} & m_{22} & \ldots & m_{2 M} \\
\vdots & \vdots & \ldots & \vdots \\
m_{N 1} & m_{N 2} & \ldots & m_{N M}
\end{array}\right]
$$

where, $N$ is the number of manufacturing processes and $M$ is the number of indicators.

- Normalizing the decision matrix elements using equation 22 and producing the normalized matrix $\bar{X}$.

$$
\begin{gathered}
\bar{x}_{i j}=\frac{m_{i j}}{\sum_{i=1}^{N} m_{i j}}, \quad ; i=1,2, \ldots, N \text { and } j=1,2, \ldots, M \\
\bar{X}=\left[\begin{array}{cccc}
\overline{x_{11}} & \overline{x_{12}} & \ldots & \overline{x_{1 M}} \\
\overline{x_{21}} & \overline{x_{22}} & \ldots & \overline{x_{2 M}} \\
\vdots & \vdots & \ldots & \vdots \\
\overline{x_{N 1}} & \overline{x_{N 2}} & \ldots & \overline{x_{N M}}
\end{array}\right]
\end{gathered}
$$

where, $j$ refers to the indicator and $i$ to the process.

- Calculating the weighted normalized value using equation 24 and producing the weighted normalized matrix $\widehat{X}$.

$$
\hat{x}_{i j}=\bar{x}_{i j} \times w_{j} ; i=1,2, \ldots, N \text { and } j=1,2, \ldots, M
$$




$$
\widehat{X}=\left[\begin{array}{cccc}
\hat{x}_{11} & \hat{x}_{12} & \ldots & \hat{x}_{1 M} \\
\hat{x}_{21} & \hat{x}_{22} & \ldots & \hat{x}_{2 M} \\
\vdots & \vdots & \ldots & \vdots \\
\hat{x}_{N 1} & \hat{x}_{N 2} & \ldots & \hat{x}_{N M}
\end{array}\right]
$$

- Calculating sums $P i$ of indicators' values for beneficial indicators, for all the processes using equation 26 :

$$
P_{i}=\sum_{j=1}^{k} \hat{x}_{i j}
$$

Where, $k$ is number of indicators that should be maximized i.e. beneficial indicators.

- Calculating sums $R i$ of indicators' values for non-beneficial indicators, for all the processes using equation 27 :

$$
R_{i}=\sum_{j=k+1}^{M} \hat{x}_{i j}
$$

- Finding the minimum value of $R_{i}$ using equation 28:

$$
R_{\text {min }}=\min R_{i} ; i=1,2, \ldots, N
$$

- Calculating the relative weight of each process $Q_{i}$ using equation 29:

$$
Q_{i}=P_{i}+\left[\left(R_{\min } \sum_{i}^{M} R_{i}\right) /\left(R_{i} \sum_{i}^{M}\left(R_{\min } / R_{i}\right)\right)\right]
$$

- Determining the optimality criterion $K$ using equation 30:

$$
K=\max Q_{i} ; i=1,2, \ldots, N
$$

- Calculating the utility degree of each process using equation 31:

$$
N_{i}=\left(Q_{i} /_{\max }\right) \times 100 \%
$$

- Rank the processes in descending order based on their utility degrees.

Table 3 summarizes the MCDM methods discussed above. 
Table 3: Summary of the MCDM methods

\begin{tabular}{|c|c|c|c|c|c|c|}
\hline \multirow{2}{*}{$\begin{array}{l}\text { MCDM } \\
\text { method }\end{array}$} & \multicolumn{2}{|c|}{ Weighting } & \multirow[t]{2}{*}{ Normalization } & \multirow[t]{2}{*}{ Aggregation/Score } & \multirow[t]{2}{*}{ Advantages } & \multirow[t]{2}{*}{ Disadvantages } \\
\hline & Subjective & Objective & & & & \\
\hline AHP & $\checkmark$ & & $\checkmark$ & $\checkmark$ & $\begin{array}{l}\text { Easy to use, } \\
\text { scalable, } \\
\text { easily } \\
\text { adjustable to } \\
\text { fit many sized } \\
\text { problem and } \\
\text { it is not data } \\
\text { intensive } \\
\end{array}$ & $\begin{array}{c}\text { Does not take } \\
\text { into accounts } \\
\text { interdependence } \\
\text { among criteria } \\
\text { and alternatives, } \\
\text { can lead to } \\
\text { inconsistencies }\end{array}$ \\
\hline ANP & $\checkmark$ & & $\checkmark$ & $\checkmark$ & $\begin{array}{c}\text { Takes into } \\
\text { account inner } \\
\text { and out } \\
\text { dependencies } \\
\end{array}$ & $\begin{array}{l}\text { Lengthy and } \\
\text { time consuming }\end{array}$ \\
\hline GRA & & & $\checkmark$ & $\checkmark$ & $\begin{array}{l}\text { Easy to use, } \\
\text { useful for } \\
\text { dealing with } \\
\text { poor, } \\
\text { incomplete, } \\
\text { and uncertain } \\
\text { information }\end{array}$ & $\begin{array}{c}\text { Different } \\
\text { distinguish } \\
\text { coefficients may } \\
\text { lead to different } \\
\text { solution results }\end{array}$ \\
\hline TOPSIS & & & $\checkmark$ & $\checkmark$ & $\begin{array}{l}\text { Simple and } \\
\text { easy to be } \\
\text { used and } \\
\text { programed, } \\
\text { takes input as } \\
\text { any number } \\
\text { of criteria and } \\
\text { attributes }\end{array}$ & $\begin{array}{c}\text { Use of } \\
\text { Euclidean } \\
\text { distance does } \\
\text { not consider the } \\
\text { correlation of } \\
\text { attributes, does } \\
\text { not consider } \\
\text { uncertainty in } \\
\text { weightings, can } \\
\text { give unreliable } \\
\text { results } \\
\end{array}$ \\
\hline Entropy & & $\checkmark$ & & & $\begin{array}{c}\text { Easy to use, } \\
\text { help avoiding } \\
\text { uncertainties } \\
\text { associated } \\
\text { with } \\
\text { subjective } \\
\text { judgments }\end{array}$ & $\begin{array}{l}\text { Not suitable for } \\
\text { qualitative } \\
\text { attributes }\end{array}$ \\
\hline ELECTRE & & & $\checkmark$ & $\checkmark$ & $\begin{array}{c}\text { Takes } \\
\text { uncertainty } \\
\text { and } \\
\text { vagueness } \\
\text { into account } \\
\end{array}$ & $\begin{array}{l}\text { Time consuming } \\
\text { and not easy to } \\
\text { understand }\end{array}$ \\
\hline COPRAS & & & $\checkmark$ & $\checkmark$ & $\begin{array}{c}\text { Simple and } \\
\text { easy to use, } \\
\text { takes into } \\
\text { account the } \\
\text { performance } \\
\text { of the } \\
\text { alternatives } \\
\text { with respect } \\
\text { to different } \\
\text { criteria and } \\
\text { the } \\
\text { corresponding } \\
\text { criteria } \\
\text { weights } \\
\end{array}$ & $\begin{array}{l}\text { Cannot deal } \\
\text { very well with } \\
\text { qualitative } \\
\text { criteria }\end{array}$ \\
\hline
\end{tabular}




\subsection{Sensitivity Analysis}

A common definition of sensitivity analysis (SA) is: "The study of how uncertainty in the output of a model (numerical or otherwise) can be apportioned to different sources of uncertainty in the model input" [86]. In MCDM methods, it is assumed that the input data, which are the weights and values of indicators, are deterministic, and the final scores are obtained based on this assumption. However, variation in input data is inevitable due to the nature of manufacturing processes. As a results, sensitivity analysis has to be performed to ensure the reliability of the results (final scores). If small changes of an input indicator result in significant changes in the final scores, then it is stated that the latter are sensitive to this indicator. This implicitly means that either the indicator should be determined more accurately [86], or the MCDM method used is too sensitive to a specific indicator and has to be changed to obtain a reliable score. If the results obtained from the sensitivity analysis are acceptable, then the decision maker can proceed to the final step which is ranking the candidate processes according to the aggregated scores obtained earlier.

2.7.1. Steps for sensitivity analysis. As stated earlier, the decision maker should analyze the sensitivity of the model that is used in the evaluation of sustainability. Figure 8 summarizes the systematic procedure to be followed for performing sensitivity analysis.

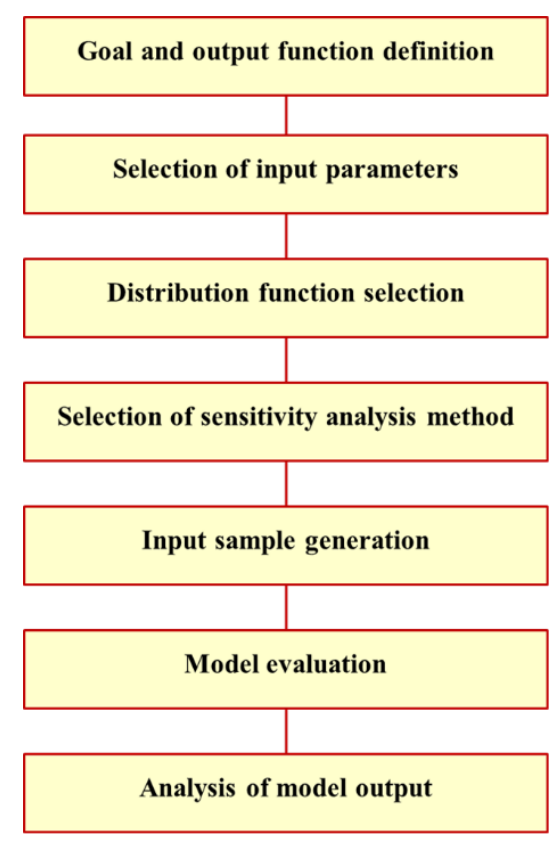

Figure 8: Steps for sensitivity analysis 
The sensitivity analysis steps are as follows [87]:

- Define the goal of the analysis and the form of the output function. In this framework, the desired goal is the sustainability assessment of manufacturing processes. The output function is a single sustainability score or index.

- Decide which indicators to be included in the analysis.

- Select suitable distribution function for each of the considered indicators. This can be taken from the literature, derived from data by fitting an empirical distribution function, based on expert's opinions, or through the definition of a correlation structure between the indicators, if possible.

- Choose a suitable sensitivity analysis method based on the questions a decision maker is trying to address and the number of model evaluations that a decision maker can afford based on the execution time. For example, to properly analyze the sustainability assessment score obtained from a MCDM method, a policymaker might need a quantitative method in order to be able to answer his/her final question. In addition, if the number of included sustainability indicators is high and the evaluation process is time-consuming, the decision maker is forced to use a simple method that needs a low number of model evaluations.

- Generate an input sample that consists of input indicators values on which the decision-maker evaluates the model. The sample is generated according to the method chosen for the sensitivity analysis.

- Evaluate the model on the generated input sample and produce the output.

- Analyze the model output and draw conclusions, or if needed, start a new iteration of the analysis.

2.7.2. Sensitivity analysis methods. In order to use the same terminology to present each sensitivity technique, a generalized model is defined as:

$$
\boldsymbol{Y}=\boldsymbol{f}(\boldsymbol{X})
$$

Where $X$ the vector of input indicators is included in the analysis, and $Y$ is the corresponding model output that could be an objective function or a time series. The following are suggested sensitivity analysis methods that are widely used, and can possibly be applied for the sustainably assessment of manufacturing processes. 
2.7.2.1. One-at-a-time sensitivity measures. Conceptually, this is the simplest method in which sensitivity measurement is usually calculated by changing the value of one indicator and fixing the values of all other indicators [88]. It is also known as 'local' sensitivity analysis. A sensitivity ranking or score can be obtained by varying the value of each indicator by a certain percentage while leaving all others constant, and quantifying the change in the sustainability score. The model result, with all parameters or indicators remaining constants, is defined as the 'base case'. This approach is designed on the behavior of the model given a specific set of indicator values. For instance, assuming the base-case scenario is with all indicator values set to their mean [89]. This method can be easily applied and interpreted. It usually requires low simulation runs in comparison to other methods. However, it does not take into account the interactions and interdependencies between the indicators. Also, it only investigates a reduced space of the input parameter or indicator around a base case.

2.7.2.2. Linear regression analysis. This method is based on establishing a linear relationship between the indicators and the model output [90]. It can provide a measure of how sensitive the model output $y$ is to an indicator $x_{i}$ :

$$
y=b_{0}+\sum_{i=1}^{n} b_{i} x_{i}
$$

Once the regression coefficients $b_{i}(i=1, \ldots, n)$ are estimated (e.g., via least squares method), the absolute standardized regression coefficient, SRC, can be taken as the sensitivity score or measure using the following relation:

$$
S R C_{i}=\left|b_{i} \frac{\hat{S}_{i}}{S}\right|
$$

Where $S_{i}$ and $\mathrm{S}$ are the estimated standard deviations for $i^{\text {th }}$ indicator and the output $y$, respectively. This method is simple and straightforward. However, it is not applicable for non-linear or non-monotonic relationships between the indicators and the sustainability score. Additionally, it cannot be applied when there exists a high level of interactions and interdependencies among the indicators.

2.7.2.3. Differential sensitivity analysis. Differential analysis, also referred to as the direct method, is based on partial differentiation of the model in aggregated form [88]. It can be thought of as the propagation of uncertainties. A first-order Taylor series approximation is applied to the dependent variable, $y$, as a function of the independent 
variables $X=(X i \ldots . X n)$. The variance of $Y, V(Y)$, is calculated using the general error propagation formula:

$$
V(Y)=\sum_{i=1}^{n}\left(\frac{\partial Y}{\partial X i}\right)^{2} V(X i)
$$

The variance in $Y$ is used to measure the uncertainty in model predictions while the variance in $X i$, weighted by the first-order partial of $Y$ with respect to $X i$, is used to measure the sensitivity of the model to $X i$. This method is a linearized theory and is valid only for small parameter uncertainties. Sensitivity analyses using partial differentiation approaches are computationally efficient. However, solving these equations can require quite intensive effort. Derivatives of simple functions may be obtained by less analytical or differencing schemes. However more complex models usually require complicated numerical procedures. The sensitivity analysis is easy to perform when an explicit algebraic equation describes the relationship between the independent variables and the dependent variable. In this case, the sensitivity coefficient, $\phi i$, for a particular independent variable can be calculated from the partial derivative of the dependent variable with respect to the independent variable, i.e.

$$
\phi i=\frac{\partial Y}{\partial X i}\left(\frac{X i}{Y}\right)
$$

Where the quotient, $X i / Y$, is introduced to normalize the coefficient by removing the effects of units. Inherent to this calculation are the assumptions that the higher ordered partials are negligible and there is no correlation between input parameters. For large sets of equations, the partial derivative can be approximated as a finite difference and output values calculated for small changes in the input parameter. Thus, if nonlinearities are neglected, the partial derivative can be approximated as,

$$
\phi i=\frac{\% \Delta Y}{\% \Delta X i}
$$

The partial derivative approach to sensitivity analysis may become so complicated that its implementation becomes impractical. Also, since this approach is only valid for small changes in indicator values, when parameter variability is allowed to take on 'realistic' values, the direct approach is seriously violated. The differential analysis is typically much more demanding to implement than other sensitivity methods and yet provides only comparable results. 
2.7.2.4. The sensitivity index. This is another simple method for sensitivity analysis where a decision maker needs to calculate the output percentage difference when varying one input parameter from its minimum value to its maximum value [88]. The 'sensitivity index' (SI) is calculated using equation 37:

$$
S I=\frac{D_{\max }-D_{\min }}{D_{\max }}
$$

where Dmin and Dmax respectively represent the minimum and maximum values of the output, which results from changing the input over its whole range of values.

Table 4 below summarizes the previously discussed sensitivity analysis methods.

Table 4: Summary of the suggested sensitivity analysis methods

\begin{tabular}{|c|c|c|c|}
\hline Method & Applicability & $\begin{array}{l}\text { Amount of } \\
\text { computation }\end{array}$ & Reliability \\
\hline $\begin{array}{c}\text { One-at-a time sensitivity } \\
\text { measure }\end{array}$ & Model-independent & Low & Low \\
\hline Linear regression analysis & Linear Models & Low & Depend on $R^{2}$ \\
\hline $\begin{array}{c}\text { Differential sensitivity } \\
\text { analysis }\end{array}$ & $\begin{array}{l}\text { Linear and non-linear } \\
\text { models }\end{array}$ & $\begin{array}{l}\text { Demanding in general, but } \\
\text { low for simple functions }\end{array}$ & $\begin{array}{c}\text { Only valid for } \\
\text { small changes in } \\
\text { indicator values }\end{array}$ \\
\hline The sensitivity index & Model-independent & Low & $\begin{array}{l}\text { provides a good } \\
\text { indication of } \\
\text { parameter and } \\
\text { model variability }\end{array}$ \\
\hline
\end{tabular}




\section{Chapter 3. Case Study}

The aim of this section is the application of the proposed framework on different welding processes, including Friction Stir Welding (FSW), Gas Metal Arc Welding (GMAW), Gas Tungsten Arc Welding (GTAW) and Shielded Metal Arc Welding (SMAW) to weld thick aluminum 5083 alloy plates. The results are used to compare the corresponding sustainability level of each process. The results can have industrial implications in terms of identify the crucial issues associated with each process, and then defining the consequent improvements of the processes and equipment towards more sustainable alternatives.

\subsection{Introduction}

Welding is universally perceived as the most important joining technology. It plays a substantial role in modern manufacturing as it is widely involved in several applications such as the automotive industry, construction, shipbuilding industry, turbine production and many other industrial segments. However, the welding processes have negative environmental impacts as they consume significant quantities of energy and resources. Also, the amounts of greenhouse gases emitted and fumes discharged by welding processes are large and can cause grievous health issue to welders exposed to them.

Limited research work have been done to evaluate the sustainability performance of welding processes [48-50, 91-94]. Sproesser et al. [91] applied a Life Cycle Assessment (LCA) tool to investigate the environmental impacts of Manual Metal Arc Welding (MMAW), Automatic Laser-Arc Hybrid Welding (LAHW), and Gas Metal Arc Welding (GMAW) with a conventional spray arc and a modified spray arc on four selected impact categories; eutrophication potential, acidification potential, global warming potential and photochemical ozone creation potential. Chang et al. [48] carried out a study that incorporated LCA and Social Life Cycle Assessment (SLCA) to evaluate the environmental and social impacts of different welding technologies. The authors found the manual welding process to be more risky to welders' health over the automatic processes. Vimal et al. [92] presented a study on sustainable Shielded Metal Arc Welding (SMAW) process. They addressed five important sustainable manufacturing strategies (green strategies), which are energy modeling and 
optimization studies, waste minimization and disposal studies, process parametric optimization, process emission studies, and employee skill training and involvement program, to study their effect on SMAW using LCA tool. Sproesser et al. [49] conducted a research to select a sustainable welding process on the basis of weight space partitions approach. The considered welding processes were manual and automatic Gas Metal Arc Welding (GMAW). The evaluation of sustainability was based on environmental and economic criteria.

Most of the frameworks and models used in evaluating the sustainability of welding process were not comprehensive as they considered a limited number of indictors that do not capture all dimensions of sustainability. To address this challenge, the proposed framework will be used to comprehensively evaluate the sustainability of several welding processes. The welding processes considered in this study are Friction Stir Welding (FSW), Gas Tungsten Arc Welding (GTAW), Gas Metal Arc Welding (GMAW) and Shielded Metal arc Welding (SMAW). An experiment was conducted to weld thick aluminum plates using these processes. The framework considers enough sustainability indicators from each dimension. A physical performance dimension is added to evaluate the quality of the welded parts produced by each process. After welding, several tests were carried out on the welded parts to quantify the physical performance indicators. The relative importance of each indicator was determined using the objective (based on indicators' values) Entropy Weight method in order to avoid any uncertainties associated with subjective (based on decision makers' experience or opinion) weighting methods. The results are used to compare the corresponding sustainability level of each process. Different Multi Criteria Decision Making (MCDM) methods are used for normalization and aggregation in order to address any possible interactions among different sustainability indicators. Sensitivity analysis of the obtained results is conducted in this study to ensure the reliability and robustness of the final scores.

The next sections discusses the experiments conducted to weld thick metallic plates using the aforementioned processes. It also presents the tests carried out on the welded parts to quantify the indicators for the physical performance dimension. After that, a detailed discussion on the sustainability model used in this study is presented including the key performance indicators for each dimension, the weighting method 
used and the MCDM methods considered for normalization and aggregation and the results of the sustainability assessment and sensitivity analysis.

\subsection{Welding Technologies}

3.2.1. Friction Stir Welding (FSW). Friction stir welding (FSW), illustrated in Figure 9 [95], is a solid state welding process in which a cylindrical rotating tool, consisting of a cylindrical shoulder and a pin projecting beneath it, is traversed along the joint line between two work pieces. This process generates heat due to friction and mechanical stirring of the metal by the pin to form the weld seam [96].

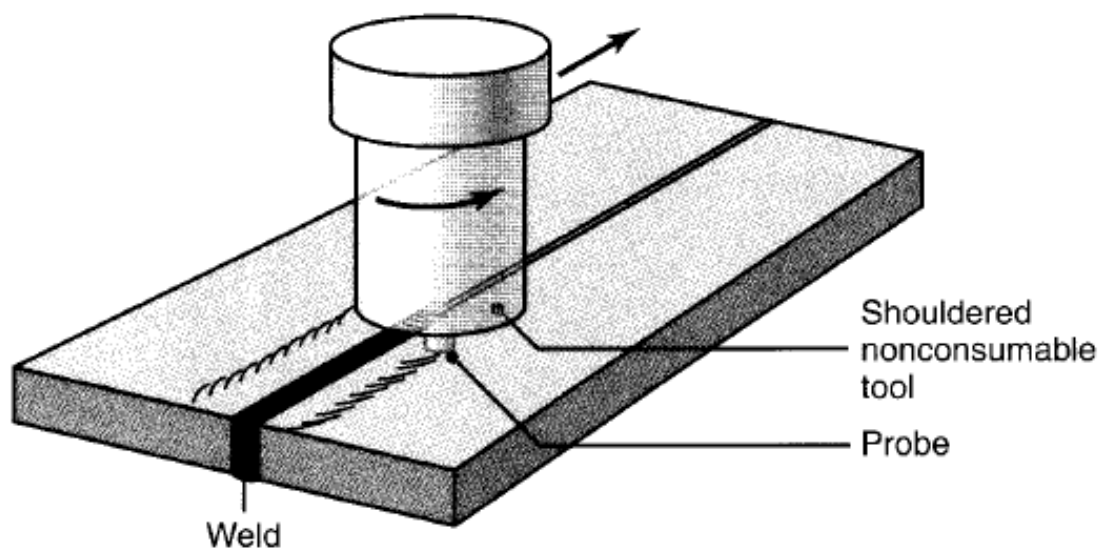

Figure 9: The principle of friction stir welding process

The heat produced by the friction and mixing does not melt the metal but softens it to a temperature under the melting point of the base material in order to avoid any operational issues related to the melting and solidification of the material [97]. FSW process does not require any filler material. FSW process is used in various industries such as automotive, aerospace, railway, and shipbuilding industries. Typical applications include butt joints on large aluminum parts. Also, it can be used to join other metals such as steel, copper, and titanium. Polymers and composites have also been joined using FSW. The advantages of FSW over other welding processes include; good mechanical properties of the weld joint, good weld shape, little shrinkage or distortion and avoidance of any problems associated with arc welding such as toxic fumes, warping and shielding issues. However, FSW also has several noteworthy drawbacks. For instance, when the tool is removed from the work piece, an exit hole is produced. Additionally, heavy-duty clamping of the parts is typically required [96]. 
3.2.2. Gas Metal Arc Welding (GMAW). Gas Metal Arc Welding (GMAW), also known as Metal Inert Gas (MIG), is an arc welding process in which a consumable electrode (bare metal wire) is used along with a shielding gas. The electrode is continually and automatically fed from a spool through the welding gun, as shown in Figure 10 [96].

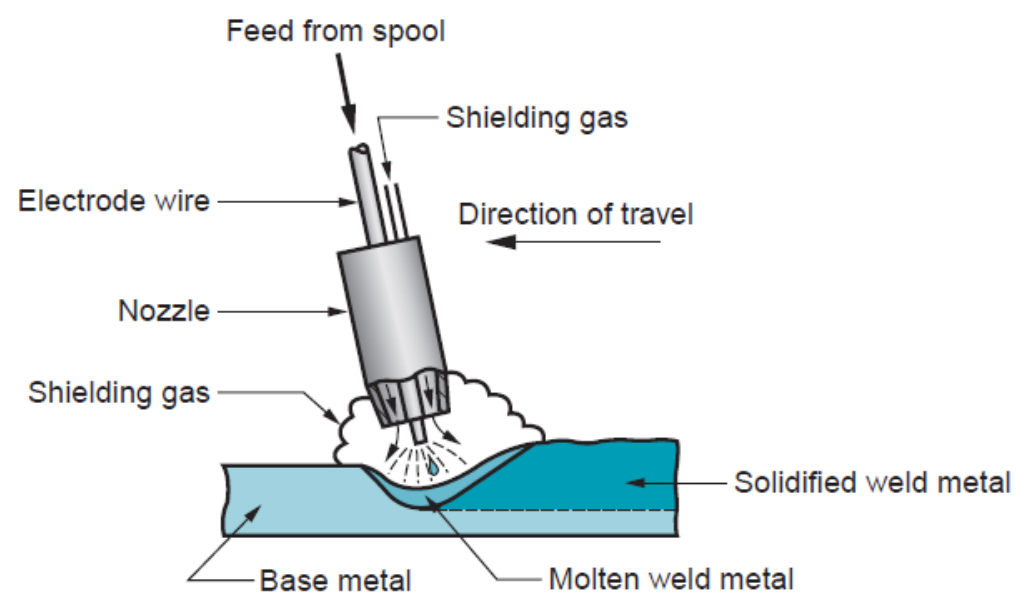

Figure 10: The principle of gas metal arc welding process

Typical shielding gases used in GMAW include inert gases such as argon and helium, and active gases such as carbon dioxide. Inert gases are used mainly for welding aluminum alloys and stainless steels, while carbon dioxide is commonly used for welding low and medium carbon steels [96]. In this process, the need for cleaning and manual grinding of the slag is eliminated as the use of bare electrode wire combined with shielding gases eliminates the slag covering on the weld bead .GMAW is widely used in factories for welding a variety of ferrous and nonferrous metals. The advantages of GMAW include shorter welding time compared to other arc welding process such as Shielded Metal Arc Welding (SMAW), because GMAW uses continuous weld wire rather than welding sticks. Also, the utilization of electrode material is higher in GMAW compared to the other processes that use stick welding. This is because in stick welding, filler material is wasted because of the remaining electrode stump. Furthermore, since no flux is used, the need for slag removal in GMAW is eliminated [96].

3.2.3. Gas Tungsten Arc Welding (GTAW). Gas tungsten arc welding (GTAW), also known as Tungsten Inert Gas (TIG), is an arc welding process in which 
a non-consumable tungsten electrode is used along with an inert gas for arc shielding, as shown in Figure 11 [96]. GTAW can be applied with or without a filler metal.

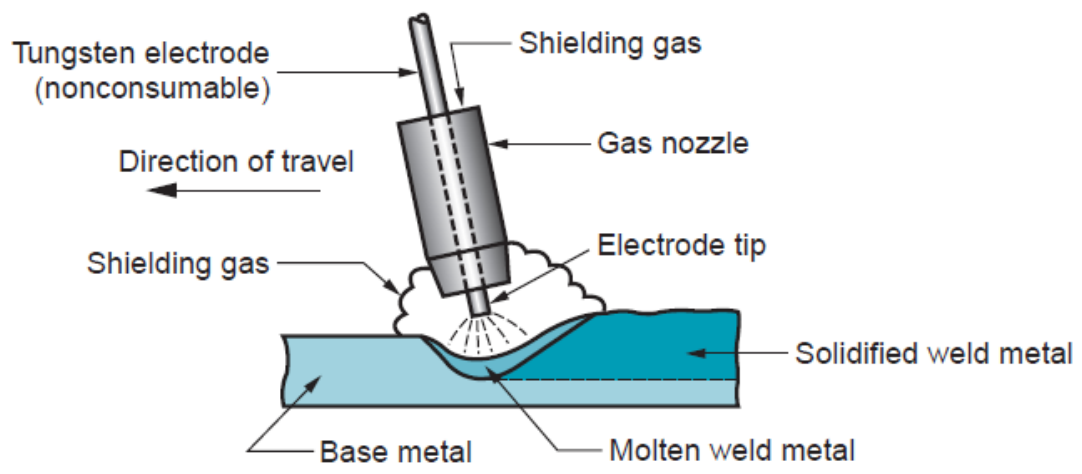

Figure 11: The principle of gas tungsten arc welding process

When a filler material is used in the process, it is supplied to the weld spool from a separate rod. The filler material is melted by the heat of the arc instead of being transferred across the arc as the case in the consumable electrode arc welding processes. Tungsten is considered an adequate electrode material since it has a high melting temperature. Usually, argon, helium or a combination of both is used as a shielding gas. A wide range of stock thicknesses of almost all metal can be joint using GTAW. Also, several combinations of dissimilar metal can be joined using GTMA. Typical manual and automatic application of GTAW include aluminum and stainless steel for almost all types of joints. Cast irons, wrought irons, and of course tungsten are difficult to weld by GTAW. Advantages of GTAW include producing welds with high quality, almost no cleaning is needed after weld since no flux is used. Also, since no filler is transferring across the arc, no weld spatter is generated.

3.2.4. Shielded Metal Arc Welding (SMAW). Shielded metal arc welding (SMAW), also known as stick welding, is an arc welding process that uses a consumable electrode. Unlike the GMAW and GTAW, this process does not use a gases for shielding. Instead, it uses an electrode that consists of a filler metal rod coated with chemicals to provide flux and shielding, as shown in Figure 12 [96]. The composition of the filler metal must be very close to that of the metal to be welded. 


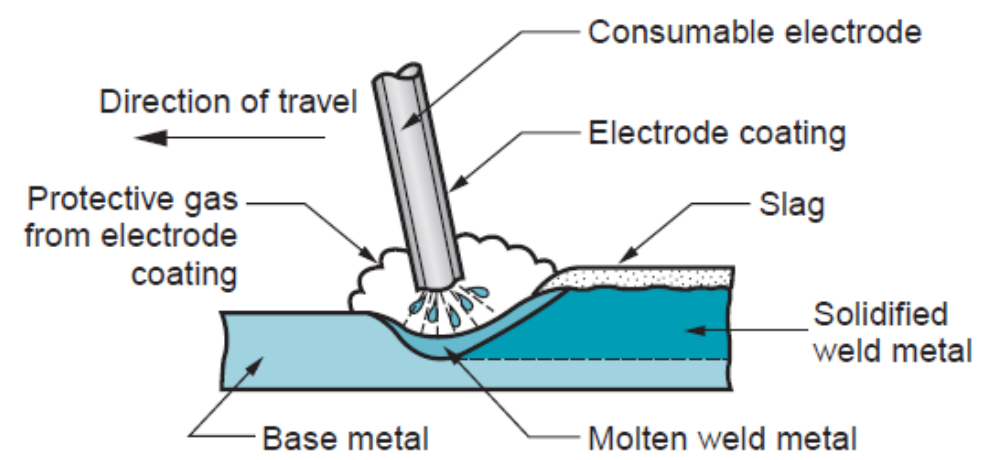

Figure 12: The principle of shielded metal arc welding process

Typically, the coating is composed of powdered cellulose, which are mainly cotton and wood powders, mixed with carbonate, oxides and other ingredients, held together by a silicate binder. Metal powders are also sometimes incorporated in the coating to increase the amount of filler material and to add alloying components. The coating is melted by the heat of the welding process which results in generating a protective slag and atmosphere for the welding operation. This also helps in stabilizing the arc and regulating rate of melting of the electrode [96]. Typical applications of SMAW include pipeline, machinery, construction, shipbuilding, job shop fabrication, and repair work. SMAW is commonly used to weld steels, stainless steels, cast irons, and some nonferrous alloys. It is not used or rarely used to weld aluminum and its alloys, titanium and copper alloys. The advantages of SMAW include low cost and easy portability of the equipment, which make this process highly versatile. However, the arc time is reduced in SMAW as the sticks should be changed periodically. Also, the coating could overheat and melt prematurely if no current level is maintained at a safe range. That is due to the variation of the length during the operation which affects the resistance heating of the electrode.

\subsection{Experimental Work}

3.3.1. Setup. The goal of the experiment was to weld two similar thick metallic plates using FSW, GMAW, GTAW and SMAW processes. The material used in this study was aluminum alloy 5083 in form of 5-mm-thick sheets, as shown in figure 13. For each process, three samples (pairs of plates) were prepared to ensure repeatability and accuracy of the results. The type of the welding joint was the butt joint. For GMAW, GTAW and SMAW, the samples were prepared with a single V-groove along 
the weld seam to facilitate filler metal penetration. However, the samples for FSW were prepared without any grooves since no filler material is used in this process.

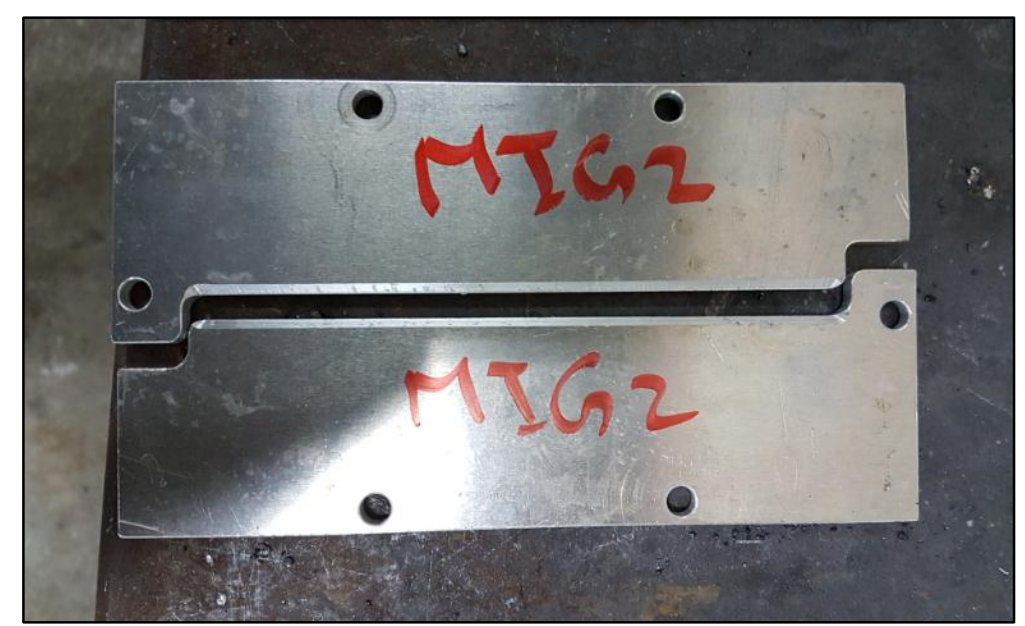

Figure 13: Metallic plates to be welded

Before welding, each sample was named based on the corresponding welding process and the corresponding trial number. For instance, the first trial for fiction stir welding was named "FSW-1", the second trial was named "FSW-2" and so on.

The FSW process was conducted using a vertical computer numerical control (CNC) machine. The main process parameters were the feed rate and the rotational speed of the spindle. The feed rate was set to $70 \mathrm{~mm} / \mathrm{min}$, while the rotational speed was set to $1100 \mathrm{rpm}$ clockwise, as per the literature [98]. For the other processes, the main parameters were the current, the voltage, the type of electrode and the type of the shielding gas. The values considered for these parameters are within the ranges used in the literature [99]. Table 5 shows the process parameters for GMAW, GTAW and SMAW. Figure 14 presents welded samples for each process.

Table 5: Processes' parameters

\begin{tabular}{cccc}
\hline Process & GMAW $($ MIG) & GTAW $($ TIG) & SMAW \\
\hline Current (A) & 152 & 210 & 133 \\
\hline Voltage $(\mathbf{V})$ & 20 & 18.5 & 71.7 \\
\hline Electrode type & ALSi5 & R 5356 & E AL43 \\
\hline Shielding Gas & $100 \%$ Argon & $100 \%$ Argon & None \\
& $(13.5 \mathrm{~L} / \mathrm{min})$ & $(15.1 \mathrm{~L} / \mathrm{min})$ &
\end{tabular}



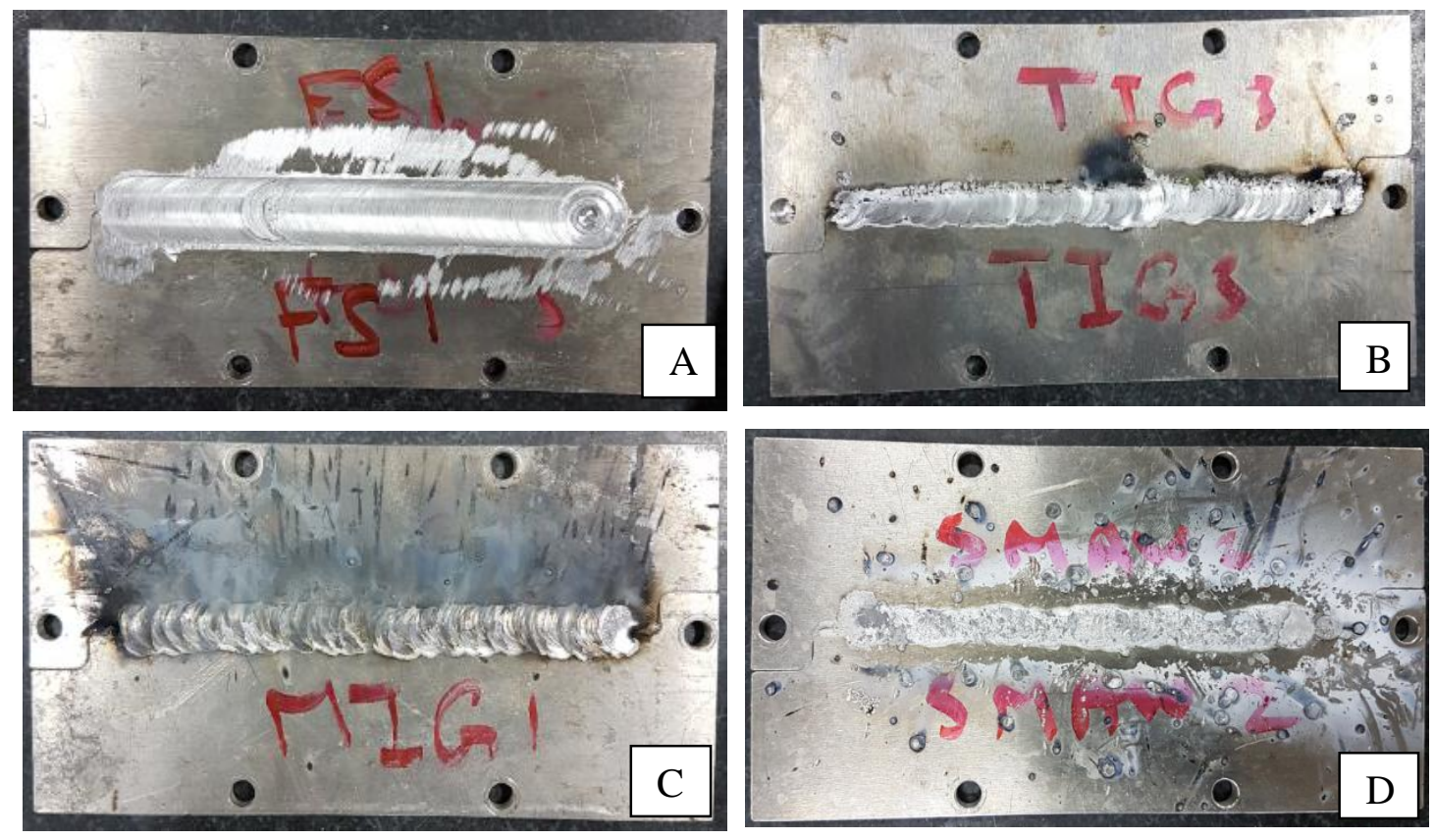

Figure 14: Welds using A) FSW, B) TIG, C) MIG and D) SMAW

3.3.2. Testing and experimental results. After welding the samples, tensile specimens were obtained transverse to the weld direction, in addition to smaller samples for microstructural investigations as well as samples for the impact toughness test, as shown in Figure 15.

3.3.2.1. Tensile test. Tensile tests were conducted at room temperature to study the stress-strain relationship for the welded parts. The tests were conducted using an Instron universal tensile testing machine that has a force capacity of $100 \mathrm{kN}$. To ensure

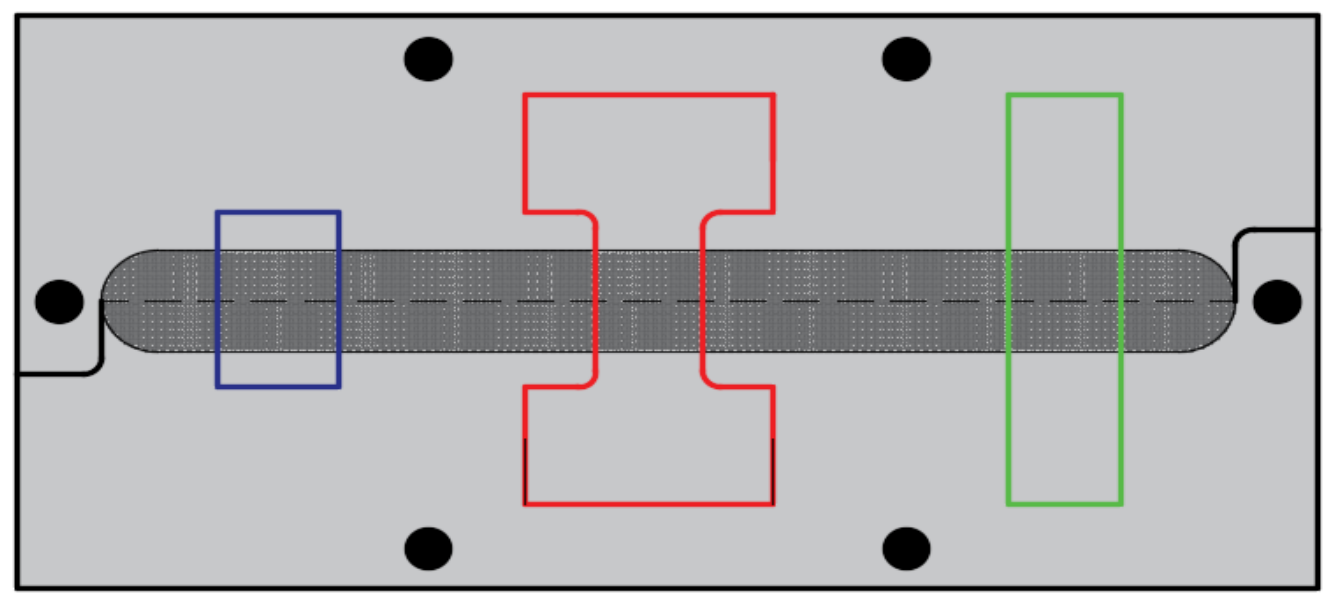

Figure 15: Tensile, microstructural and impact toughness test specimens 
the accuracy and reliability of the experimental results, all tests were conducted under the same conditions. For each process, three test specimens were prepared, so a total of 15 specimens were prepared including three specimens for the base material (without weld). The specifications of the test samples where determined according to the American Society for Testing and Materials-E8 (ASTM-E8) [100]. Figure 16 shows a

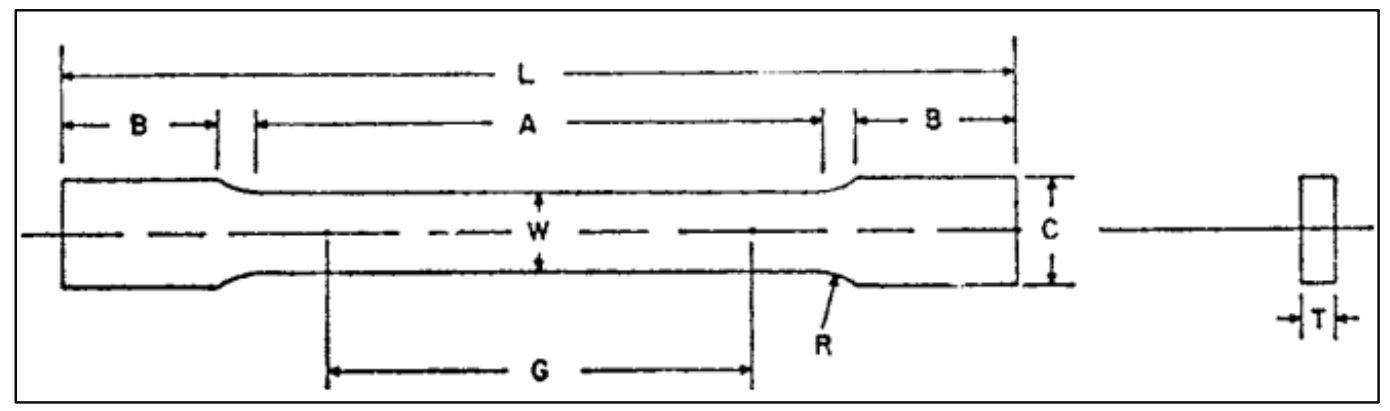

Figure 16: Standard tensile test specimen

standard plate-type test specimen used for testing metallic materials in plate form, with a nominal thickness of $5 \mathrm{~mm}$ (0.188 in.) or over.

Table 6 shows the dimensions of the test specimens used in this study. Figure 17 and Figure 18 show a test specimen before conducting the test and after the test, respectively.

Table 6: Dimensions of the tensile test specimens

\begin{tabular}{c|c|c|c|c|c|c}
\hline $\begin{array}{c}\text { L-Overall } \\
\text { length } \\
(\mathbf{m m})\end{array}$ & $\begin{array}{c}\text { W-Width } \\
(\mathbf{m m})\end{array}$ & $\begin{array}{c}\text { T- } \\
\text { Thickness } \\
(\mathbf{m m})\end{array}$ & $\begin{array}{c}\text { A-Length } \\
\text { of reduced } \\
\text { section } \\
(\mathbf{m m})\end{array}$ & $\begin{array}{c}\text { R-Fillet } \\
\text { radius } \\
(\mathbf{m m})\end{array}$ & $\begin{array}{c}\text { B-Length } \\
\text { of grip } \\
\text { section } \\
(\mathbf{m m})\end{array}$ & $\begin{array}{c}\text { C-Width } \\
\text { of grip } \\
\text { section } \\
(\mathbf{m m})\end{array}$ \\
\hline 73.91 & 10 & 5 & 27.91 & 6 & 17 & 15 \\
\hline
\end{tabular}

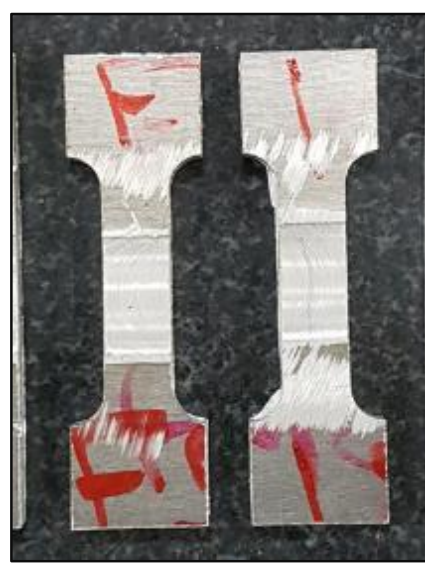

Figure 17: Specimens for tensile test 


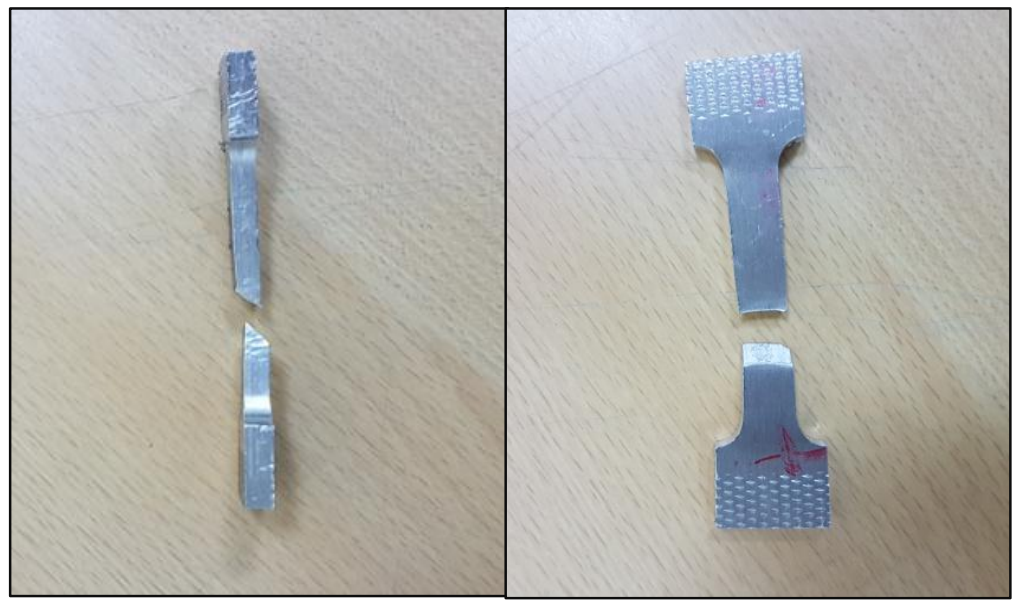

Figure 18: Tensile test specimens after fracture

The tensile stress-stain curves for samples produced by each welding process were obtained experimentally by the tensile test. Figures 19 shows the stress-strain curves for the base metal, and samples produced by FSW, TIG, MIG and SMAW, respectively. From Figure 4, data of yield strength, tensile strength and ductility of the welded parts were obtained and recorded in Table 7.

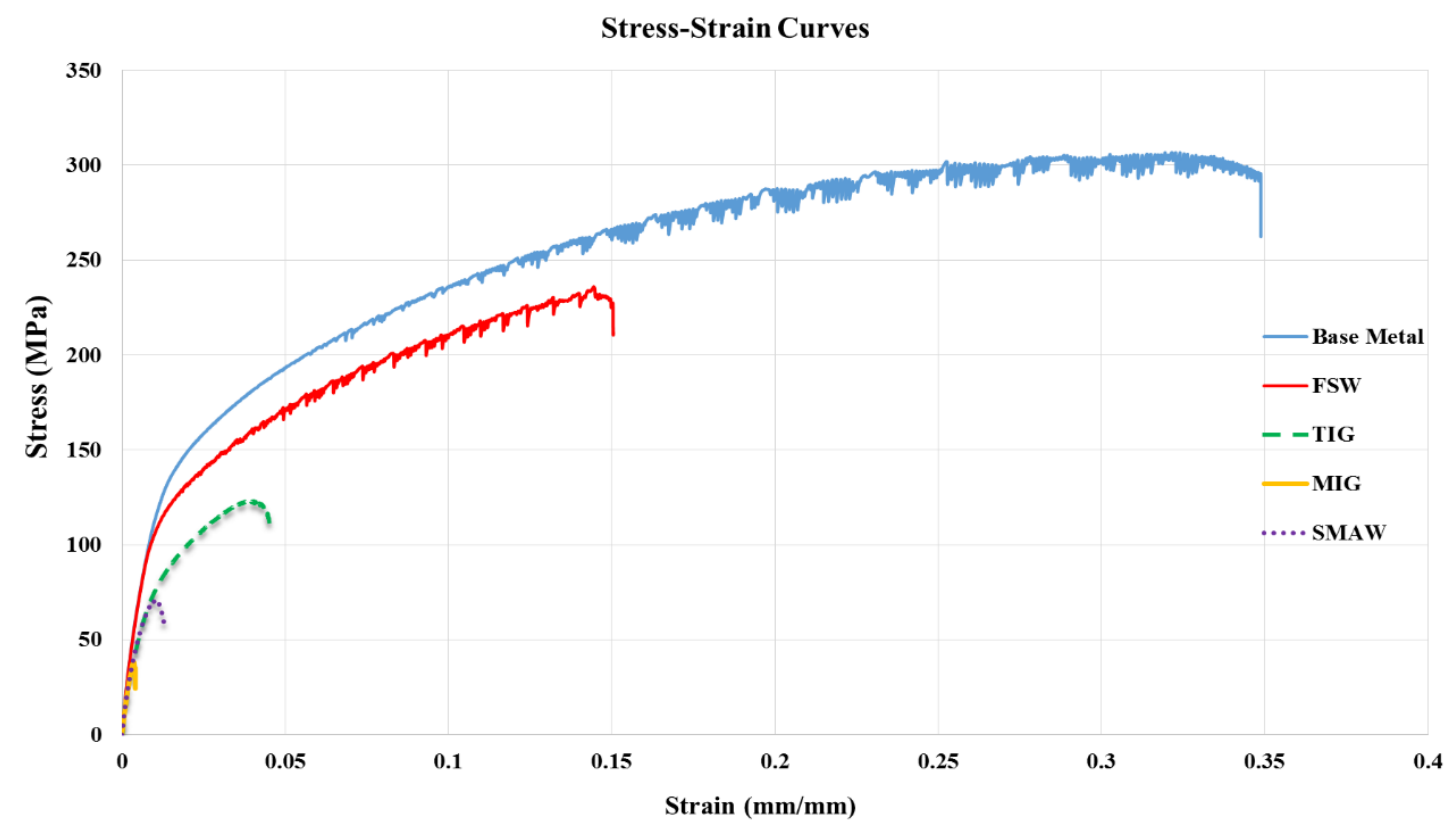

Figure 19: Stress-Strain curves for welded base and welded samples 
Table 7: Mechanical properties obtained from the stress-strain curves

\begin{tabular}{cccc} 
Indicator & $\begin{array}{c}\text { Yield Stress } \\
(\mathbf{M P a})\end{array}$ & $\begin{array}{c}\text { Ultimate Tensile Stress } \\
(\mathbf{M P a})\end{array}$ & Ductility (\%) \\
\hline Base Metal & 141.96 & 296.73 & 34.9 \\
\hline FSW & 113.6 & 222.7 & 15.1 \\
\hline TIG & 78.2 & 113.5 & 4.50 \\
\hline MIG & 36.1 & 36.1 & 0.41 \\
\hline SMAW & 66.1 & 66.1 & 1.31 \\
\hline
\end{tabular}

The stress-strain curves for the base metal and welded joints are in agreement with the curves found in literature [98, 101-106]. The deviation in the yield stress, tensile stress and ductility between the FSW joints and the base metal is lower than the deviation between the other processes and the base metal. The FSW joints have larger tensile strength and ductility compared to the TIG, MIG and SMAW joints that exhibits more brittle behavior. This is due to the fine recrystallized grains formed in the FSW joints and smaller range for dissolution and coarsening of precipitates. Unlikely, cast dendritic and coarser grain structure and liquation are formed in the TIG, MIG and SMAW joints, which provides smaller tensile strength and poor ductility [103].

3.3.2.2. Micro hardness test. The hardness of a material is defined as the resistance of the material to permanent indentation [96]. Generally, a material with good hardness means that it is resistant to wear and scratching. Wear and scratches are very important features for many applications in engineering such as most of the tooling used in manufacturing. Material properties are widely assessed using hardness test as they are convenient and quick. In this study, a micro hardness Vickers test was conducted. This test uses a pyramid shaped indenter made of diamond. The concept of this test is based on the fact that impressions made by this indenter are similar in terms of geometry regardless of the applied load [96]. Accordingly, loads of various size are applied, depending on the hardness of the material to be measured. The Vickers Hardness (HV) is then determined from equation (38):

$$
H V=1854.4 F / d^{2}
$$


Where $F$ is the applied test force in $g f$, and $d$ is the diagonal length of the indentation in um. The micro hardness test was performed at room temperature using the QV-1000DM digital micro hardness testing machine, shown in Figure 20.

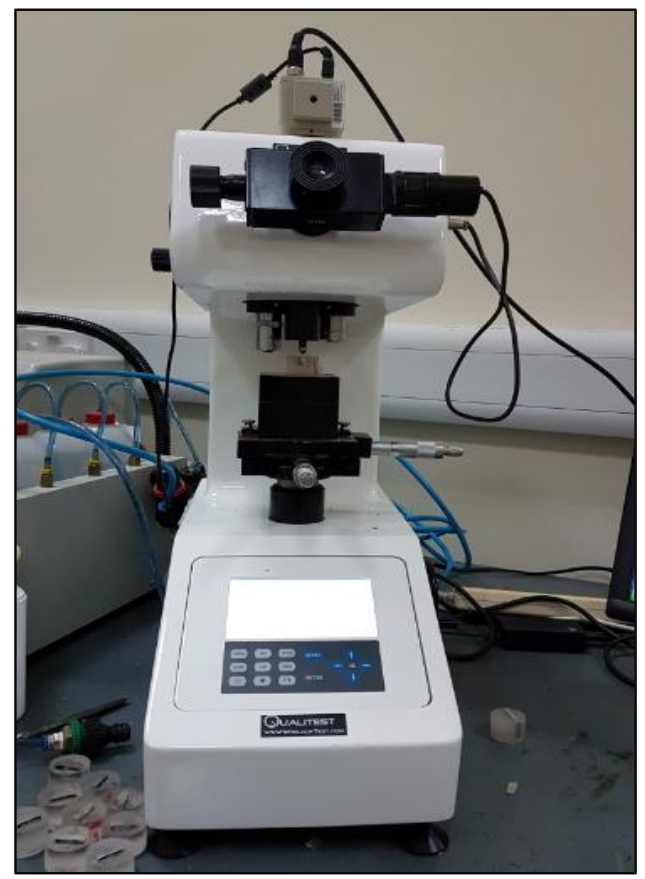

Figure 20: Micro-hardness test machine

This tester consists mainly of a worktable and lifting system, turret, measuring microscope, auto-loading mechanism, and control and display system. On the turret, an indenter and two objectives, 40x and 10x, are mounted. The 40x objective is used for both observation and measurement, while the 10x is used only for observation. The hardness is determined be penetrating the diamond pyramid indent by a known load into the surface of a test specimen, and then measuring the diagonal of the indentation that is left on the surface of the specimen after removing the test force.

Before conducting the test, the machine was verified by making a series of impression on a standardized micro Vickers hardness block. The block had a hardness number of $460 \mathrm{HV}$. According to the ASTM-E92 [107], the normal loading time (dwell time) is from 10 to $15 \mathrm{~s}$ unless otherwise is specified. The test parameters were as follows:

- Applied load: 200 gf (1.961 N).

- Dwell time: $10 \mathrm{~s}$. 
- Magnification: 40x

From each welded plate, three small samples were cut from the weld seam. So a total of 15 samples were prepared including the three samples from the base material. Each specimen was place in a rubber mold as shown in Figure 21.

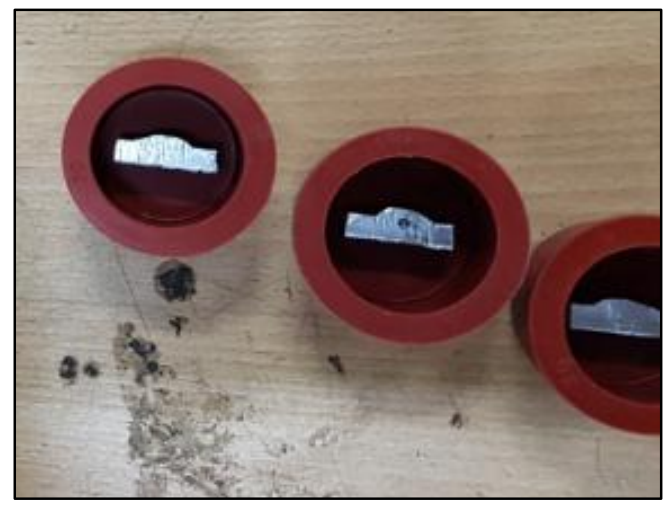

Figure 21: Micro-hardness samples placed in mounting cups

To prepare the samples for the test, ClaroCit powder and ClaroCit liquid where mixed in a mixing cup with a ratio of $20: 12$ by weight. The powder was poured into the liquid while stirring thoroughly for a period of half a minute without introducing any air bubbles into the mixture. Immediately after the components were mixed, the polymerization of the resin started and the viscosity increased. The necessary amount of resin was carefully poured over the specimens placed in the rubber mounting cups (molds). This was done as soon as possible before complete solidification of the mixture and to get the best filling. After that, the poured mixed was left for 20 minutes at room temperature for curing. Finally, the mounts where removed from the mounting cups, as shown in Figure 22. The surface of each specimen was machined using the milling machine to remove any excess material and to flatten the surface. All the samples were then polished to remove any scratches from the samples' surfaces and to ensure the specimens are highly plane and reflective and no foreign material is introduced. The micro hardness readings were taken in the middle of the weld zone and $2 \mathrm{~mm}$ from the top surface for all samples. The micro hardness was measured along the transverse surface of the weld. The average of 15 readings was considered for each process and the results are presented in Figure 23, where the error bars in each column show the maximum and minimum micro hardness value for each weld. 


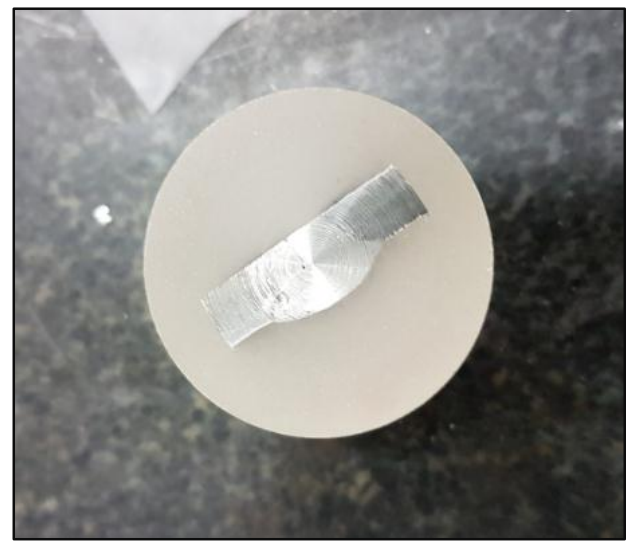

Figure 22: Micro-hardness sample ready for test

As shown in Figure 23, the friction stir welding produced samples with average micro hardness value very close to the base material. Both the TIG and MIG processes produces samples with hardness values larger than the base material. However, the samples produces by the SAMW had hardness values lower than the base material. The hardness of a material is related to the size of the grains [98, 108-110]. According to the Hall-Pitch relation [111], more grain growth and results in lower micro hardness. However, refining the grain size beyond $20 \mathrm{~nm}$ might not produce higher strength, and might even result in an "inverse Hall-Petch" behavior where the hardness of the material decreases with finer grain size [111].

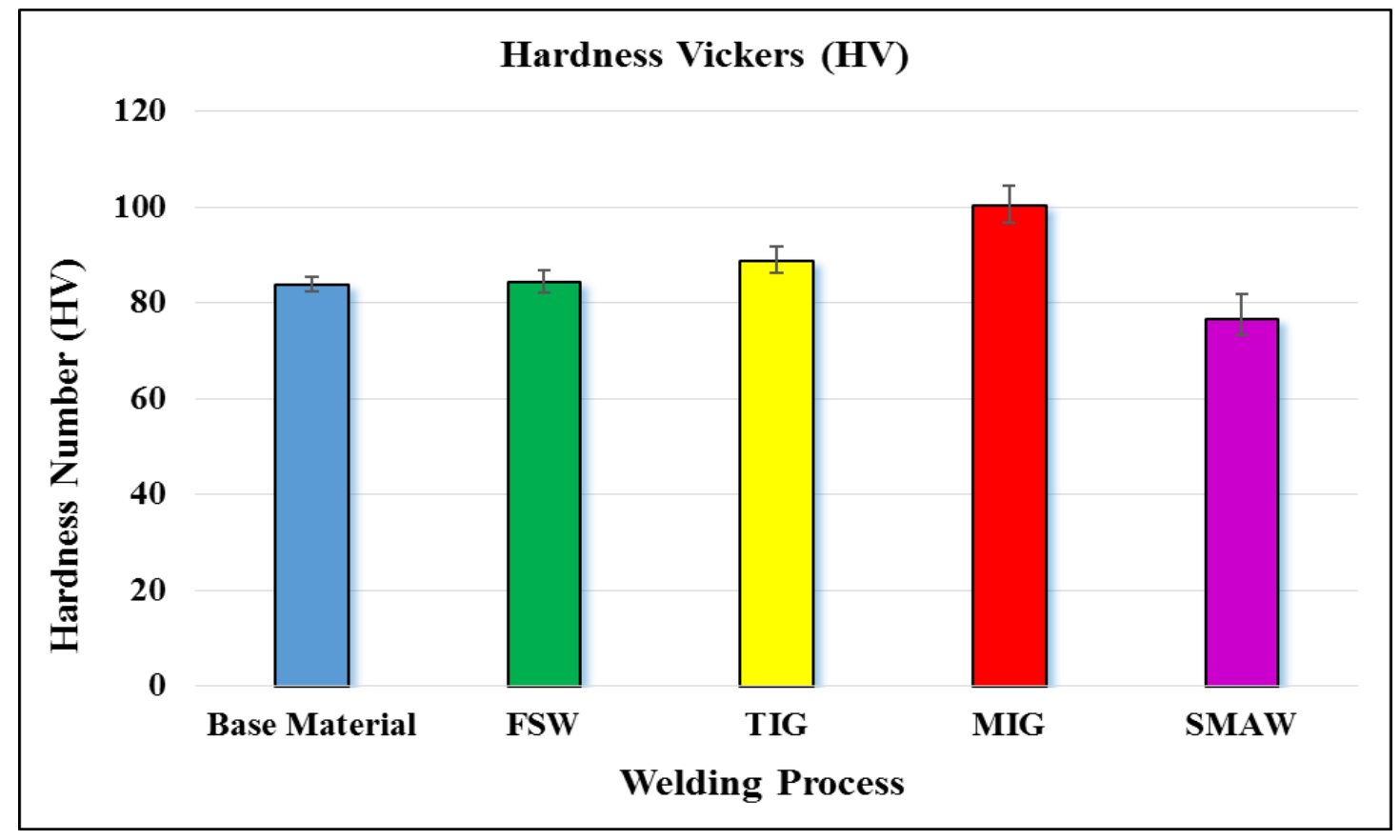

Figure 23: Micro hardness of welded joints 
3.3.2.3. Impact toughness test. The impact toughness, also known as the fracture toughness, is a measurement for the amount of energy absorbed by a notched specimen when fractured due to an impact load. The impact test performed in this study was the Charpy Impact test that is applied on a V-notched simple-beam specimen, such as the one shown in Figure 24. The test was conducted at room temperature. The Charpy test machine shown in Figure 25 consists mainly of a pendulum connected with a hummer of a known weight, a pointer, a scale an anvils were the specimen are placed.

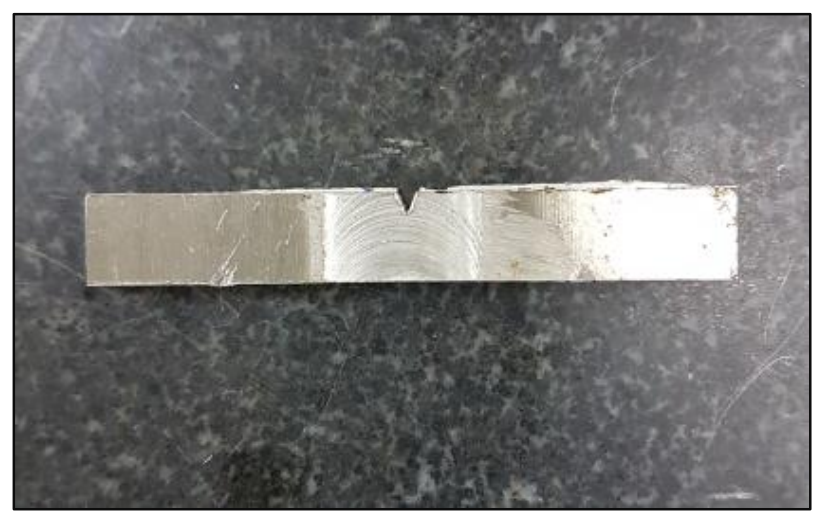

Figure 24: Impact test sample

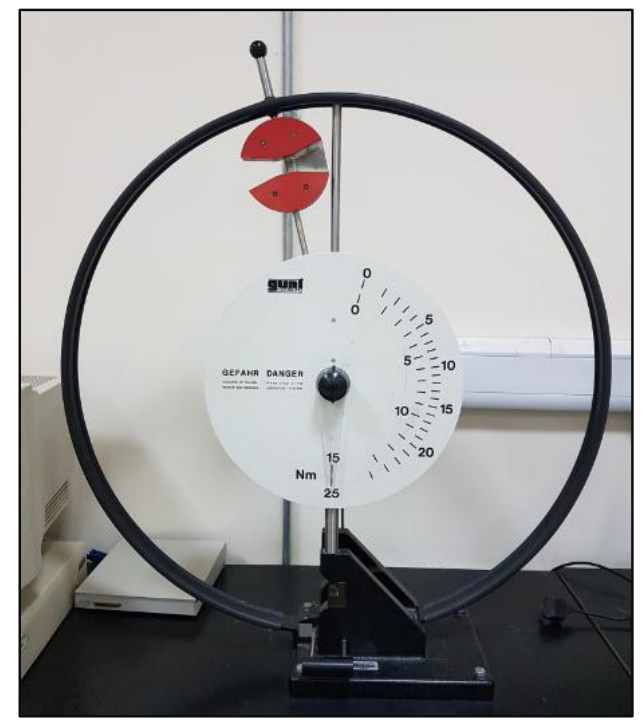

Figure 25: Charpy impact test machine 
The test specimens were taken from the base material (without welding) and from the welded samples. A total of 15 test specimens were prepared (three for the base material and three for each welding process). The dimensions of the test specimen were determined according to the American Society for Testing and Materials-E23 (ASTME23) [112]. Each test specimen had a length of $55 \mathrm{~mm}$ and a width of $10 \mathrm{~mm}$. However, the thickness of the specimen was restricted to $5 \mathrm{~mm}$ as this is the thickness of the plate used in the experiment. Figure 26 shows the standard dimensions of the test specimen.

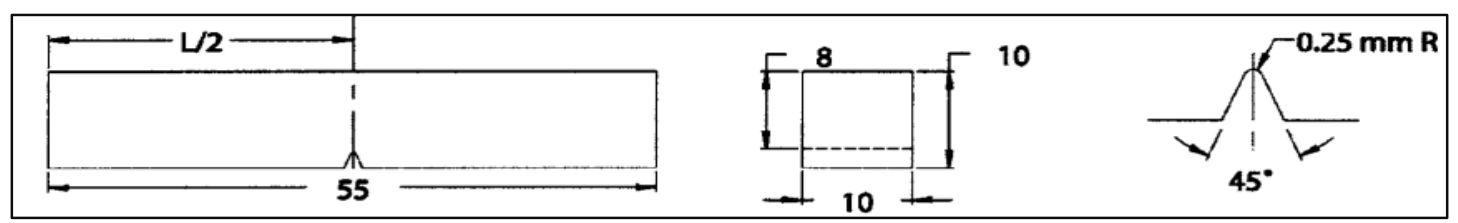

Figure 26: Standard impact test specimen's dimensions

Before conducting the test, the friction within the machine was inspected. This was done by raising the pendulum to the latched position (starting position), moving the pointer to the maximum energy capacity of the range being used, and releasing the pendulum without any specimen placed on the anvils. In case of friction absence, the indicator should read zero on the scale. However, the indicator showed a value of 1.8 N.m. which corresponds to the energy losses due to friction. After testing for friction, the machine was prepared by lifting the pendulum to the latched position. At this position, the energy pointer was set at the maximum scale reading. Then, the test specimen was positioned on the anvils as shown in Figure 27, and the pendulum was released.

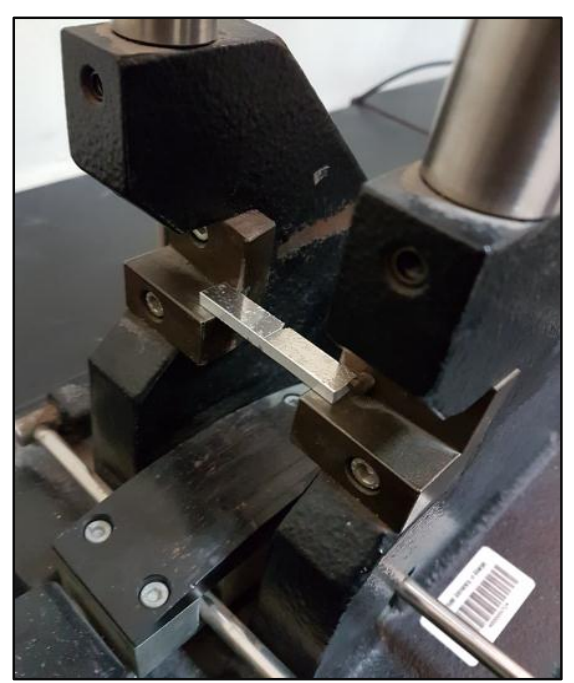

Figure 27: Test specimen placed on the anvils 
The difference between the energy in the striking hummer at the moment of impact with the specimen and the energy the remains after the fracture of the specimen is the absorbed energy. This value is indicated by the scale on the machine after is has been corrected for energy losses due to windage and friction. Figure 28 shows the results of the impact test, where the error bars in each column show the maximum and minimum impact toughness for each process. An average of impact toughness of three samples for each process as well as the base metal was considered.

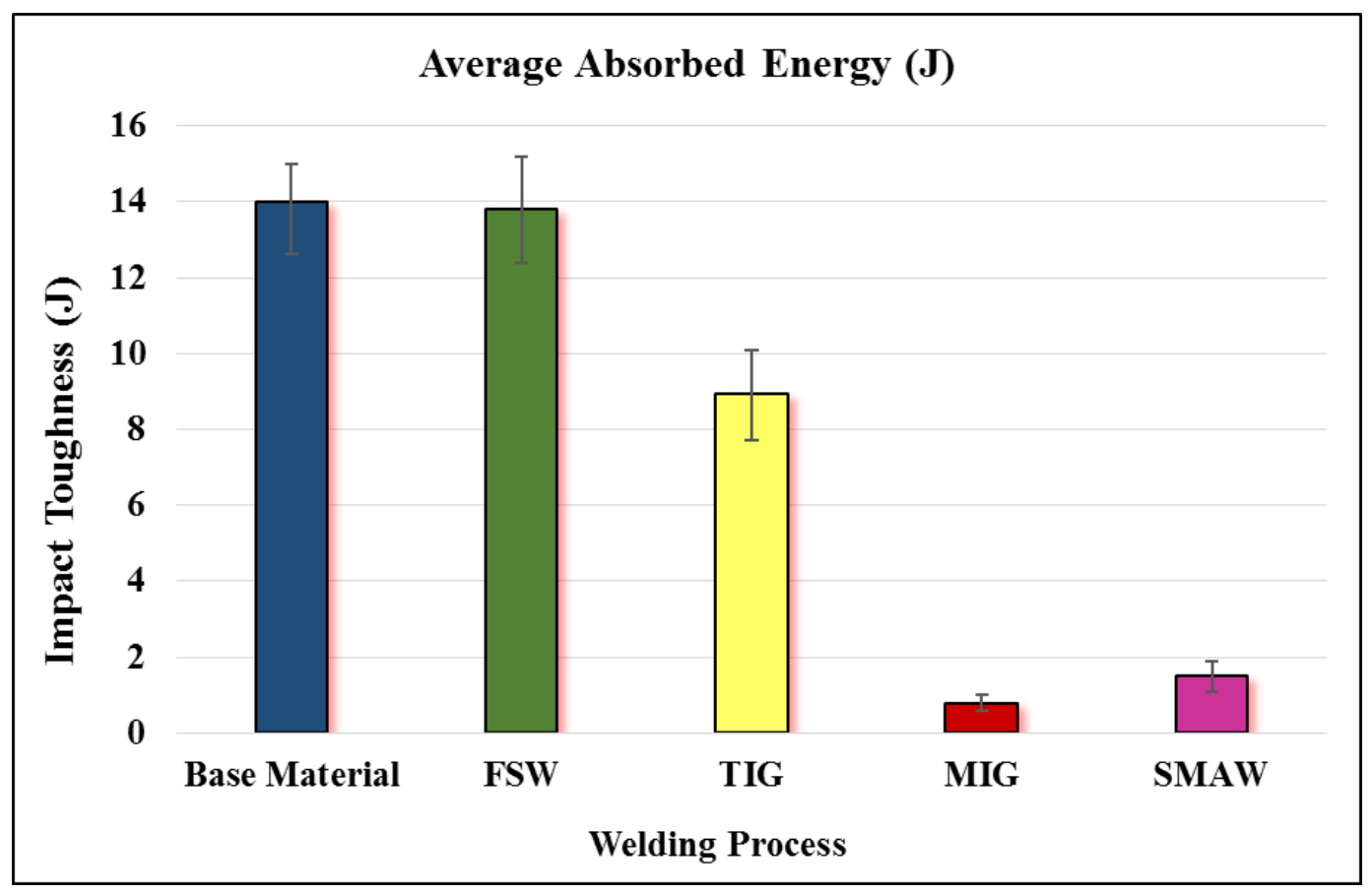

Figure 28: Impact toughness of welded joints

As shown in Figure 28, the impact toughness of the FSW joints is higher than the toughness of the joins produced by TIG, MIG and SMAW processes. From the stress-strain curve shown in figure 19, the ductility, which is in a direct relationship with the toughness, of the FSW welds is higher than the ductility of the TIG, MIG and SMAW welds. As a result, the FSW welds have higher capability of absorbing impact energy before fracture. The ductility of the TIG weld is higher than the MIG and SMAW, and hence, it has higher energy absorption capability. The MIG weld has the lowest ductility, and therefore it exhibits brittle behavior and poor energy absorption capability during impact test. 


\subsection{Sustainability Assessment}

3.4.1. Sustainability model. This section discusses the structure of the algorithm followed in this to evaluate the sustainability performance of welding processes. Figure 29 shows a flow chart for the applied framework. The first step in this algorithm is to define the goal of the analysis, which is selecting the most sustainable welding process for the case under consideration. Once the objective is well defined, all dimensions of sustainability need to be considered to have a comprehensive evaluation. A dimension of physical performance is added as a fourth dimension to investigate the quality of the welded part produced by each welding process. Then, the key sustainability indicators, including qualitative and quantitative ones, have to be carefully selected to capture all sustainability dimensions. Weights are assigned to each indicator using the objective (based on indicators' value) entropy method to avoid any uncertainties associated with subjective weighting methods (based on decision-maker's experience) [76]. The indicators are then normalized into dimensionless quantities and aggregated into single scores using MCDM methods. Three MCDM methods were examined separately in this study which are the Grey Relation Analysis (GRA), Technique for Order Preferences by Similarity to Ideal Solutions (TOPSIS) and the COmplex PRoportional ASsessment Method (COPRAS). Sensitivity analysis is then conducted on the aggregated scores obtained by each MCDM method. If the results are found to be not very sensitive to small changes in the indicators' values or the assigned weights, then the decision-maker can use the obtained scores to rank the different alternative processes and choose the best one. Otherwise, modifications such as changing the methods used for weighting, normalization and aggregation are required. In this study, sensitivity analysis is conducted using the method of One-at-a-time sensitivity measures. 


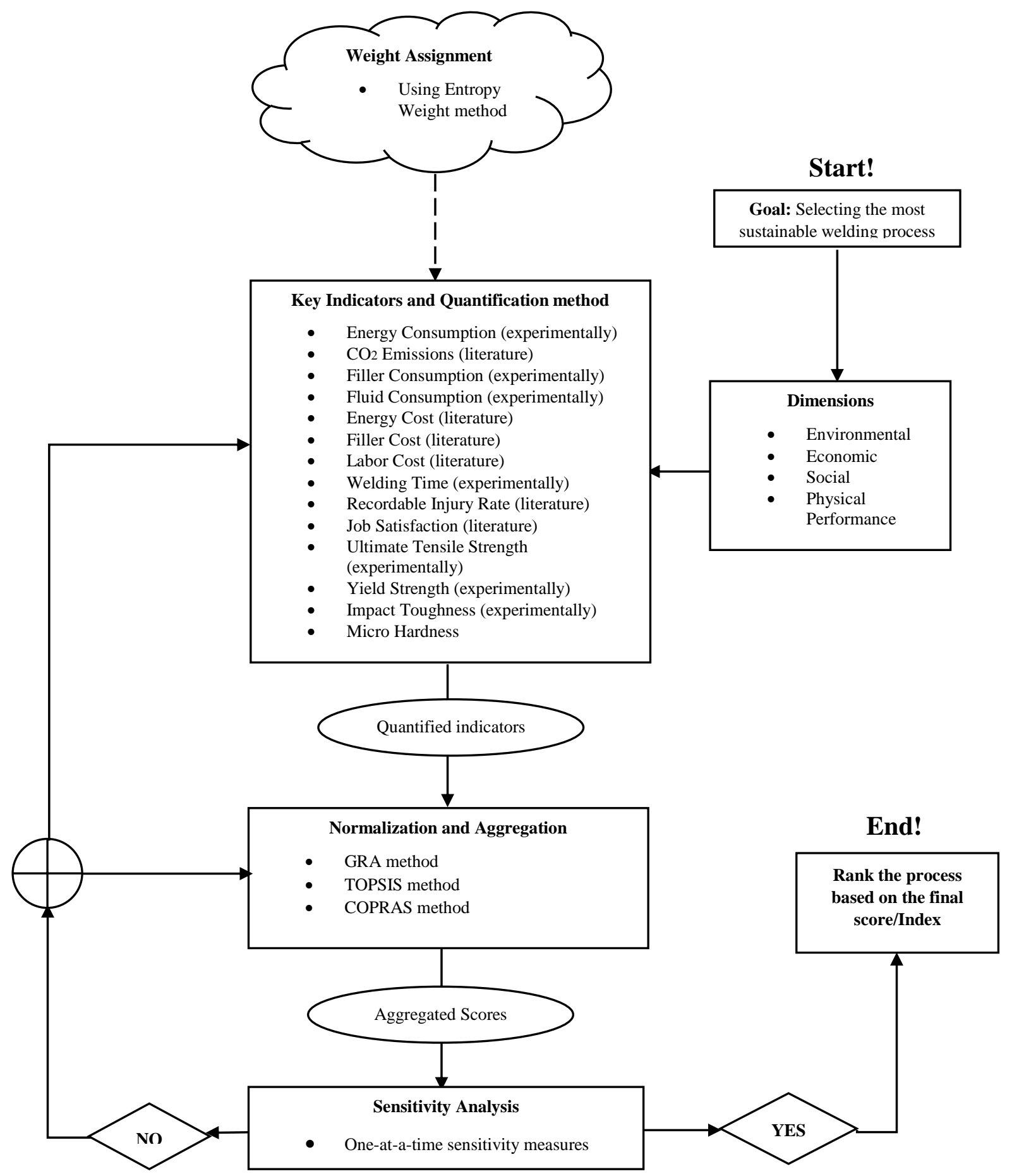

Figure 29: General Algorithm for Sustainability Assessment of Welding Processes 
3.4.2. Indicators for sustainability assessment. This section presents the selected key indicators for sustainability assessment and the methods used to quantify each indicator. All sustainability dimensions were covered by considering enough key performance indicators from each dimension, as shown in Figure 30. As mentioned earlier, a dimension for physical performance is added to the analysis to investigate the quality and performance of the welded joints.

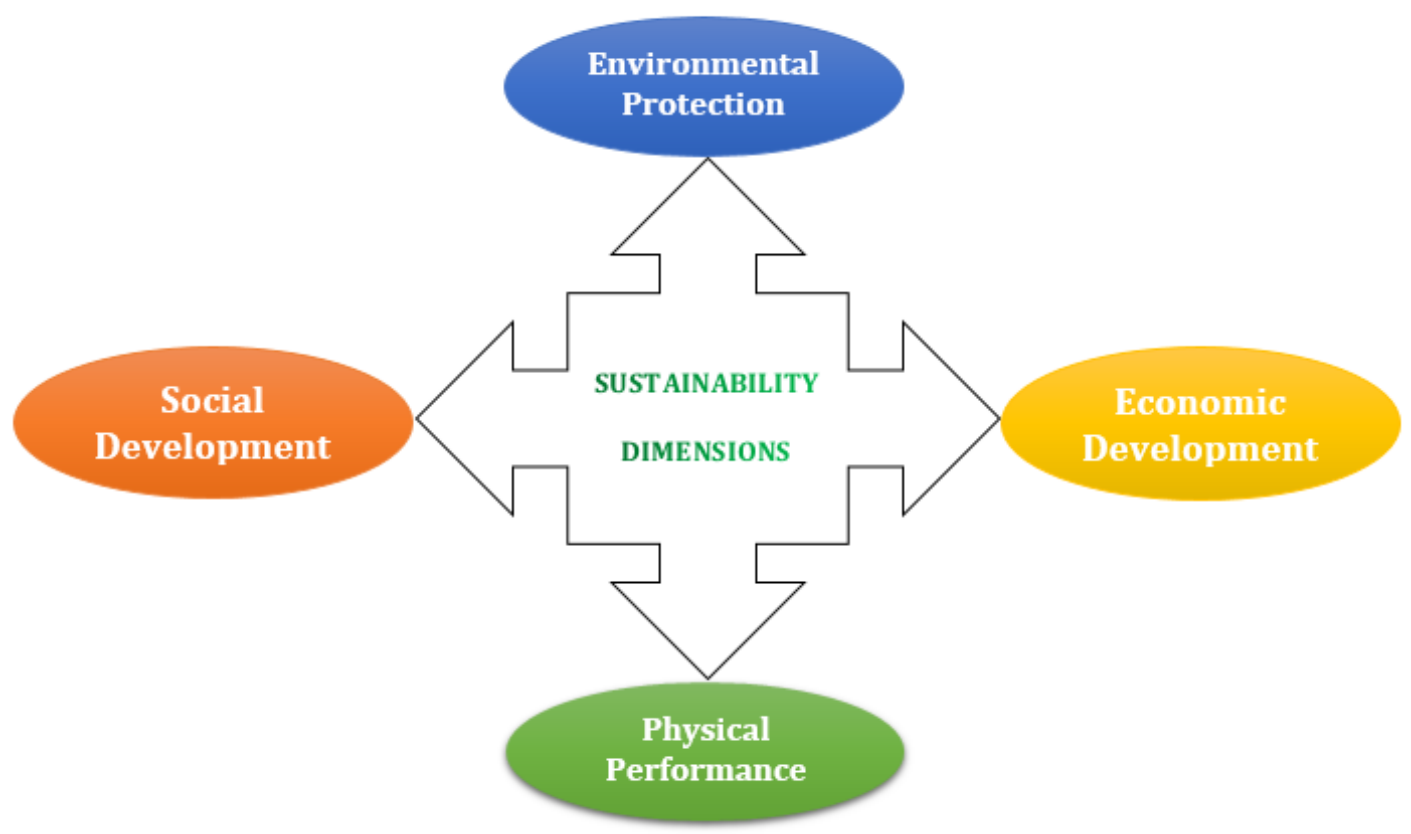

Figure 30: Sustainability Dimensions

The sustainability indicators were chosen based on the following characteristics $[35,53]:$

Relevant and deliver meaningful aspect of sustainability for the welding processes.

Easy to understand even by non-expert people.

$>$ Cover all sustainability dimensions.

$>$ Measurable with the available tools and data accessible.

Based on these features, the key performance indicators considered in this study are:

- Energy Consumption (EC) (kWh): Energy consumption (EC) is a nonbeneficial environmental indicator that represents the amount of electricity consumed by each process. Higher level of energy consumption is not desired 
as it negatively affects the environment by increasing the amount of $\mathrm{CO}_{2}$ emissions, and increasing the overall cost of the process. For TIG, MIG and SMAW, the power consumption was calculated simply using equation (39) as following:

$$
\text { Power consumption }(k W)=\frac{D C \text { voltage }(V) \times \operatorname{Current}(A)}{1000}
$$

For FSW, the data for the power consumption at each second within the operation time interval of the $\mathrm{CNC}$ milling machine were directly obtained from the machine using a power data logger. Table 8 summarizes the data for power consumption of the four processes.

Table 8: Power consumption for each process

\begin{tabular}{cc}
\hline Process & Power consumption (kW) \\
\hline FSW & 2.1 \\
\hline TIG & 3.89 \\
\hline MIG & 3.04 \\
\hline SMAW & 9.54 \\
\hline
\end{tabular}

- CO2 emissions: $\mathrm{CO} 2$ emission is a non-beneficial environmental indicator. It is a very important indicator that should be considered when evaluating the sustainability of any manufacturing process. $\mathrm{CO}_{2}$ is a primary greenhouse gas that has detrimental impact on the environment as it causes air pollution and global warming which is responsible for the increase in the earth temperature. $\mathrm{CO} 2$ can also be toxic and causes health issues to human beings. The amount of $\mathrm{CO} 2$ emission is directly related to the amount of electricity consumed during each welding process. In this study, $\mathrm{CO} 2$ emission is calculated by multiplying the energy consumption (in $\mathrm{kWh}$ ) by the amount of $\mathrm{CO} 2$ (in $\mathrm{kg}$ ) produced per each kWh. According to the Carbon Neutral Charitable Fund [113], one kWh of electricity, will generate around $0.92 \mathrm{~kg}$ of $\mathrm{CO} 2$ emissions to the atmosphere. The average of $\mathrm{CO} 2$ emissions of three samples was taken for each process. 
Table 9 summarizes the amount of $\mathrm{CO} 2$ emissions produces by each welding process.

Table 9: $\mathrm{CO} 2$ emissions produced by each process

\begin{tabular}{ccc} 
Process & Energy Consumption (kWh) & CO2 emissions $(\mathbf{k g})$ \\
\hline FSW & 0.094 & 0.0883 \\
\hline TIG & 0.090 & 0.0847 \\
MIG & 0.047 & 0.0443 \\
\hline SMAW & 0.018 & 0.0168
\end{tabular}

- Filler material consumption: The filler material consumption (FM) is a nonbeneficial environmental indicator that represents the amount of filler needed by each welding process to join the two plates. To measure the amount of filler material consumed by each process, the mass of each sample was measured using a balance before and after welding. The difference between the mass of the plates after welding and before welding is the mass of the filler material. The average of filler material consumption of three samples was taken for each process. Table 10 shows the amount of filler material consumed by each process. Since the FSW does not require any filler material, then the mass of the plates before and after the welding should remain the same. However, the mass of the plates was reduced after performing the welding, and that is due to removing the metal chips generated from the weld seam.

Table 10: Filler material consumption

\begin{tabular}{cc}
\hline Process & Filler material consumption (lb) \\
\hline FSW & 0.0000 \\
\hline TIG & 0.0149 \\
MIG & 0.0135 \\
SMAW & 0.0044 \\
\hline
\end{tabular}

- Fluid consumption: Fluid consumption (FC) is the amount of fluid used by each process including cleaners, lubricants, oils, shielding gases, coolants, etc. It is considered as a non-beneficial environmental indicator. The lower the 
amount of fluid consumed, the better the process. In this study, the only fluid consumed is the gas used for shielding. Unlike the TIG and MIG, the FSW and the SMAW do not require any shielding gases and thus they do not consume any amount of fluid. The amount of shielding gas consumed by the TIG and MIG processes was calculated simply by multiplying the gas flow rate by the average welding time of each process. Table 11 summarizes the data for the amount of shielding gas consumed by each process.

Table 11: Shielding gas consumption

\begin{tabular}{cccc}
\hline Process & $\begin{array}{c}\text { Shielding gas flow rate } \\
(\mathbf{L} / \mathbf{m i n})\end{array}$ & $\begin{array}{c}\text { Average } \\
\text { welding time (s) }\end{array}$ & $\begin{array}{c}\text { Shielding gas } \\
\text { consumption (L) }\end{array}$ \\
\hline FSW & None & 154 & None \\
\hline TIG & 15.1 & 83.7 & 21.06 \\
\hline MIG & 13.5 & 58 & 13.05 \\
\hline SMAW & None & 6.3 & None \\
\hline
\end{tabular}

- Energy cost: The energy cost (ECo) is an economic indicator that is directly related to the amount of electrical energy consumed during a process. Similar to the power consumption, the energy cost is considered a non-beneficial indicator. In this study, the energy cost was calculated by multiplying the energy consumption values (in $\mathrm{kWh}$ ) by the electricity tariff (charge rate) in the United Arab Emirates as specified by Dubai Electricity and Water Authority (DEWA) [114]. Table 12 shows the cost of energy for each welding process.

Table 12: Energy cost of each process

\begin{tabular}{ccc}
\hline Process & Energy Consumption (kWh) & Energy Cost (Fills) \\
\hline FSW & 0.094 & 2.16 \\
\hline TIG & 0.090 & 2.07 \\
\hline MIG & 0.047 & 1.08 \\
\hline SMAW & 0.018 & 0.41
\end{tabular}


The TIG and FSW welding have larger energy cost compared to the MIG and SMAW, and that is because the welding time for the FSW is very large which means it consumes a significant amount of energy during operation. TIG welding on the other hand, uses very high voltage values to operate which significantly contributes to the amount of electricity consumed and hence the energy cost. Although SMAW welding has the highest energy consumption per second of time, but it is the least costly one in terms of energy cost and that is because the SMWA is a very fast process. That is, it has a small welding time that makes it consumes the least amount of energy within its time interval of operation compared to the other processes.

- Filler cost (FC): The cost of the filler material is an economic indicator that is directly related to the filler material consumption. Similar the filler consumption, the cost of the filler material is considered as a non-beneficial indicator. The data for the filler material cost were obtained from the literature $[115,116]$, and are presented in Table 13.

Table 13: Filler cost of each process

\begin{tabular}{ccc}
\hline Process & Filler material & Cost of the filler material $(\mathbf{\$} / \mathbf{l b})$. \\
\hline FSW & None & None \\
\hline TIG & R 5356 & 9.12 \\
\hline MIG & ALSi5 & 9.12 \\
\hline SMAW & E AL43 & 15.84
\end{tabular}

- Labor cost and Job satisfaction: Labor cost (LC) is an economic indicator that represents the amount of money that should be paid to welders to perform certain welding Operation. Job satisfaction (JS) is a social indicator that represents the level of satisfaction of welders with their monetary compensation. In this study, job satisfaction and labor cost are the same in terms of numerical values. However, they are interpreted differently. Job satisfaction, as stated earlier, is a social beneficial indicator in which higher values are desired, while labor cost is a non-beneficial economic indicator in which lower values are desired. The data for labor cost and job satisfaction were obtained from literature [117-120] and they are represented in Table 14. 
Table 14: Labor cost/ Job satisfaction of each process

\begin{tabular}{cc}
\hline Process & Labor cost/ Job satisfaction $\mathbf{( \$ / h r . )}$ \\
\hline FSW & 18.21 \\
\hline TIG & 18.12 \\
\hline MIG & 15.18 \\
\hline SMAW & 18.35
\end{tabular}

- Welding time (WT): The time needed to perform the welding is a nonbeneficial economic indicator. The lower the welding time, the better the process. The time was measured for each sample using a timer. Table 15 represents the average welding time for each process.

Table 15: Average welding time of each process

\begin{tabular}{cc}
\hline Process & Average welding time (s) \\
FSW & 154 \\
\hline TIG & 83.7 \\
\hline MIG & 58 \\
\hline SMAW & 6.33
\end{tabular}

- Recordable injury rate (RIR): Safety is a very important factor that should be considered when assessing any manufacturing process, especially in welding as it involves the exposure of welders to high temperatures and toxic gases. Safety is a social beneficial indicator in which higher level of it is desired. In this study, safety is represented by the recordable injury rate. That is, the number of injuries and illnesses per 10,000 full-time workers [121], as represented in Table 16.

Table 16: recordable injury rate of each process

\begin{tabular}{cc}
\hline Process & RIR \\
\hline FSW & 38.5 \\
\hline TIG & 182.6 \\
\hline MIG & 182.6 \\
\hline SMAW & 182.6 \\
\hline
\end{tabular}


- Ultimate tensile strength and yield strength: Yield and Ultimate strength are beneficial indicators that belong to the dimension of physical performance. The yield point, also known as the elastic limit, is a strength characteristic of the material. Typically, the yield stress is identified in the stress-strain curve by drawing a strain line parallel to the linear portion of the curve by with strain offset of $0.2 \%$. The stress value at the intersection of this line with the curve is the yield strength of the material [96]. The Ultimate tensile strength, or simply the tensile strength, is also a strength characteristic of the material. It is the engineering stress at which the applied load reaches a maximum value. In other words, it is the stress at the highest point on the engineering stress-strain curve. The tensile stress-stain curves for samples produced by each welding process were obtained experimentally by the tensile test discussed in section 3.3.2.1, and the results of the yield strength the tensile strength for each process are recorded in Table 7.

- Micro-hardness (MH): The micro-hardness is a beneficial indicator that belongs to the dimension of the physical performance. The micro-hardness values of samples produced by each welding process as well as the base metal were determined experimentally by the micro-hardness test discussed in section 3.3.2.2, and the results are shown in Figure 23.

- Impact toughness (IT): The impact toughness is a beneficial indicator that belongs to the dimension of physical performance. The impact toughness values of specimens produced by the welding process as well as the base metal were measured experimentally by the impact test discussed in section 3.3.2.3, and the results are shown in Figure 28.

Table 17 summarizes the key indicators considered in this study, their corresponding dimensions, types and quantification methods. 
Table 17: Selected key indicators

\begin{tabular}{|c|c|c|c|}
\hline Indicator & Dimension & Type & Quantification method \\
\hline $\begin{array}{l}\text { Energy } \\
\text { consumption } \\
(\mathbf{E C})(\mathbf{k W h})\end{array}$ & Environmental & $\begin{array}{c}\text { Non- } \\
\text { beneficial }\end{array}$ & $\begin{array}{l}\text { For TIG, MIG and SMAW: } E C=\frac{D C \text { voltage }(V) \times \text { Current }(A)}{1000} \\
\text { For FSW: power data logger }\end{array}$ \\
\hline $\begin{array}{c}\text { CO2 emissions } \\
(\mathrm{kg})\end{array}$ & Environmental & $\begin{array}{c}\text { Non- } \\
\text { beneficial }\end{array}$ & CO2 emmissions $=$ Power Consumption $\times 0.92[113]$ \\
\hline $\begin{array}{l}\text { Filler Material } \\
\text { Consumption } \\
\text { (FM) (lb) }\end{array}$ & Environmental & $\begin{array}{l}\text { Non- } \\
\text { beneficial }\end{array}$ & Mass of plates after welding - mass of plates before welding \\
\hline $\begin{array}{l}\text { Shielding Gas } \\
\text { Consumption } \\
\text { (SGC) (L) }\end{array}$ & Environmental & $\begin{array}{c}\text { Non- } \\
\text { beneficial }\end{array}$ & $\begin{array}{l}\text { For TIG and MIG: Gas flow rate } \times \text { the average welding time } \\
\text { For FSW and SMAW: Does not require shielding gas }\end{array}$ \\
\hline $\begin{array}{l}\text { Energy Cost } \\
\text { (ECo) (fils) }\end{array}$ & Economic & $\begin{array}{c}\text { Non- } \\
\text { beneficial }\end{array}$ & $E C \times$ Electricity tariff (charge rate) \\
\hline $\begin{array}{l}\text { Filler Material } \\
\text { Cost (FMCo) } \\
\text { (\$) }\end{array}$ & Economic & $\begin{array}{l}\text { Non- } \\
\text { beneficial }\end{array}$ & From literature \\
\hline $\begin{array}{l}\text { Labor Cost } \\
\quad(\text { LC) }\end{array}$ & Economic & $\begin{array}{c}\text { Non- } \\
\text { beneficial }\end{array}$ & From Literature \\
\hline $\begin{array}{l}\text { Welding Time } \\
\text { (WT) (s) }\end{array}$ & Economic & $\begin{array}{c}\text { Non- } \\
\text { beneficial }\end{array}$ & Timer \\
\hline $\begin{array}{c}\text { Job } \\
\text { Satisfaction } \\
\text { (JS) }\end{array}$ & Social & Beneficial & From Literature \\
\hline $\begin{array}{l}\text { Recordable } \\
\text { Injury Rate } \\
\text { (RIR) }\end{array}$ & Social & $\begin{array}{c}\text { Non- } \\
\text { beneficial }\end{array}$ & From Literature \\
\hline $\begin{array}{c}\text { Ultimate } \\
\text { Tensile } \\
\text { Strength } \\
\text { (UTS) (MPa) }\end{array}$ & $\begin{array}{c}\text { Physical } \\
\text { Performance }\end{array}$ & Beneficial & Experimentally \\
\hline $\begin{array}{l}\text { Ultimate Yield } \\
\text { Strength } \\
\text { (UTS) (MPa) }\end{array}$ & $\begin{array}{c}\text { Physical } \\
\text { Performance }\end{array}$ & Beneficial & Experimentally \\
\hline $\begin{array}{l}\text { Impact } \\
\text { toughness (IT) } \\
\text { (N.m.): }\end{array}$ & $\begin{array}{c}\text { Physical } \\
\text { Performance }\end{array}$ & Beneficial & Experimentally \\
\hline $\begin{array}{c}\text { Micro } \\
\text { hardness (MH) } \\
(\text { HV) }\end{array}$ & $\begin{array}{c}\text { Physical } \\
\text { Performance }\end{array}$ & Beneficial & Experimentally \\
\hline
\end{tabular}


3.4.3. Weighting of indicators. After choosing the relevant performance indicators, fixed weights were assigned to each indicator in order to determine the relative importance of each indicator. In this study, weights were assigned to the indicators using the entropy weight method, which is an objective weighting method, to avoid any uncertainties associated by subjective methods. In this method, the indicator with performance values that are widely different from each other have higher importance for the problem due to more influence on ranking outcomes. In other words, an indicator will have less importance if all alternatives have similar performance values for that indicator. The procedure of this method were discussed in section 2.6.5.

3.4.4. Normalization and aggregation. After assigning weights to the indicators, they were normalized into dimensionless quantities for comparison, and then were aggregated into single scores for ranking. Three MCDM methods were implemented independently for normalization and aggregation scores in order to account for interactions among indicators. The MCDM considered in this study the TOPSIS method, GRA method and the COPRAS method.

Before normalization, all the data and information available for the indicators were recorded in a decision matrix. The matrix consists of $m$ alternative and $n$ indicators. Each row of this matrix represents one alternative and each column represents one indicator. So, an element $x_{i j}$ in the decision matrix represents the value of the $j^{\text {th }}$ indicator in original real values for the $i^{t h}$ alternative process. The procedure for each method were discussed in section 2.6.

3.5. Sustainability Assessment Results and Discussion. Each indicator was quantified experimentally or based on the available date in literature as discussed earlier. Table 18 shows the quantified indicators. In decision making processes, this table is known as the evaluation table (matrix) or the performance table.

Table 18: The evaluation matrix (table)

\begin{tabular}{|c|c|c|c|c|c|c|c|c|c|c|c|c|c|c|}
\hline Process & EC $(\mathrm{kWh})$ & $\mathrm{CO} 2(\mathrm{~kg})$ & FM (lb) & FC (L) & EC (fils) & FC (\$) & LC (\$) & Time (s) & RIR & JS (\$) & UTS (Mpa) & YS (Mpa) & IT (N.m) & MH (HV) \\
\hline FS W & 0.094 & 0.088 & 0.000 & 0 & 2.16 & 0.00 & 0.78 & 154.0 & 38.5 & 0.78 & 222.7 & 113.6 & 13.8 & 84.2 \\
\hline TIG & 0.090 & 0.085 & 0.015 & 21.01 & 2.07 & 0.14 & 0.42 & 83.7 & 182.6 & 0.42 & 113.5 & 78.2 & 8.9 & 88.6 \\
\hline MIG & 0.047 & 0.044 & 0.014 & 12.54 & 1.08 & 0.12 & 0.24 & 58.0 & 182.6 & 0.24 & 36.1 & 36.1 & 0.8 & 100.2 \\
\hline SMAW & 0.018 & 0.017 & 0.004 & 0 & 0.41 & 0.07 & 0.03 & 6.3 & 182.6 & 0.03 & 69.5 & 66.1 & 1.5 & 76.7 \\
\hline
\end{tabular}


Table 19 shows the weight assigned to each indicator by the entropy weight method. As shown in Table 19, the recordable injury rate has the largest weight since there is a wide difference in the value of this indicator between the FSW and the other processes. However, the fluid consumption has the lowest weight as the values for the four processes are not far away from each other. Tables 20-22 represents the normalized decision matrix based on GRA, TOPSIS and COPRAS method, respectively.

Table 19: Indicators' weights assigned using the entropy method

\begin{tabular}{|c|c|c|c|c|c|c|c|c|c|c|c|c|c|c|}
\hline Indicator & EC (kWh) & CO2 (kg) & FM (lb) & FC (L) & EC (fils) & FC (\$) & LC (\$) & Time (s) & RIR & JS (\$) & UTS (Mpa) & YS (Mpa) & IT (N.m) & MH (HV) \\
\hline Wj & 0.07 & 0.07 & 0.06 & $\mathbf{0 . 0 4}$ & 0.07 & $\mathbf{0 . 1 1}$ & $\mathbf{0 . 0 8}$ & $\mathbf{0 . 0 4}$ & $\mathbf{0 . 1 6}$ & $\mathbf{0 . 0 8}$ & $\mathbf{0 . 0 6}$ & $\mathbf{0 . 0 4}$ & $\mathbf{0 . 0 7}$ & $\mathbf{0 . 0 5}$ \\
\hline
\end{tabular}

Table 20: Normalized matrix using GRA

\begin{tabular}{|c|c|c|c|c|c|c|c|c|c|c|c|c|c|c|}
\hline Process & EC (kWh) & CO2 (kg) & FM (lb) & FC (L) & EC (fils) & FC (\$) & LC (\$) & Time (s) & RIR & JS (\$) & UTS (MPa) & YS (MPa) & IT (N.m) & MH (HV) \\
\hline FSW & 0.00 & 0.00 & 1.00 & 1.00 & 0.00 & 1.00 & 0.00 & 0.00 & 1.00 & 1.00 & 1.00 & 1.00 & 1.00 & 0.32 \\
\hline TIG & 0.05 & 0.05 & 0.00 & 0.00 & 0.05 & 0.00 & 0.48 & 0.48 & 0.00 & 0.52 & 0.41 & 0.54 & 0.63 & 0.51 \\
\hline MIG & 0.62 & 0.62 & 0.09 & 0.40 & 0.62 & 0.09 & 0.72 & 0.65 & 0.00 & 0.28 & 0.00 & 0.00 & 0.00 & 1.00 \\
\hline SMAW & 1.00 & 1.00 & 0.70 & 1.00 & 1.00 & 0.49 & 1.00 & 1.00 & 0.00 & 0.00 & 0.18 & 0.39 & 0.06 & 0.00 \\
\hline
\end{tabular}

Table 21: Normalized matrix using TOPSIS

\begin{tabular}{|c|c|c|c|c|c|c|c|c|c|c|c|c|c|c|}
\hline Process & EC (kWh) & CO2 (kg) & FM (lb) & FC (L) & EC (fils) & FC (\$) & LC (\$) & Time (s) & RIR & JS (\$) & UTS (Mpa) & YS (Mpa) & IT (N.m) & MH (HV) \\
\hline FS W & $\mathbf{0 . 6 7 3}$ & $\mathbf{0 . 6 7 3}$ & $\mathbf{0 . 0 0 0}$ & $\mathbf{0 . 0 0 0}$ & $\mathbf{0 . 6 7 3}$ & $\mathbf{0 . 0 0 0}$ & $\mathbf{0 . 8 4 7}$ & $\mathbf{0 . 8 3 4}$ & $\mathbf{0 . 1 2 1}$ & $\mathbf{0 . 8 4 7}$ & $\mathbf{0 . 8 5 0}$ & $\mathbf{0 . 7 2 3}$ & $\mathbf{0 . 8 3 5}$ & $\mathbf{0 . 4 7 9}$ \\
\hline TIG & $\mathbf{0 . 6 4 6}$ & $\mathbf{0 . 6 4 6}$ & $\mathbf{0 . 7 2 3}$ & $\mathbf{0 . 8 5 9}$ & $\mathbf{0 . 6 4 6}$ & $\mathbf{0 . 6 9 2}$ & $\mathbf{0 . 4 5 8}$ & $\mathbf{0 . 4 5 3}$ & $\mathbf{0 . 5 7 3}$ & $\mathbf{0 . 4 5 8}$ & $\mathbf{0 . 4 3 3}$ & $\mathbf{0 . 4 9 8}$ & $\mathbf{0 . 5 4 1}$ & $\mathbf{0 . 5 0 4}$ \\
\hline MIG & $\mathbf{0 . 3 3 7}$ & $\mathbf{0 . 3 3 7}$ & $\mathbf{0 . 6 5 6}$ & $\mathbf{0 . 5 1 3}$ & $\mathbf{0 . 3 3 7}$ & $\mathbf{0 . 6 2 8}$ & $\mathbf{0 . 2 6 6}$ & $\mathbf{0 . 3 1 4}$ & $\mathbf{0 . 5 7 3}$ & $\mathbf{0 . 2 6 6}$ & $\mathbf{0 . 1 3 8}$ & $\mathbf{0 . 2 3 0}$ & $\mathbf{0 . 0 4 6}$ & $\mathbf{0 . 5 7 0}$ \\
\hline SMAW & $\mathbf{0 . 1 2 8}$ & $\mathbf{0 . 1 2 8}$ & $\mathbf{0 . 2 1 4}$ & $\mathbf{0 . 0 0 0}$ & $\mathbf{0 . 1 2 8}$ & $\mathbf{0 . 3 5 6}$ & $\mathbf{0 . 0 3 5}$ & $\mathbf{0 . 0 3 4}$ & $\mathbf{0 . 5 7 3}$ & $\mathbf{0 . 0 3 5}$ & $\mathbf{0 . 2 6 5}$ & $\mathbf{0 . 4 2 0}$ & $\mathbf{0 . 0 9 1}$ & $\mathbf{0 . 4 3 7}$ \\
\hline
\end{tabular}

Table 22: Normalized matrix using COPRAS

\begin{tabular}{|c|c|c|c|c|c|c|c|c|c|c|c|c|c|c|}
\hline Process & EC (kWh) & $\mathrm{CO2}(\mathrm{kg})$ & FM (Ib) & FC (L) & EC (fils) & FC (\$) & LC (\$) & Time (s) & RIR & JS (\$) & UTS (MPa) & YS (MPa) & IT (N.m) & MH (HV) \\
\hline FSW & 0.377 & 0.377 & \begin{tabular}{|l|}
0.000 \\
\end{tabular} & 0.000 & \begin{tabular}{|l|}
0.377 \\
\end{tabular} & 0.000 & 0.527 & 0.510 & 0.066 & 0.527 & 0.504 & \begin{tabular}{|c|}
0.387 \\
\end{tabular} & 0.552 & 0.241 \\
\hline TIG & 0.362 & 0.362 & 0.454 & 0.626 & 0.362 & 0.413 & 0.285 & 0.277 & 0.311 & 0.285 & 0.257 & 0.266 & 0.357 & 0.253 \\
\hline MIG & 0.189 & 0.189 & 0.412 & 0.374 & 0.189 & 0.375 & 0.166 & 0.192 & 0.311 & 0.166 & 0.082 & 0.123 & 0.031 & 0.287 \\
\hline SMAW & 0.072 & 0.072 & 0.134 & 0.000 & 0.072 & 0.212 & 0.022 & 0.021 & 0.311 & 0.022 & 0.157 & 0.225 & 0.060 & 0.219 \\
\hline
\end{tabular}

Tables 23-25 represents the aggregated scores of each welding processes based on TOPSIS, GRA and COPRAS method, respectively.

Table 23: Aggregated scores based on TOPSIS

\begin{tabular}{ccccc}
\hline Process & Si+ & Si- & Pi & Ranking \\
\hline FSW & 0.09805 & 0.153916 & 0.610861 & 1 \\
\hline TIG & 0.14733 & 0.063083 & 0.2998 & 4 \\
\hline MIG & 0.14318 & 0.070033 & 0.328459 & 3 \\
\hline SMAW & 0.12376 & 0.115454 & 0.482646 & 2 \\
\hline
\end{tabular}


Table 24: Aggregated scores based on GRA

\begin{tabular}{ccc}
\hline Process & $\boldsymbol{\Gamma}(\boldsymbol{X o}, \boldsymbol{X i})$ & Ranking \\
\hline FSW & 0.75347 & 1 \\
\hline TIG & 0.40847 & 4 \\
\hline MIG & 0.46243 & 3 \\
\hline SMAW & 0.62513 & 2
\end{tabular}

Table 25: Aggregated scores based on COPRAS

\begin{tabular}{ccccc} 
Process & $\boldsymbol{P i}$ & $\boldsymbol{R} \boldsymbol{i}$ & $\boldsymbol{Q i}$ & Ranking \\
\hline FSW & 0.137700016 & 0.15220913 & 0.317486 & 1 \\
\hline TIG & 0.08572067 & 0.25918171 & 0.191303 & 3 \\
\hline MIG & 0.038708684 & 0.19256423 & 0.180817 & 4 \\
\hline SMAW & 0.034668031 & 0.09924753 & 0.310393 & 2
\end{tabular}

Based on the results obtained from the three MCDM methods, it can be observed that the aggregated score for the FSW is the highest in all the MCDM used in the analysis. Similarly, the SMAW process has the second highest scores in all the MCDM methods. However, the MIG process has the lowest score based on the COPRAS method, while the TIG has the lowest score based on the TOPSIS and GRA. Table 26 and Figure 31 summarize the sustainability ranking and scores for the welding processes.

Table 26: Ranking of alternatives

\begin{tabular}{cccc}
\hline Process & TOPSIS & GRA & COPRAS \\
\hline FSW & 1 & 1 & 1 \\
\hline TIG & 4 & 4 & 3 \\
\hline MIG & 3 & 3 & 4 \\
\hline SMAW & 2 & 2 & 2 \\
\hline
\end{tabular}




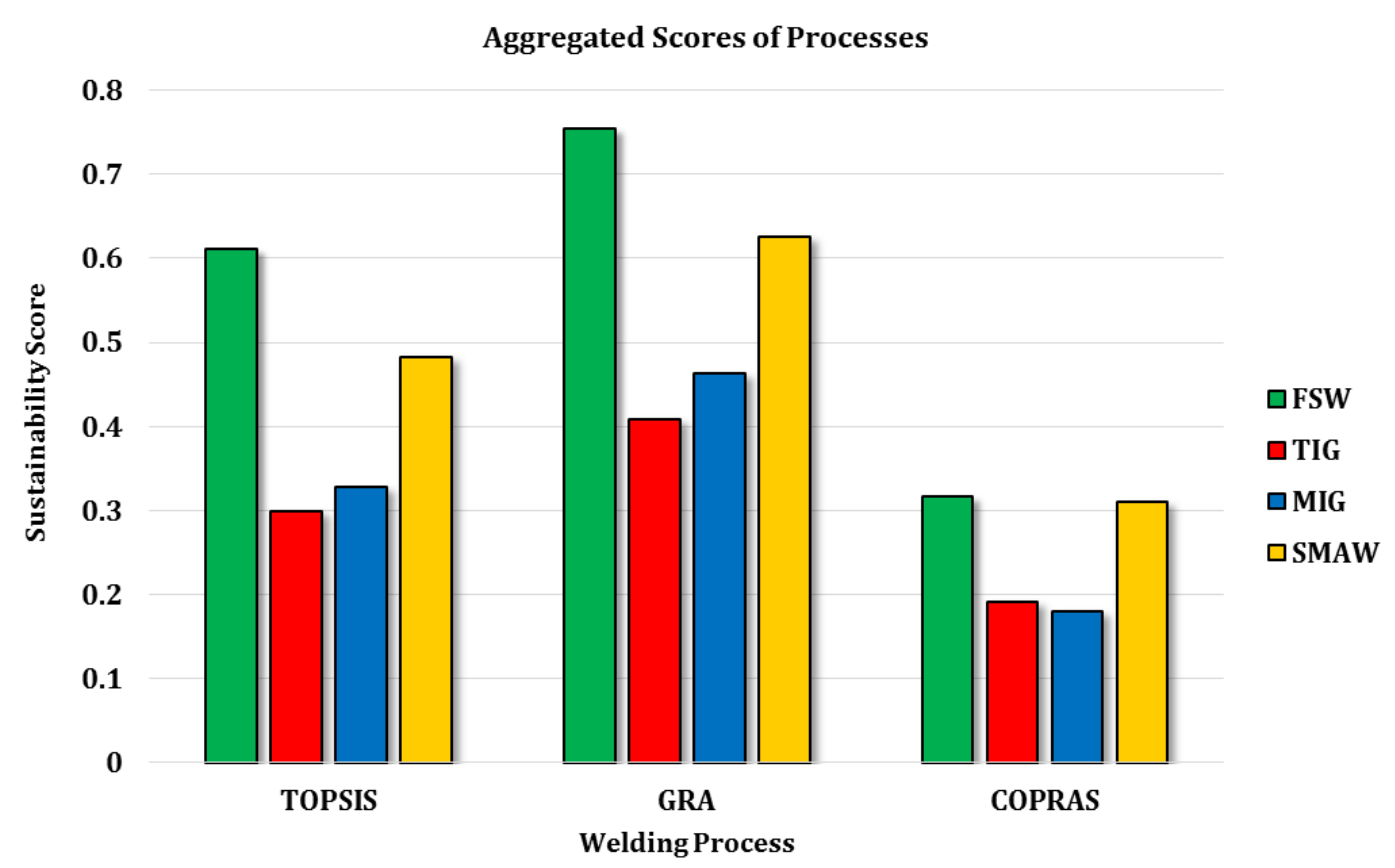

Figure 31: Sustainability assessment results

The difference in the ranking of the TIG and MIG processes could possibly be due to the different normalization and aggregation methods used by the various MCDM methods. Since the TIG and MIG indicators have values relatively close to each other, then any change in the normalization and aggregation technique will probably affect the final score and hence will affect the rank of the process. For instance, the TIG process is more sustainable than the MIG when using the TOPSIS and GRA methods for evaluation. However, when the COPRAS method is used, then the MIG is more sustainable than the TIG. This change in the ranking could generate confusion for the decision makers when they aim to choose the suitable MCDM method for evaluation. Therefore, sensitivity analysis should be conducted for the suggested MCDM method to select the least sensitive one. Unlike the TIG and MIG, the rank of the FSW and the SMAW was the same regardless of the MCDM method used. That is because the corresponding indicators of the FSW and the SMAW have values that are widely different and also relatively far away from the TIG and MIG indicators' values. Therefore, any change in the normalization and aggregation methods used will less likely cause a change in the rank of the FSW and the SMAW. It can be noticed that the FSW process has the highest sustainability scores, but that does not necessarily indicates that it has the best performance for all the sustainability indicators. For instance, the MIG process has the largest micro-hardness values, which makes it the 
best process with regards to this indicator. However, it is the worst candidate in terms of the impact toughness indicator. Similarly, all the other processes have the best performance with respect to some indicators, and the worst performance with respect to others. Therefore, the use of MCDM methods will take into account these interactions among the indicators and processes, and will provide an overall sustainability performance score.

\subsection{Sensitivity Analysis.}

As stated earlier, the input data in MCDM methods are usually assumed to be deterministic and the final results obtained from these methods are based on this assumption. However, in reality, the variation in input data cannot be avoided due to the nature of manufacturing processes. Therefore, sensitivity analysis should be carried to ensure the reliability of the results (final scores). If any small change in the value of an input indicator resulted in a significant changes in the final results, then it is stated that the latter are sensitive to this indicator.

In this study, sensitivity analysis is conducted by using the one-at-a-time sensitivity analysis method discussed in section 2.7.2.1. The performance value of one indicator of a certain process will be varied, and the variation of the final sustainability scores of each MCDM method will be observed. The variables that will be varied are the energy consumption and the welding time, because any change in the values of these indicators will directly affect and change the values of other indicators such as the energy cost, $\mathrm{CO} 2$ emissions and Labor cost. The values of the energy consumption was changed by $5 \%$ and $10 \%$ for each welding process individually. Then, the absolute values of the percent change of the final sustainability scores were investigated for the three MCDM methods. The same procedure was carried out for the welding time. Table 27 and Table 28 show the result of sensitivity analysis with respect to the energy consumption and welding time, respectively. 
Table 27: Sensitivity analysis with respect to energy consumption

\begin{tabular}{|c|c|c|c|c|c|c|c|}
\hline \multirow{3}{*}{$\begin{array}{l}\text { Changing energy } \\
\text { consumption for } \\
\text { one process at a } \\
\text { time }\end{array}$} & \multirow[t]{3}{*}{ Process } & \multicolumn{6}{|c|}{$\begin{array}{l}\text { Absolute percent change (\%) in the final scores by each MCDM } \\
\text { method due to a change in a single input by } 5 \% \text { and } 10 \%\end{array}$} \\
\hline & & \multicolumn{2}{|c|}{ TOPSIS } & \multicolumn{2}{|c|}{ GRA } & \multicolumn{2}{|c|}{ COPRAS } \\
\hline & & $5 \%$ & $10 \%$ & $5 \%$ & $10 \%$ & $5 \%$ & $10 \%$ \\
\hline \multirow{4}{*}{ FSW } & FSW & 1.65 & 2.63 & 1.53 & 2.57 & 1.59 & 2.57 \\
\hline & TIG & 2.05 & 3.46 & 1.06 & 1.86 & 1.03 & 1.77 \\
\hline & MIG & 1.08 & 1.60 & 0.01 & 0.05 & 0.70 & 1.14 \\
\hline & SMAW & 1.57 & 2.49 & 1.65 & 2.76 & 1.85 & 3.05 \\
\hline \multirow{4}{*}{ TIG } & FSW & 2.90 & 2.06 & 2.04 & 1.39 & 2.75 & 2.01 \\
\hline & TIG & 3.26 & 3.57 & 1.27 & 1.19 & 1.74 & 2.31 \\
\hline & MIG & 3.85 & 5.46 & 0.96 & 1.57 & 1.51 & 1.43 \\
\hline & SMAW & 3.01 & 3.37 & 2.26 & 2.00 & 3.00 & 2.65 \\
\hline \multirow{4}{*}{ MIG } & FSW & 0.03 & 0.07 & 0.09 & 0.19 & 0.12 & 0.21 \\
\hline & TIG & 0.02 & 0.05 & 0.02 & 0.05 & 0.08 & 0.16 \\
\hline & MIG & 1.29 & 2.55 & 0.85 & 1.64 & 0.64 & 1.26 \\
\hline & SMAW & 0.02 & 0.07 & 0.09 & 0.20 & 0.20 & 0.42 \\
\hline \multirow{4}{*}{ SMLWW } & FSW & 0.28 & 0.56 & 0.04 & 0.07 & 0.27 & 0.54 \\
\hline & TIG & 0.21 & 0.41 & 0.02 & 0.04 & 0.18 & 0.36 \\
\hline & MIG & 0.02 & 0.04 & 0.20 & 0.41 & 0.19 & 0.37 \\
\hline & SMAW & 0.27 & 0.53 & 0.04 & 0.08 & 0.50 & 0.99 \\
\hline
\end{tabular}

Table 28: Sensitivity analysis with respect to welding time

\begin{tabular}{|c|c|c|c|c|c|c|c|}
\hline \multirow{3}{*}{$\begin{array}{l}\text { Changing } \\
\text { welding time for } \\
\text { one process at a } \\
\text { time }\end{array}$} & \multirow{3}{*}{ Process } & \multicolumn{6}{|c|}{$\begin{array}{l}\text { Absolute percent change (\%) in the final scores by each MCDM } \\
\text { method due to a change in a single input by } 5 \% \text { and } 10 \%\end{array}$} \\
\hline & & \multicolumn{2}{|c|}{ TOPSIS } & \multicolumn{2}{|c|}{ GRA } & \multicolumn{2}{|c|}{ COPRAS } \\
\hline & & $5 \%$ & $10 \%$ & $5 \%$ & $10 \%$ & $5 \%$ & $10 \%$ \\
\hline \multirow{4}{*}{ FSW } & FSW & 0.03 & 0.06 & 0.09 & 0.17 & 0.06 & 0.12 \\
\hline & TIG & 0.73 & 1.42 & 0.10 & 0.21 & 0.02 & 0.05 \\
\hline & MIG & 0.61 & 1.17 & 0.17 & 0.33 & 0.05 & 0.10 \\
\hline & SMAW & 0.24 & 0.46 & 0.11 & 0.21 & 0.08 & 0.15 \\
\hline \multirow{4}{*}{ TIG } & FSW & 0.11 & 0.23 & 0.10 & 0.20 & 0.16 & 0.33 \\
\hline & TIG & 0.50 & 0.96 & 0.08 & 0.13 & 0.06 & 0.10 \\
\hline & MIG & 0.00 & 0.02 & 0.05 & 0.10 & 0.02 & 0.03 \\
\hline & SMAW & 0.25 & 0.51 & 0.11 & 0.23 & 0.14 & 0.30 \\
\hline \multirow{4}{*}{ MIG } & FSW & 0.03 & 0.06 & 0.01 & 0.03 & 0.05 & 0.09 \\
\hline & TIG & 0.15 & 0.30 & 0.00 & 0.00 & 0.06 & 0.12 \\
\hline & MIG & 0.58 & 1.14 & 0.23 & 0.45 & 0.05 & 0.10 \\
\hline & SMAW & 0.01 & 0.03 & 0.02 & 0.03 & 0.02 & 0.05 \\
\hline \multirow{4}{*}{ SMAW } & FSW & 0.04 & 0.08 & 0.00 & 0.01 & 0.04 & 0.08 \\
\hline & TIG & 0.07 & 0.13 & 0.00 & 0.01 & 0.02 & 0.03 \\
\hline & MIG & 0.04 & 0.08 & 0.02 & 0.04 & 0.03 & 0.05 \\
\hline & SMAW & 0.03 & 0.05 & 0.01 & 0.01 & 0.06 & 0.13 \\
\hline
\end{tabular}


It can be observed from the sensitivity analysis results that the changes in the output values with respect to changes in some input values are insignificant and acceptable for the three MCDM methods. This implies that three methods are sufficiently adequate to be used for sustainability assessment of welding processes for this study. Relatively, the GRA has the lowest percent change of the final scores' values for almost all the scenarios as shown in Table 27 and Table 28. Also, the GRA method has the least amount of computations compared to the TOPSIS method and the COPRAS method. As a result, it can be concluded that the GRA method is the best MCDM method for this case study. It is important to note that for a different case study with different processes, indicators and conditions, another MCDM method could be relatively superior. The results of sensitivity analysis will always be different, and will lead to different conclusions depending on the case study under consideration. 


\section{Chapter 4. Conclusion and Future Outlook}

Sustainability assessment is an effective tool for decision and policy making processes in the industry, especially in the manufacturing sector. Most of the sustainability assessment work done in the field of manufacturing focused on the product level rather than the process level, although the manufacturing processes contribute significantly to the consumption of the energy resources as well as to the amounts of hazardouz emissions. Furthermore, most of these practices focused on evaluting the environmental impact, some focused on the economic or social impacts, while very limited tried to integrate the three sustainability aspects in the evaluation. In this work, a general framewrok for sustainability assesssment of manufacturing processes is proposed. The main features of this framwork are:

- It covers the three dimensions of sustainability which are economic development, social development, and environmental protection.

- It reduces the uncertainities associated with subjective weighting methods by using a combination of subjective and objective weighting techniques. The successful implementation of the proposed framework requires the participation of diverse stakeholders in the phase of assigning weights to the dimennsions and indicators.

- It accounts for the interaction among different indicators by using Multi-Criteria Decision Making methods for normalization and aggregation.

- Sensitivity analysis is integrtaed into the proposed framework to ensure the reliabilty of the obtained results. If the scores of the used MCDM method are very sensitive to slight changes in indicators values or weights, a different MCDM method should be used.

A case study was conducted that applied the proposed framework to evaluate the sustainability performance of four welding processes; Friction Stir Welding (FSW), Gas Metal Arc Welding (GMAW), Gas Tungsten Arc Welding (GTAW) and Shielded Metal Arc Welding (SMAW). The indicators considered in the study covered the main dimensions of sustainability, which are the environmental, economic and social aspects. The physical performance dimension was added in the assessment as well to investigate 
the quality of the welded plates. The main highlights of the case study have been presented as follows:

- The FSW process has been found to be the most sustainable welding process for this case study based on the TOPSIS, GRA and COPRAS methods.

- The MIG process is the least sustainable welding process according to the COPRAS method, while the TIG process is the least sustainable process according to the TOPSIS and GRA methods.

- The sensitivity analysis showed that the three MCDM methods used in this study were not sensitive to small change in some input value which makes either one of them suitable for this case study. However, since the GRA is relatively the least sensitive one and has less amount of computations, it is considered as the best option for this case study.

There is also a scope for extending this work in the future by applying the proposed framework to evaluate the sustainability performance of other manufacturing process such as casting and forming. In addition, it will be interesting to evaluate the sustainability performance of products by integrating this framework with a product sustainability assessment framework such as the LCA, to evaluate the sustainability of all the stages of manufacturing involved in producing the complete product as well as the sustainability of the product throughout its lifetime. The results can help the industry to identify the crucial issues associated with each process, and then to improve the processes and equipment towards more sustainable alternatives. 


\section{References}

[1] B. Ness, E. Urbel-Piirsalu, S. Anderberg, and L. Olsson, "Categorising tools for sustainability assessment," Ecological Economics, vol. 60, no. 3, pp. 498-508, 1/15/ 2007.

[2] N. R. Council, Our Common Journey: A Transition Toward Sustainability. Washington, DC: The National Academies Press, 1999, p. 384.

[3] U. Nations, "Report of the World Summit on Sustainable Development," 2002, Available: http://www.un-documents.net/aconf199-20.pdf. [Accessed: Feb. 14, 2018].

[4] S. Sala, B. Ciuffo, and P. Nijkamp, "A systemic framework for sustainability assessment," Ecological Economics, vol. 119, pp. 314-325, November 2015.

[5] T. Waas, J. Hugé, T. Block, T. Wright, F. Benitez-Capistros, and A. Verbruggen, "Sustainability Assessment and Indicators: Tools in a DecisionMaking Strategy for Sustainable Development," Sustainability, vol. 6, no. 9, pp. $5512-5534,2014$.

[6] R. K. Singh, H. R. Murty, S. K. Gupta, and A. K. Dikshit, "An overview of sustainability assessment methodologies," Ecological Indicators, vol. 15, no. 1, pp. 281-299, April 2012.

[7] N. H. Afgan, M. G. Carvalho, and N. V. Hovanov, "Energy system assessment with sustainability indicators," Energy Policy, vol. 28, no. 9, pp. 603-612, July 2000.

[8] N. H. Afgan and M. G. Carvalho, "Sustainability assessment of a hybrid energy system," Energy Policy, vol. 36, no. 8, pp. 2903-2910, August 2008.

[9] F. Begić and N. H. Afgan, "Sustainability assessment tool for the decision making in selection of energy system-Bosnian case," Energy, vol. 32, no. 10, pp. 1979-1985, October 2007.

[10] A. Evans, V. Strezov, and T. J. Evans, "Assessment of sustainability indicators for renewable energy technologies," Renewable and Sustainable Energy Reviews, vol. 13, no. 5, pp. 1082-1088, June 2009.

[11] S. Singh, E. U. Olugu, and S. N. Musa, "Development of Sustainable Manufacturing Performance Evaluation Expert System for Small and Medium Enterprises," Procedia CIRP, vol. 40, pp. 608-613, January 2016.

[12] J. Pope, D. Annandale, and A. Morrison-Saunders, "Conceptualising sustainability assessment," Environmental Impact Assessment Review, vol. 24, no. 6, pp. 595-616, August 2004.

[13] C. Labuschagne, A. C. Brent, and R. P. G. van Erck, "Assessing the sustainability performances of industries," Journal of Cleaner Production, vol. 13, no. 4, pp. 373-385, March 2005.

[14] T. Hacking and P. Guthrie, "A framework for clarifying the meaning of Triple Bottom-Line, Integrated, and Sustainability Assessment," Environmental Impact Assessment Review, vol. 28, no. 2-3, pp. 73-89, February 2008. 
[15] D. Krajnc and P. Glavič, "A model for integrated assessment of sustainable development," Resources, Conservation and Recycling, vol. 43, no. 2, pp. 189208, January 2005.

[16] Y. Xing, R. M. W. Horner, M. A. El-Haram, and J. Bebbington, "A framework model for assessing sustainability impacts of urban development," Accounting Forum, vol. 33, no. 3, pp. 209-224, September 2009.

[17] A. J. Balkema, H. A. Preisig, R. Otterpohl, and F. J. D. Lambert, "Indicators for the sustainability assessment of wastewater treatment systems," Urban Water, vol. 4, no. 2, pp. 153-161, June 2002.

[18] A. Azapagic, "Developing a framework for sustainable development indicators for the mining and minerals industry," Journal of Cleaner Production, vol. 12, no. 6, pp. 639-662, August 2004.

[19] R. Mateus and L. Bragança, "Sustainability assessment and rating of buildings: Developing the methodology SBToolPT-H," Building and Environment, vol. 46, no. 10, pp. 1962-1971, October 2011.

[20] A. Haapio and P. Viitaniemi, "A critical review of building environmental assessment tools," Environmental Impact Assessment Review, vol. 28, no. 7, pp. 469-482, October 2008.

[21] M. Mani, J. Madan, J. H. Lee, K. W. Lyons, and S. K. Gupta, "Sustainability characterisation for manufacturing processes," International Journal of Production Research, Article vol. 52, no. 20, pp. 5895-5912, 2014.

[22] "Greenhouse gas emissions by economic activity, EU-28, 2008 and 2013 (\% of total emissions in CO2 equivalents,)", 2016. [Online]. Available: https://ec.europa.eu/eurostat/statistics-explained/index.php

[23] N. Bhanot, P. V. Rao, and S. G. Deshmukh, "An Assessment of Sustainability for Turning Process in an Automobile Firm," Procedia CIRP, vol. 48, pp. 538$543,2016$.

[24] G. Ingarao, G. Ambrogio, F. Gagliardi, and R. Di Lorenzo, "A sustainability point of view on sheet metal forming operations: material wasting and energy consumption in incremental forming and stamping processes," Journal of Cleaner Production, vol. 29-30, pp. 255-268, July 2012.

[25] B. S. Linke, G. J. Corman, D. A. Dornfeld, and S. Tönissen, "Sustainability indicators for discrete manufacturing processes applied to grinding technology," Journal of Manufacturing Systems, vol. 32, no. 4, pp. 556-563, October 2013.

[26] B. Sabine Linke, "Sustainability Indicators for Grinding Applied to Dressing Strategies," Journal of Manufacturing Science and Engineering, vol. 135, no. 5, pp. 54502-54507, 2013.

[27] B. Linke, J. Das, M. Lam, and C. Ly, "Sustainability Indicators for Finishing Operations based on Process Performance and Part Quality," Procedia CIRP, vol. 14, pp. 564-569, January 2014.

[28] A. C. Olinto, "Vector space theory of sustainability assessment of industrial processes," (in English), Clean Technologies and Environmental Policy, vol. 16, no. 8, pp. 1815-1820, December 2014. 
[29] T. Lu et al., "Metrics-Based Sustainability Assessment of a Drilling Process," in Sustainable Manufacturing: Shaping Global Value Creation, G. Seliger, Ed. Berlin, Heidelberg: Springer Berlin Heidelberg, 2012, pp. 59-64.

[30] A. D. Jayal, F. Badurdeen, O. W. Dillon Jr, and I. S. Jawahir, "Sustainable manufacturing: Modeling and optimization challenges at the product, process and system levels," CIRP Journal of Manufacturing Science and Technology, vol. 2, no. 3, pp. 144-152, 2010.

[31] T. Lu and I. S. Jawahir, "Metrics-based Sustainability Evaluation of Cryogenic Machining," Procedia CIRP, vol. 29, pp. 520-525, January 2015.

[32] A. Moldavska and T. Welo, "On the Applicability of Sustainability Assessment Tools in Manufacturing," Procedia CIRP, vol. 29, pp. 621-626, January 2015.

[33] Y. Lee Ju, "A framework for a research inventory of sustainability assessment in manufacturing," (in eng), Journal of Cleaner Production, vol. 79, pp. 207218, 2014.

[34] S. Singh, E. U. Olugu, and A. Fallahpour, "Fuzzy-based sustainable manufacturing assessment model for SMEs," Clean Technologies and Environmental Policy, vol. 16, no. 5, pp. 847-860, 2014.

[35] H. X. Tan, Z. Yeo, R. Ng, T. B. Tjandra, and B. Song, "A Sustainability Indicator Framework for Singapore Small and Medium-Sized Manufacturing Enterprises," Procedia CIRP, vol. 29, pp. 132-137, January 2015.

[36] G. Egilmez, M. Kucukvar, and O. Tatari, "Sustainability assessment of U.S. manufacturing sectors: an economic input output-based frontier approach," Journal of Cleaner Production, vol. 53, pp. 91-102, August 2013.

[37] B. Hapuwatte, K. D. Seevers, F. Badurdeen, and I. S. Jawahir, "Total Life Cycle Sustainability Analysis of Additively Manufactured Products," Procedia CIRP, vol. 48, pp. 376-381, January 2016.

[38] E. Yucel and M. Gunay, "An evaluation on machining processes for sustainable manufacturing," Gazi University Journal Of Science, vol. 26, no. 2, pp. 241$252,2013$.

[39] P. W. Marksberry and I. S. Jawahir, "A comprehensive tool-wear/tool-life performance model in the evaluation of NDM (near dry machining) for sustainable manufacturing," International Journal of Machine Tools and Manufacture, vol. 48, no. 7-8, pp. 878-886, June 2008.

[40] X. Zhang et al., "A Metrics-Based Methodology for Establishing Product Sustainability Index (ProdSI) for Manufactured Products," in Leveraging Technology for a Sustainable World: Proceedings of the 19th CIRP Conference on Life Cycle Engineering, University of California at Berkeley, Berkeley, USA, 2012, pp. 435-441.

[41] I. Jawahir, O. Dillon, K. Rouch, K. J. Joshi, A. Venkatachalam, and I. H. Jaafar, "Total life-cycle considerations in product design for sustainability: A framework for comprehensive evaluation," in Proceedings of the 10th International Research/Expert Conference, Barcelona, Spain, 2006, pp. 1-10. 
[42] X. Zhang, "A new metric-based LCA method for assessing the sustainability performance of metallic automotive components," M.S. thesis, University of Kentucky, Kentucky, 2012.

[43] X. Zhang et al., "A Metrics-Based Methodology for Establishing Product Sustainability Index (ProdSI) for Manufactured Products," in Leveraging Technology for a Sustainable World: Proceedings of the 19th CIRP Conference on Life Cycle Engineering, University of California at Berkeley, Berkeley, USA, 2012, pp. 435-441.

[44] S. Dambhare, S. Deshmukh, A. Borade, A. Digalwar, and M. Phate, "Sustainability Issues in Turning Process: A Study in Indian Machining Industry," Procedia CIRP, vol. 26, pp. 379-384, 2015/01/01 2015.

[45] I. S. Jawahir and A. D. Jayal, "Product and Process Innovation for Modeling of Sustainable Machining Processes," in Advances in Sustainable Manufacturing: Proceedings of the 8th Global Conference on Sustainable Manufacturing, 2011, Springer-Verlag Berlin Heidelberg. doi: pp. 10.1007/978-3-642-20183-7.

[46] H. A. Hegab, B. Darras, and H. A. Kishawy, "Towards sustainability assessment of machining processes," Journal of Cleaner Production, vol. 170, no. Supplement C, pp. 694-703, January 2018.

[47] P. Singh, A. Singh, J. Madan, and M. Mani, "A Combuter-Aided System for Sustainability Assessment for the Die casting Processes," presented at the ASME 2012 International Manufacturing Science and Engineering Conference, Notre Dame, Indiana, USA, 2012.

[48] Y.-J. Chang et al., "Environmental and Social Life Cycle Assessment of Welding Technologies," Procedia CIRP, vol. 26, pp. 293-298, January 2015.

[49] G. Sproesser et al., "Sustainable Welding Process Selection Based on Weight Space Partitions," Procedia CIRP, vol. 40, pp. 127-132, January 2016.

[50] K. S. Sangwan, C. Herrmann, P. Egede, V. Bhakar, and J. Singer, "Life Cycle Assessment of Arc Welding and Gas Welding Processes," Procedia CIRP, vol. 48, pp. 62-67, January 2016.

[51] C. B. Joung, J. Carrell, P. Sarkar, and S. C. Feng, "Categorization of indicators for sustainable manufacturing," Ecological Indicators, vol. 24, pp. 148-157, January 2013.

[52] R. Zhao, H. Su, X. Chen, and Y. Yu, "Commercially Available Materials Selection in Sustainable Design: An Integrated Multi-Attribute Decision Making Approach," Sustainability, vol. 8, no. 1, p. 79, 2016.

[53] (2009). Sustainability Measures; Indicators of Sustainability. Available: http://www.sustainablemeasures.com/indicators. [Accessed: Jan. 20, 2018].

[54] G. G. R. Initiative, "Sustainability Reporting Guidelines," Available: https://www.globalreporting.org/Pages/default.aspx. [Accessed: Jan. 20, 2018].

[55] S. Index, "2005 Environmental Sustainability Index," Benchmarking National Environmental Stewardship. Available: http://www.ciesin. org/indicators/ESI/downloads.html. [Accessed: Dec. 4, 2017]. 
[56] "Indicators of Sustainable Development: Guidelines and Methodologies," The United Nations, New York, 2007, vol. 2018. Available: http://www.un.org/Available:esa/sustdev/natlinfo/indicators/uidelines.pdf. [Accessed: Dec. 17, 2017].

[57] W. P. Schmidt and A. Taylor, "Ford of Europe's product sustainability index," in Proceedings of 13th CIRP International Conference on Life Cycle Engineering. Leuven, 2006, pp. 5-10.

[58] A. Jahan, F. Mustapha, S. M. Sapuan, M. Y. Ismail, and M. Bahraminasab, "A framework for weighting of criteria in ranking stage of material selection process," The International Journal of Advanced Manufacturing Technology, journal article vol. 58, no. 1, pp. 411-420, 2012.

[59] P. Chatterjee, V. M. Athawale, and S. Chakraborty, "Materials selection using complex proportional assessment and evaluation of mixed data methods," Materials \& Design, vol. 32, no. 2, pp. 851-860, February 2011.

[60] S. R. Maity, P. Chatterjee, and S. Chakraborty, "Cutting tool material selection using grey complex proportional assessment method," Materials \& Design, vol. 36, pp. 372-378, April 2012.

[61] P. Chatterjee and S. Chakraborty, "Material selection using preferential ranking methods," Materials \& Design, vol. 35, pp. 384-393, March 2012.

[62] A. Jahan, F. Mustapha, M. Y. Ismail, S. M. Sapuan, and M. Bahraminasab, "A comprehensive VIKOR method for material selection," Materials \& Design, vol. 32, no. 3, pp. 1215-1221, March 2011.

[63] R. Kumar, Jagadish, and A. Ray, "Selection of Material for Optimal Design Using Multi-criteria Decision Making," Procedia Materials Science, vol. 6, pp. 590-596, January 2014.

[64] J. W. K. Chan and T. K. L. Tong, "Multi-criteria material selections and endof-life product strategy: Grey relational analysis approach," Materials \& Design, vol. 28, no. 5, pp. 1539-1546, 2007.

[65] J. Si, L. Marjanovic-Halburd, F. Nasiri, and S. Bell, "Assessment of buildingintegrated green technologies: A review and case study on applications of MultiCriteria Decision Making (MCDM) method," Sustainable Cities and Society, vol. 27, pp. 106-115, November 2016.

[66] E. Mulliner, N. Malys, and V. Maliene, "Comparative analysis of MCDM methods for the assessment of sustainable housing affordability," Omega, vol. 59, Part B, pp. 146-156, March 2016.

[67] M. M. Keshtkar, "Performance analysis of a counter flow wet cooling tower and selection of optimum operative condition by MCDM-TOPSIS method," Applied Thermal Engineering, vol. 114, pp. 776-784, March 2017.

[68] Q. Z. Yang, B. H. Chua, and B. Song, "A Matrix Evaluation Model for Sustainability Assessment of Manufacturing Technologies," World Academy of Science, Engineering and Technology, vol. 32, pp. 493-498, 2009. 
[69] E. Amrina, C. Ramadhani, and A. L. Vilsi, "A Fuzzy Multi Criteria Approach for Sustainable Manufacturing Evaluation in Cement Industry," Procedia CIRP, vol. 40, pp. 619-624, January 2016.

[70] T. Saaty, "Decision making with the analytic hierarchy process," International Journal of Services Sciences, vol. 1, no. 1, pp. 83-98, 2008.

[71] R. V. Rao, "Improved Multiple Attribute Decision Making Methods," in Decision Making in Manufacturing Environment Using Graph Theory and Fuzzy Multiple Attribute Decision Making Methods, vol. 2, London: Springer London, 2013, pp. 7-39.

[72] M. Velasquez and P. T. Hester, "An analysis of multi-criteria decision making methods," International Journal of Operations Research, vol. 10, no. 2, pp. 5666, 2013.

[73] A. S. Milani, A. Shanian, C. Lynam, and T. Scarinci, "An application of the analytic network process in multiple criteria material selection," Materials \& Design, vol. 44, pp. 622-632, February 2013.

[74] Y. Kuo, T. Yang, and G.-W. Huang, "The use of grey relational analysis in solving multiple attribute decision-making problems," Computers \& Industrial Engineering, vol. 55, no. 1, pp. 80-93, August 2008.

[75] C.-L. Hwang and K. Yoon, "Methods for Multiple Attribute Decision Making," in Multiple Attribute Decision Making: Methods and Applications A State-ofthe-Art SurveyBerlin, Heidelberg: Springer Berlin Heidelberg, 1981, pp. 58191.

[76] Z.-h. Zou, Y. Yun, and J.-n. Sun, "Entropy method for determination of weight of evaluating indicators in fuzzy synthetic evaluation for water quality assessment," Journal of Environmental Sciences, vol. 18, no. 5, pp. 1020-1023, September 2006.

[77] B. Roy, "The outranking approach and the foundations of ELECTRE methods," Theory and decision, vol. 31, no. 1, pp. 49-73, 1991.

[78] A. Shanian and O. Savadogo, "A methodological concept for material selection of highly sensitive components based on multiple criteria decision analysis," Expert Systems with Applications, vol. 36, no. 2, pp. 1362-1370, 2009.

[79] A. Shanian, A. Milani, C. Carson, and R. Abeyaratne, "A new application of ELECTRE III and revised Simos' procedure for group material selection under weighting uncertainty," Knowledge-Based Systems, vol. 21, no. 7, pp. 709-720, 2008.

[80] J. C. Leyva-Lopez and E. Fernandez-Gonzalez, "A new method for group decision support based on ELECTRE III methodology," European Journal of Operational Research, vol. 148, no. 1, pp. 14-27, 2003.

[81] M. G. Yücel and A. Görener, "Decision Making for Company Acquisition by ELECTRE Method," International Journal of Supply Chain Management, vol. 5, no. 1, pp. 75-83, 2016. 
[82] A.-U. Rehman and A. Subash Babu, "The evaluation of manufacturing systems using concordance and disconcordance properties," International Journal of Services and Operations Management, vol. 5, no. 3, pp. 326-349, 2009.

[83] R. K. Gavade, "Multi-Criteria Decision Making: An overview of different selection problems and methods," Int. J. of Computer Science and Information Technologies ((IJCSIT), vol. 5, no. 4, pp. 5643-5646, 2014.

[84] M. Viteikiene and E. K. Zavadskas, "Evaluating the sustainability of Vilnius city residential areas," Journal of civil engineering and management, vol. 13, no. 2, pp. 149-155, 2007.

[85] E. K. Zavadskas, A. Kaklauskas, F. Peldschus, and Z. Turskis, "Multi-attribute assessment of road design solutions by using the COPRAS method," Baltic Journal of Road \& Bridge Engineering, vol. 2, no. 4, pp. 195-209, 2007.

[86] R. Simanaviciene and L. Ustinovichius, "Sensitivity Analysis for Multiple Criteria Decision Making Methods: TOPSIS and SAW," Procedia - Social and Behavioral Sciences, vol. 2, no. 6, pp. 7743-7744, January 2010.

[87] A. Saltelli, S. Tarantola, F. Campolongo and M. Ratto, Sensitivity analysis in practice : a guide to assessing scientific models. Hoboken, Ney Jersey: Wiley, 2004.

[88] D. M. Hamby, "A review of techniques for parameter sensitivity analysis of environmental models," Environmental Monitoring and Assessment, journal article vol. 32, no. 2, pp. 135-154, 1994.

[89] W. Tian, "A review of sensitivity analysis methods in building energy analysis," Renewable and Sustainable Energy Reviews, vol. 20, pp. 411-419, April 2013.

[90] J. Yang, "Convergence and uncertainty analyses in Monte-Carlo based sensitivity analysis," Environmental Modelling \&amp; Software, vol. 26, no. 4, pp. 444-457, April 2011.

[91] G. Sproesser, Y.-J. Chang, A. Pittner, M. Finkbeiner, and M. Rethmeier, "Life Cycle Assessment of welding technologies for thick metal plate welds," Journal of Cleaner Production, vol. 108, pp. 46-53, December 2015.

[92] K. E. K. Vimal, S. Vinodh, and A. Raja, "Modelling, assessment and deployment of strategies for ensuring sustainable shielded metal arc welding process - a case study," Journal of Cleaner Production, vol. 93, pp. 364-377, April 2015.

[93] I. Alkahla and S. Pervaiz, "Sustainability assessment of shielded metal arc welding (SMAW) process," in IOP Conference Series: Materials Science and Engineering, 2017, vol. 244, no. 1, pp. 012001.

[94] M. Bevilacqua, F. E. Ciarapica, A. D’Orazio, A. Forcellese, and M. Simoncini, "Sustainability Analysis of Friction Stir Welding of AA5754 Sheets," Procedia CIRP, vol. 62, pp. 529-534, January 2017.

[95] S. Kalpakjian and S. R. Schmid, Manufacturing engineering and technology. Pearson Upper Saddle River, NJ, USA, 2014.

[96] M. P. Groover, Fundamentals of modern manufacturing: materials processes, and systems. John Wiley \& Sons, 2007. 
[97] G. Buffa, D. Campanella, R. Di Lorenzo, L. Fratini, and G. Ingarao, "Analysis of Electrical Energy Demands in Friction Stir Welding of Aluminum Alloys," Procedia Engineering, vol. 183, pp. 206-212, January 2017.

[98] E. E. Kishta and B. Darras, "Experimental investigation of underwater frictionstir welding of 5083 marine-grade aluminum alloy," Proceedings of the Institution of Mechanical Engineers, Part B: Journal of Engineering Manufacture, vol. 230, no. 3, pp. 458-465, 2016.

[99] A. Narayanan, C. Mathew, V. Y. Baby, and J. Joseph, "Influence of gas tungsten arc welding parameters in aluminium 5083 alloy," International Journal of Engineering Science and Innovative Technology, vol. 2, no. 5, pp. 269-277, 2013.

[100] E. ASTM, "8M. Standard test methods of tension testing of metallic materials [metric]," Annual book of ASTM standards, vol. 3, 2003.

[101] B. M. Darras, F. H. Abed, S. Pervaiz, and A. Abdu-Latif, "Analysis of damage in 5083 aluminum alloy deformed at different strainrates," Materials Science and Engineering, vol. 568, pp. 143-149, 2013/04/15/ 2013.

[102] B. M. Darras, F. H. Abed, A. Abdul-Latif, and S. Pervaiz, "Experimental investigation of deformation in 5083 marine-grade aluminum alloy at elevated temperatures," Journal of Materials Engineering and Performance, vol. 24, no. 4, pp. 1663-1668, 2015.

[103] C. Sharma, V. Upadhyay, and A. Tripathi, "Effect of Welding Processes on Tensile Behavior of Aluminum Alloy Joints," International Journal of Mechanical and Mechatronic Engineering, vol. 9, no. 12, pp. 2051-2054, 2015.

[104] A. K. Bodukuri, K. Eswaraiah, K. Rajendar, and S. A, "Comparison of Aluminum Alloy 5083 properties on TIGW and FSW Processes," Materials Today: Proceedings, vol. 4, no. 9, pp. 10197-10201, January 2017.

[105] Y. Liu et al., "Microstructure and mechanical properties of aluminum 5083 weldments by gas tungsten arc and gas metal arc welding," Materials Science and Engineering: A, vol. 549, pp. 7-13, July 2012.

[106] B. Darras and E. Kishta, "Submerged friction stir processing of AZ31 Magnesium alloy," Materials \& Design, vol. 47, pp. 133-137, 2013.

[107] "Standard Test Method for Vickers Hardness of Metallic Materials," in ASTM, May 2017. [Online]. Available: https://www.koopaco.com/standards/ASTME92-17-3-01-standard-test-vickers-knoop-hardness.pdf. [Accessed: Dec. 24, 2017].

[108] D. Klobčar, L. Kosec, A. Smolej, and A. Pietras, "Friction-stir welding of aluminium alloy 5083," Materials and Technology, vol. 5, no. 46, pp. 483-488, 2012.

[109] B. M. Darras, I. M. Deiab, and A. Naser, "Prediction of friction stir processed AZ31 magnesium alloy micro-hardness using artificial neural networks," Advanced Materials Research, vol. 1043, pp. 91-95, 2014. 
[110] B. Darras, M. Khraisheh, F. Abu-Farha, and M. Omar, "Friction stir processing of commercial AZ31 magnesium alloy," Journal of materials processing technology, vol. 191, no. 1-3, pp. 77-81, 2007.

[111] J. Morris Jr, "The influence of grain size on the mechanical properties of steel," May 2001. [Online]. Available: https://www.osti.gov/servlets/purl/861397. [Accessed: Nov. 24, 2017].

[112] E. ASTM, "Standard Test Methods for Notched Bar Impact Testing of Metallic Materials," 2008). Standard Test Methods for Rockwell Hardness of Metallic Materials. E18-08a. ASTM, Ed.(2008). Standard Test Methods for Tension Testing of Metallic Materials. E, vol. 8, 2007.

[113] C. N. C. Fund. (2018). My Carbon Calculator. Available: https://cncf.com.au/carbon-calculator/\#electricity

[114] (2018). Tariff Calculator. Available:

https://www.dewa.gov.ae/en/customer/services/consumptionservices/calculator

[115] MATHESON. MATHESON 4043 Alloy Stick Wire (GMAW) Available: https://store.mathesongas.com/4043-alloy-stick-wire-gmaw-tig-choose-boxweight-wire-diameter/

[116] Amazon. Blue Demon E4043 3/32" x 12" 1LB Tube Aluminum Covered Arc Welding Electrode. Available: https://www.amazon.com/Blue-DemonAluminum-Covered-Electrode/dp/B010HWU7N0

[117] (2017). Computer Numerically Controlled (CNC) Machinist Salary. Available: https://www.payscale.com/research/US/Job=Computer_Numerically_Controll ed_(CNC)_Machinist/Hourly_Rate

[118] (2017). Tig Welder Salary. Available: https://www.payscale.com/research/US/Job=Tig_Welder/Hourly_Rate

[119] (2017). Mig Welder Salary. Available: https://www.payscale.com/research/US/Job=Mig_Welder/Hourly_Rate

[120] (2017). Welder with Shielded Metal Arc Welding (SMAW) Skills Salary. Available:

https://www.payscale.com/research/US/Job=Welder/Hourly_Rate/64dbbe71/S hielded-Metal-Arc-Welding-SMAW

[121] "Nonfatal Occupational Injuries and Illnesses Requiring Days from Work," 2013. [Online]. Avialable: https://www.bls.gov/news.release/pdf/osh2.pdf. [Accessed: April 24, 2018]. 


\section{Vita}

Mohammed Hassoun Saad was born in 1993, in Kosti, Sudan. He received his primary and secondary education in Sharjah, United Arab Emirates. He received his B.Sc. degree in Mechanical Engineering from the American University of Sharjah (AUS) University in 2015. His name has been listed several times in the Dean's Honour list and Chancellor Honour list.

In February 2016, he joined the Mechanical Engineering master's program in the American University of Sharjah as a graduate teaching assistant. His research area interests are in sustainability assessment and manufacturing processes. During his master's study, he received the PI TAU SIGMA - Beta Xi membership, which is given to professionals and students on a basis of sound engineering ability, scholarship (upper $35 \%$ ), personality, and probable future success in their chosen field of Mechanical Engineering.

Recently, Saad and his master's advisors Dr. Basil Darras and Dr. Mohammad Nazzal, have published a journal paper titled "A General Framework for Sustainability Assessment f Manufacturing Processes". The paper has been publish in the "Ecological Indicators" journal by Elsevier. 